\title{
Bulletin de Patrologie
}

\author{
Matthieu Cassin \\ IRHT (CNRS)
}

Cette année, j'ai plaisir à noter que les livres de plusieurs éditeurs qui jusqu'ici soit ne me parvenaient pas, soit ne me parvenaient plus, figurent de nouveau au sommaire de ce Bulletin, par exemple ceux des éditions Brill. Que le secrétaire de rédaction de la présente revue soit particulièrement remercié pour son travail efficace afin d'obtenir les livres. En revanche, d'autres maisons d'édition paraissent adopter une politique inquiétante, qui consiste à refuser d'envoyer des livres trop coûteux - c'est le cas cette année des Oxford University Press : cela conduit à ne pouvoir rendre compte de livres importants, comme la somme de W. Kinzig sur les professions de foi ou la traduction anglaise du Traité des principes d'Origène par J. Behr. Si une telle décision devait se confirmer, le travail même du Bulletin perdrait rapidement son sens.

On verra que le contenu du présent Bulletin témoigne, comme les années passées, de déséquilibres réels entre les périodes, les langues et champs disciplinaires; le fait est sûrement dû pour partie au domaine de compétence privilégié du recenseur, mais pas uniquement. Les auteurs grecs à partir $d u \mathrm{IV}^{\mathrm{e}}$ siècle occupent une place prépondérante, même si une floraison de publications sur Jérôme et l'Ambrosiaster compense pour partie ce travers. On relèvera aussi un beau bouquet de livres sur le monachisme et les Pères du désert.

\section{Auteurs grecs jusqu'au III siècle \\ Évêques martyrs}

Version remaniée d'une thèse de doctorat de l'Université Notre-Dame, le livre de Justin BuOL s'attache aux figures d'évêques martyrs au $2^{\mathrm{e}}$ siècle $^{1}$, en fait à trois individus, Ignace d'Antioche, Polycarpe de Smyrne et Pothin de Lyon, et plus particulièrement à la valeur et à la portée de leur mort. Comme souvent dans les thèses américaines, une bonne moitié de l'ouvrage est consacrée à une mise en contexte de ce que l'auteur appelle " effective death », c'est-à-dire la mort efficace d'un responsable d'une communauté, dont le sacrifice remplit un rôle positif pour ceux pour qui il offre sa vie. Après un très bref chapitre introductif, l'auteur étudie successivement le contexte non chrétien (chapitre 2), qui rassemble tant la deuotio romaine que le $\varphi \alpha \rho \mu \alpha \kappa o ́ \varsigma$ grec ou encore les gymnasiarques d'Alexandrie et les philosophes romains en conflit avec l'empereur, et même les martyrs juifs, c'est-à-dire ici les Maccabées. Les troisième et quatrième chapitres sont consacrés respectivement à Jésus et à Paul, modèles par excellence de la vie chrétienne donnée ; dans ces deux chapitres, l'auteur étudie à la fois les modèles interprétatifs qui sont fournis par les textes néotestamentaires pour comprendre la portée conférée à ces morts, ainsi que les référents non chrétiens qui sont repris et remotivés dans ce contexte. La seconde moitié du livre porte sur les trois évêques martyrs qui constituent le cœur du propos de J. Buol, avant un chapitre conclusif qui ouvre sur l'usage que fait Irénée de Lyon des figures de ses prédécesseurs morts martyrs. Un très bref appendice présente quatre autres évêques martyrs du $2^{\mathrm{e}}$ siècle, Télesphore de Rome, Publius d'Athènes, Thraséas d'Eumèneia et Sagaris de Laodicée, pour lesquels nous bénéficions de renseignements bien moins développés. Une très ample bibliographie et des index (textes cités, auteurs modernes, sujets) referment le livre.

\footnotetext{
${ }^{1}$ Justin BuOL, Martyred for the Church. Memorializations of the Effective Deaths of Bishop Martyrs in the Second Century CE, Tübingen, Mohr Siebeck (coll. «Wissenschaftliche Untersuchungen zum Neuen Testament, 2. Reihe » 471), $2018 ; 23,2 \times 15,5, \mathrm{X}+334$ p. ISBN 978-3-16-156389-8.
} 
Le postulat de départ de l'auteur est qu'il existe des traits caractéristiques des évêques, parmi le groupe plus large des martyrs chrétiens, qui les singularise non seulement par rapport aux laïcs, mais aussi par rapport aux autres ministres - tout en sachant que la hiérarchie des ministères est encore loin d'être clairement établie, surtout au début de la période envisagée. Ces traits consisteraient, à l'image de plusieurs autres morts antiques, mais surtout de celles de Jésus et de Paul, en ce qu'elles sont efficaces pour le salut, physique et spirituel, de leur communauté ; en outre, elles seraient caractérisées par le fait que le souvenir de ces morts serait lié à l'opposition aux doctrines erronées, ou plutôt utilisées dans le cadre de la lutte pour l'établissement d'une doctrine droite, distincte des fausses doctrines. Irénée serait particulièrement représentatif de cet aspect, en ce qu'il revendiquerait explicitement l'autorité de ces évêques martyrs. Si ces conclusions sont globalement acceptables - même si on notera en passant que, lorsqu'il invoque l'autorité de ces figures, Irénée ne rappelle pas leur statut d'évêque martyr, qui leur conférerait précisément leur force, selon l'auteur, mais les replace dans la succession apostolique - on voit cependant mal comment il est possible à l'auteur de dégager des traits qui puissent caractériser l'évêque, parmi les martyrs, sans comparer ces martyrs particuliers que seraient les évêques aux autres martyrs, et en particulier aux clercs. Faute d'une telle comparaison, la démonstration de J. Buol, si intéressante que soit la mise en série des dossiers qu'il propose, ne paraît pas probante. En outre, si l'appui principal de l'analyse est constitué par les textes provenant des évêques martyrs, lorsqu'ils sont disponibles (Ignace et, pour partie, Polycarpe), l'interprétation est aussi largement fondée sur le regard rétrospectif que les communautés portent sur ces martyrs. Sans doute aurait-il été utile de distinguer plus clairement ces points de vue, celui de l'évêque sur sa mort à venir, d'une part - à l'exemple du dossier paulinien étudié au quatrième chapitre ${ }^{2}$ - et celui des survivants ou des successeurs sur la mort d'un évêque - à l'image des évangiles à propos de la mort du Christ, au troisième chapitre.

On aurait aimé aussi voir aborder la figure d'Étienne quis s'il n'est pas évêque, joue cependant un rôle fondamental comme premier martyr, et diacre. Les études détaillées, en particulier sur des termes grecs, si elles présentent souvent un intérêt réel, sont parfois

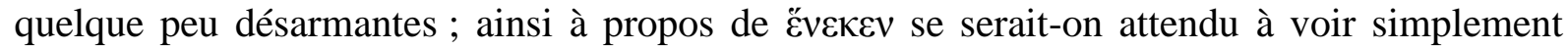
rappeler que la préposition/postposition indique normalement la cause finale, sans avoir à y consacrer plus d'une page. On espérait aussi que certains jugements à l'emporte-pièce, par exemple sur Eusèbe de Césarée, n'étaient plus d'actualité ${ }^{3}$. Enfin, l'objet choisi contraint l'auteur à de trop longues notes, du fait de la bibliographie surabondante à propos des deux premiers siècles.

Ce livre, dont l'objet présente un réel intérêt, ne constitue donc pas une contribution significative à un domaine déjà très souvent étudié, malgré l'affirmation mainte fois répétée de l'auteur sur la nouveauté de son objet ; il offre cependant des analyses d'un intérêt certain, que la comparaison avec les autres martyrs chrétiens aurait pu rendre plus probantes.

Origène

Si Origène est l'un des auteurs qui fascinent le plus les savants, comme l'a montré encore récemment l'émotion et l'intérêt suscités par la redécouverte de plusieurs de ses homélies sur les Psaumes, il reste cependant une figure pour partie obscure, et ce alors même qu'Eusèbe de Césarée lui a consacré toute une section de son Histoire ecclésiastique. L'un des points les plus controversés de cette biographie tient à l'identification - ou non - entre l'Origène

\footnotetext{
${ }^{2}$ On s'étonne d'ailleurs que l'auteur prenne en bloc tous les textes attribués à Paul et ne cherche pas à en distinguer les nuances, alors même qu'il rappelle dans ses nombreuses et longues notes que l'authenticité paulinienne d'un certain nombre des épîtres est non seulement discutée, mais unanimement rejetée.

${ }^{3}$ « Well-known to later historians for his apologetic motives, political biases, lack of understanding of Latin (and therefore much of Christian history in the West), failure to grasp the development of Christian theology, free-wheeling approach to citations of source material and gullibility regarding inauthentic material » (p. 211).
} 
théologien et exégète chrétien et l'Origène, élève d'Ammonios Saccas et condisciple de Plotin, et corrélativement, entre un ou plusieurs Ammonios, platonicien, péripatéticien et chrétien, actifs à Alexandrie pendant une période un peu longue. Les données essentielles sont fournies par Porphyre et par Eusèbe. Balbina BäBLER et Heinz-Günther NESSELRATH ont organisé à Göttingen en juillet 2016 un workshop sur ce thème, qui a été rapidement publié ${ }^{4}$. Le volume qui en est issu rassemble huit contributions, qui abordent le sujet sous des angles divers $^{5}$ : philologie, histoire du christianisme, histoire des doctrines platoniciennes, chronologie, histoire de la théologie, etc. Les points de vue sont variés et les positions sur l'identification ou la distinction des personnes tout aussi diverses : il ne faut pas chercher dans cet ouvrage une solution à la question si souvent agitée. Certes, les contributions à ce sujet ont été nombreuses ces dernières années, avec en particulier une synthèse remarquable de Marco Zambon $^{6}$, après un important article de Richard Goulet, plus ancien ${ }^{7}$. Le présent volume est cependant loin d'être inutile, dans la mesure où il reprend sous plusieurs facettes les éléments de ce dossier complexe, dans lequel il y a forcément eu des erreurs dès l'Antiquité Porphyre, Eusèbe ou l'un et l'autre se sont nécessairement trompés sur plusieurs points de leur présentation du dossier d'Origène et d'Ammonios - et met en perspective les différentes hypothèses. Il ouvre également la discussion sur la réception néoplatonicienne des rares extraits de l'Origène platonicien - ou des écrits platoniciens d'Origène - qui nous soient conservés, dans le Commentaire au Timée de Proclus, et plus largement sur l'articulation entre platonisme et christianisme chez Origène, vieille question sans cesse reprise et jamais résolue, dont la double figure d'Origène reste un symbole et une clef. Il est évident que, pour ce dernier domaine, l'enquête ne peut être exhaustive. Il aurait été utile aux lecteurs de rassembler la bibliographie, dispersée après chaque contribution, dans une bibliographie générale, qui présente en particulier, par ordre chronologique, l'ensemble des contributions importantes pour la discussion de la question soulevée. Le recenseur ne cache pas sa préférence pour la distinction des deux Origène, qui lui semble mieux rendre compte des données antiques ; il n'en reste pas moins que ces études, par la diversité de leurs arguments et de leurs points de vue, enrichit et nourrit le débat et la réflexion.

\section{Méthode d'Olympe}

Après la figure massive d'Origène, Méthode d'Olympe, qui fut pour partie son adversaire, paraît occuper peu de place tant par ses œuvres conservées que par les études qu'il a suscitées. La transmission des œuvres de Méthode d'Olympe dans leur langue d'origine, le Grec, est en effet très limitée ; la seule œuvre préservée en son entier est le Banquet. De plus, les autres œuvres conservées en leur intégralité n'ont été transmises qu'en slavon, et nous n'en possédons toujours pas d'édition critique d'ensemble. Aussi l'étude des œuvres de Méthode,

\footnotetext{
${ }^{4}$ Balbina BÄBler et Heinz-Günther NeSSELRATH (éd.), Origenes der Christ und Origenes der Platoniker, Tübingen, Mohr Siebeck (coll. «Studies in Education and Religion in Ancient and Pre-Modern History in the Mediterranean and Its Environs », 2), 2018 ; 24 × 16, relié, XII + 211 p. ISBN : 978-3-16-155855-9.

${ }^{5}$ Heinz-Günther NESSELRATH, « Einleitung », p. 1-11; Christoph RIEDWEG, « Das Origenes-Problem aus der Sicht eines Klassischen Philologen », p. 13-39; Peter GEMEINHARDT, «Origenes simplex vel duplex? Das Origenes-Problem aus der Sicht eines Kirchengeschichtlers », p. 41-59; Theo KoBUSCH, «Produktive Rezeption. Zum Platonismus des ,christlichen Philosophen' Origenes », p. 61-89; Winrich LÖHR, «Der platonische Ideenkosmos bei Origenes », p. 91-108 ; Andrea VILLANI, «Platon und der Platonismus in Origenes' Contra Celsum », p. 109-127 ; Ilinca TANASEANU-DöBLER, «Die Origeneis des Porphyrios », p. 129-163; Jens HALFWASSEN, «Was wissen wir über die Metaphysik des Platonikers Origenes?», p. 165-178; Balbina BÄBLER, «Origenes und Eusebios’ Chronik und Kirchengeschichte », p. 179-199.

${ }^{6}$ M. ZAMBON, «Porfirio e Origene, uno status quaestionis », dans S. MORLET (éd.), Le traité de Porphyre contre les chrétiens. Un siècle de recherches, nouvelles questions. Actes du colloque international organisé les 8 et 9 septembre 2009 à l'Université de Paris IV-Sorbonne, Paris, 2011, p. 107-164.

${ }^{7}$ R. Goulet, «Porphyre, Ammonius, les deux Origène et les autres », Revue de l'histoire des religions 57 , 1977, p. 471-496 [= IDEM, Études sur les Vies de philosophes de l'Antiquité tardive. Diogène Laërce, Porphyre de Tyr, Eunape de Sardes, Paris, 2001, p. 267-290].
} 
si elle n'a pas été nulle, loin de là, ne serait-ce qu'à cause de l'attention attirée sur l'auteur et ses écrits du fait de sa controverse avec Origène, ne s'est pas encore développée au même niveau que celle d'autres auteurs patristiques dont les œuvres ont été préservées dans leur langue d'origine. Le volume collectif édité par Katharina $\mathrm{BRACHT}^{8}$ et qui rassemble les actes d'un colloque tenu à Iéna en février 2015 , avec quinze contributions ${ }^{9}$, se propose de fournir un état des lieux des travaux sur cet auteur et d'ouvrir de nouvelles pistes de recherche. Il n'est pas question, dans le cadre de ce bulletin, de présenter en détail les apports des différentes contributions; on dégagera simplement les lignes principales du volume. L'article introductif présente un état de la question sur Méthode, ainsi que le contenu du volume ; il se termine par un utile tableau récapitulatif, qui présente les différentes œuvres conservées en tout ou partie, ou simplement connues, ainsi que les témoins qui nous les font connaître. Plusieurs contributions étudient le Banquet, en particulier sous l'angle de son genre et de ses référents littéraires, mais aussi de son contenu ou encore de l'éclairage que l'œuvre peut apporter à la connaissance de cercles intellectuels féminins dans l'Asie mineure de l'époque. Figurent également dans le livre des approches plus transversales, par exemple sur la question du millénarisme supposé de Méthode ou sur les rapports entre virginité et christologie, qui s'ancrent principalement dans le Banquet mais s'ouvrent également à d'autres œuvres. J. Sieber propose une étude préparatoire à une nouvelle édition du Banquet, à partir d'une étude de cas. D'autres contributions étudient le De resurrectione, ou encore, à partir de leur traduction slave, le De lepra et le De autexusio. Ces traductions slavones ne nous sont parvenues que dans des manuscrits du $16^{\mathrm{e}}$ siècle ou plus tardifs, alors qu'on a proposé de dater leur réalisation, sous forme de corpus, du $10^{\mathrm{e}}$ siècle. Leur rapport au texte grec d'origine paraît très variable, quand il est possible de le vérifier à partir des fragments grecs conservés, allant de la traduction mot à mot à une traduction pour le sens ; en outre, cette traduction est marquée par d'importants abrègements, étudiés ici dans le cas du De lepra. On relèvera encore l'étude de N. Kiel, sur l'utilisation du De resurrectione du pseudo-Justin dans le traité homonyme de Méthode. Le volume s'achève par deux études consacrées à la réception arménienne de Méthode, et par d'abondants index.

Si ces actes de colloque ne peuvent prétendre offrir au lecteur un état des lieux complet des études sur Méthode et de la connaissance de ces œuvres, ils proposent cependant un intéressant panorama et dessine les grandes lignes des études actuelles sur l'auteur. L'édition critique du texte slave reste un desideratum, de même que sa comparaison avec les fragments

\footnotetext{
${ }^{8}$ Katharina BRACHT (éd.), Methodius of Olympus: State of the Art and New Perspectives, Berlin, Boston, de Gruyter (coll. «Texte und Untersuchungen zur Geschichte der altchristlichen Literatur », 178), 2017; 24,5 × 17,5, relié, XI + 319 p. ISBN 978-3-11-044109-3.

${ }^{9}$ Katharina BRACHT, «Methodius of Olympus: State of the Art and New Perspectives », p. 1-17 ; Dawn LAVAlle Norman, «Coming Late to the Table. Methodius in the Context of Sympotic Literary Development », p. 18-37; Katharina BRACHT, «Eros as Chastity. Transformation of a Myth in the Symposium of Methodius of Olympus », p. 38-62 ; Mirosław MEKZNER, « Methodius: Millenarist or Anti-Millenarist?», p. 63-84 ; Amy Brown Hughes, «Agency, Restraint, and Desire. Virginity and Christology in Methodius of Olympus », p. 85-102 ; Federica CANDIDO, «The Symposium of Methodius: A Witness to the Existence of Circles of Christian Women in Asia Minor? Some Conjectures about an Interpretation that goes beyond Literal Fiction », p. 103-124 ; Jon F. DECHOW, «Methodius Conceptual World in His Treatise De resurrectione », p. 125-148; Selene ZORZI, «Bilder und Vorstellungen des Todes in Methodius' Schrift De resurrectione », p. 149-165 ; Roberta FrANCHI, «Where Does the Impulse to Evil Come from? Free Will, Disobedience, and Desire in Methodius' thought», p. 166-197; Janina SIEBER, « Methodius' Symposium from a Philological Perspective. The Value of a New Translation and Edition on the Basis of symp. 1.1.1-7 », p. 198-206 ; Anna JOURAVEL, «Beobachtungen zu Methodius' Schrift De lepra», p. 207-235; Yannis KAKRIDIS, «Die argumentative Form von Methodios’ De autexusio in der slavischen Übersetzung », p. 236-253 ; Nikolai KIEL, «Die Rezeption von Ps-Justins Auferstehungsschrfit bei Methodius von Olympus », p. 254-270; Susanne ZEILFELDER, «Zum Problem der Willensfreiheit bei Eznik von Kołb und Methodius von Olympus », p. 271283 ; Armenuhi Drost-AbGARJAN, « Die Rezeption des Methodius von Patara in der armenischen liturgischen Literatur », p. 284-292.
} 
grecs, dont le texte devrait sûrement être mis à jour, car il repose toujours sur l'édition fondatrice de Bonwetsch (1917).

\section{Auteurs latins jusqu'au III siècle}

L'épaisse apologie d'Arnobe, dont quatre livres sur sept (I, III, VI-VII) étaient déjà disponibles dans la série latine de la Collection des Universités de France, bénéficie maintenant d'une édition et traduction de son livre II, par Mireille ARMISEN-MARCHETTI ${ }^{10}$. Daté, à partir d'une référence à la fondation de Rome, de 297 par l'éditrice à la suite d'une grande part de la critique, ce livre que l'auteur décrit comme une digression au sein de l'œuvre est présenté brièvement dans l'introduction initiale. M. Armisen-Marchetti montre comment ce livre, après la justification du christianisme et avant l'attaque de la religion païenne, s'attaque aux positions des philosophes païens. L'essentiel de l'introduction est ensuite consacré à présenter la culture d'Arnobe - assez riche, mais où la Bible fait étrangement défaut - et ses adversaires. La justification de l'édition proprement dite est réduite : seuls deux manuscrits transmettent le texte, et le second est une copie du premier. L'enjeu réside essentiellement dans la reconnaissance de la nature des corrections que portent ces deux manuscrits, selon qu'elles sont anciennes ou d'époque humaniste. Ce sont en effet les conjectures qui occupent l'essentiel de l'apparat et des discussions philologiques du volume.

Le texte latin est accompagné d'une traduction française, fort claire, et d'un épais commentaire (p. 83-287), qui mêle justification du texte retenu, enquête philologique, linguistique et littéraire, et explication du contenu. Sans doute est-ce en ce dernier domaine où le lecteur aurait parfois aimé un peu plus sinon de précisions, du moins de références pour guider son travail, par exemple à propos de divers apocryphes évoqués par l'auteur, ou encore de certains philosophes comme Cronius, pour lesquels il aurait au moins fallu renvoyer au précieux Dictionnaire des philosophes antiques dirigé par Richard Goulet (ici C 223). De même, sur la question de la théurgie chez Porphyre, il n'aurait pas été inutile de renvoyer le lecteur aux deux volumes publiés récemment par H.-D. Saffrey dans la série grecque de la même collection : Porphyre, Lettre à Anébon l'Égyptien, et Jamblique, Réponse à la Lettre à Anébon de Porphyre, sans se limiter aux études qui concernent les seuls fragments du De regressu animae de Porphyre. Non que l'auteur ignore ces références, sans aucun doute, mais le lecteur aurait pu y être utilement renvoyé, surtout dans le domaine grec qui ne sera peutêtre pas aussi familier aux latinistes qui aborderont sans doute les premiers ce livre. Les références chrétiennes sont en revanche beaucoup plus rares, mis à part quelques rapprochements avec Tertullien; c'est que les positions d'Arnobe paraissent assez isolées, moins dans leur orientation générale que dans leur éventuelle dépendance à des sources directes. Le volume est complété par un index de mots choisis, un autre des noms propres, et un troisième, très bref, des titres d'œuvres citées.

Deux livres seulement manquent donc encore à l'édition de l'ouvrage d'Arnobe ; avec ce riche volume, on dispose maintenant d'un outil utile pour aborder l'étude du deuxième livre, qui s'attaque si directement aux positions philosophiques.

\section{Auteurs grecs à partir du IV siècle}

\section{Eusèbe de Césarée}

Eusèbe de Césarée, qui forme un pont entre les auteurs de la période précédent et le $\mathrm{IV}^{\mathrm{e}}$ siècle, est bien plus souvent abordé comme historien que comme théologien ; ce sont

\footnotetext{
${ }^{10}$ Mireille Armisen-MarchetTI, Arnobe, Contre les Gentils (Contre les Païens). II, Livre II, Paris, Belles Lettres (coll. «Collection des Universités de France, série latine »), $2018 ; 19,5 \times 12,5$, XLVII + 302 p. (dont 81 doubles), $59 €$. ISBN : 978-2-251-01480-7.
} 
pourtant ses traités contre Marcel d'Ancyre que Kelley MCCARTHY SPOERL et Markus VINZENT ont traduit et annoté ${ }^{11}$. Le Contre Marcel et la Théologie ecclésiastique n'ont presque jamais été traduits en langue moderne, mis à part une traduction italienne du deuxième traité. Ces deux textes fondamentaux, qui constituent des réfutations suivies d'un même traité contre Astérios de Marcel d'Ancyre et qui paraissent dater l'un et l'autre de la fin de la vie d'Eusèbe, plus particulièrement de la décennie 330, n'ont pas pour autant été laissés de côté jusqu'à ce jour, mais on ne disposait pas d'un moyen aisé de les aborder, autrement que par le texte original. La bibliographie sur Marcel d'Ancyre est pourtant relativement abondante ces dernières décennies et les chercheurs ont proposé, de manière plus ou moins convaincante, de lui attribuer plusieurs œuvres transmises sous le nom d'autres auteurs ; de même, les études sur Astérios se sont assez largement développées, dans la mesure où l'on a $\mathrm{vu}$ en lui l'une des origines des positions théologiques de l'arianisme. Dans les deux domaines, Markus Vinzent a joué un rôle important. La place accordée aux deux textes d'Eusèbe dans les recherches sur cet auteur est cependant beaucoup plus limitée, et on peut espérer que le présent volume aidera à l'étude de cette dimension de sa pensée. Ce sont cependant deux textes violemment polémiques, qui répondent eux-mêmes à un texte polémique : la figure qu'ils permettent de tracer tant des positions théologiques de Marcel que de celles d'Eusèbe ne peut donc être acceptée sans nuances et corrections.

Le livre s'ouvre par une assez longue introduction, qui présente d'abord le contexte théologique et historique du débat, puis les positions d'Astérios à travers la réfutation de Marcel, la réfutation de Marcel par Eusèbe et les positions théologiques d'Eusèbe que permettent de dégager ces traités. On ne reviendra pas en détail ici sur cet exposé, riche bien qu'il soit appuyé pour l'essentiel uniquement sur les deux textes traduits dans ce volume. Certains points sont bien connus, comme la position unanimement reprochée à Marcel d'Ancyre, qui ne distinguait le Verbe du Père qu'à partir de son Incarnation - position qui fit accuser Marcel de sabellianisme. D'autres le sont peut-être moins, comme la négation de la présence d'une âme humaine dans le Christ par Eusèbe ou l'insistance de ce dernier, contre Marcel, sur la permanence de l'Incarnation après qu'elle a rempli son rôle, le Christ ressuscité étant le modèle de la résurrection des chrétiens. Une dernière section de l'introduction porte sur la postérité des deux œuvres anti-marcelliennes d'Eusèbe, qui n'est pas sans intérêt ; elle demanderait cependant à être largement complétée. On permettra au recenseur de rappeler qu'il avait montré naguère que Grégoire de Nysse connaissait directement ces textes et dialoguait implicitement avec eux dans son Contre Eunome III.1, en particulier à propos de $\operatorname{Pr} 8,22$ mais aussi de l'interprétation prophétique et/ou proverbiale du livre des Proverbes, si bien qu'on a pu montrer que Grégoire répondait, dans ce passage, assez largement à Eusèbe $^{12} ; \mathrm{M}$. DelCogliano avait également fait une suggestion semblable à propos du Contre Eunome de Basile de Césarée ${ }^{13}$.

Ces remarques ne sont cependant qu'un premier témoignage de l'intérêt que cette traduction suscite : ces deux textes eusébiens ont en effet sûrement joué un rôle plus large que

11 Kelley McCARthy Spoerl et Markus VinZent, Eusebius of Caesarea, Against Marcellus and On Ecclesiastical Theology, Washington D.C., The Cathollic University of America Press (coll. « The Fathers of the Church, A New Translation », 135), 2018 ; 21,5 × 14, relié, XXI + 368 p. ISBN 978-0-8132-2991-1.

${ }^{12}$ Voir M. CASsin, L'écriture de la controverse chez Grégoire de Nysse. Polémique littéraire et exégèse dans le Contre Eunome, Paris (coll. «Études augustiniennes, série Antiquité » 193), 2012, p. 236-237, 241-244, 257 268 ; voir également p. 327-329, à propos de Jn 1.

${ }_{13}$ M. DelCogliano, "Basil of Caesarea on Proverbs 8,22 and the Source of Pro-Nicene Theology », Journal of Theological Studies 59, 2008, p. 183-190, ici p. 187-189. Voir déjà, pour les deux auteurs mentionnés ici, l'étude de M. VAN PARYS, «Exégèse et théologie dans les livres Contre Eunome de Grégoire de Nysse : textes scripturaires controversés et élaboration théologique », dans M. HARL (éd.), Écriture et culture philosophique dans la pensée de Grégoire de Nysse, Leiden, 1971, p. 169-196, ici p. 179-186, et IDEM, « Exégèse et théologie trinitaire : Pr 8, 22 chez les Pères cappadociens », Irénikon 43, 1970, p. 362-379. 
ce qu'on a pu dire jusqu'à présent, comme le confirme leur influence directe sur Basile de Césarée et Grégoire de Nysse. Leur rôle et leur influence ne se limitent pas aux décennies qui suivirent immédiatement leur rédaction. Le présent volume ne prétend pas épuiser leur étude, ni celle de leur réception; son apport principal est une traduction, aide essentielle pour les travaux à venir.

\section{Basile de Césarée}

Un épais volume propose une traduction italienne, accompagnée d'une ample introduction de plus de cent pages, des Homélies sur les Psaumes de Basile de Césarée (In Ps 1, 7, 14A-B, 28, 29, 32, 33, 44, 45, 48, 59, 61, 114, 115) et de diverses homélies (Sur le commencement des Proverbes; Sur «Je détruirai mes greniers... »; Sur «Sois attentif à toi-même »; Sur "Au commencement était le Verbe ») ; la traduction est due à Simona GIANI, et a été revue, introduite et commentée par Giorgio MAZZANTI ${ }^{14}$. Cette traduction annotée est complétée par divers appendices : une mise en stiques ou en cola du texte grec de plusieurs passages des homélies, dont les auteurs estiment que la structure rhétorique doit être rendue visible, présentation qui correspond à la présentation de la traduction italienne de ces sections ; des index nombreux, parfois très développés, comme un index thématique qui se présente plutôt comme des notes complémentaires ou un guide thématique que comme un index véritable, et parfois de forme plus attendue, comme pour l'index scripturaire - on trouve également dans cette section un "indice ricorrenze », un peu surprenant, ainsi qu'un index exégétique qui rassemble les termes techniques grecs, mais sous des rubriques et des sous-rubriques en italien, alors même que le texte grec n'est pas donné intégralement dans le volume. La composition du livre est donc quelque peu surprenante, et rien dans l'introduction ne vient justifier les choix faits en la matière. Cette introduction présente d'abord, assez rapidement, les grandes lignes de la vie de Basile et de son ancrage ascétique - point sur lequel l'auteur reprend assez largement les interprétations de F. Fatti - avant d'étudier plus en détail les Homélies sur les Psaumes, leur contenu et leur méthode - mais étrangement pas du tout les autres homélies exégétiques traduites dans le livre. Aucune homélie ne bénéficie d'une présentation dédiée : c'est le corpus des homélies exégétiques dans son ensemble qui intéresse G. Mazzanti. Aussi le lecteur ne sait-il pas même quelle édition a été utilisée pour traduire le texte, par exemple pour Sur «Soit attentif à toi-même», homélie éditée jadis par S. Y. Rudberg. De ce fait aussi, les notes sont parfois trop longues, au point qu'il ne reste plus qu'une ligne de traduction en haut de page. Peut-être la composition d'ensemble du livre aurait-elle gagné à être discutée par l'éditeur commercial, qui ne semble pas avoir poussé ici bien loin le travail.

Ce livre, cependant, a l'immense mérite de fournir une traduction annotée de l'ensemble des Homélies sur les Psaumes de Basile et de quelques autres homélies, tâche que personne n'avait entreprise depuis bien des années ${ }^{15}$. Une édition critique de ce corpus est toujours attendue et prendra nécessairement beaucoup de temps à pouvoir être réalisée ; on ne peut qu'espérer que le projet d'édition globale de Basile de Césarée, lancé par Volker H. Drecoll, puisse aboutir. En attendant une telle ressource, essentielle, on ne peut que se réjouir de la parution de cette traduction, dont les spécialistes de Basile auront à cœur de vérifier l'exactitude. Elle facilitera en tout cas grandement l'accès à ces textes, dont la langue n'est pas particulièrement complexe, mais dont la totalité atteint à une taille imposante.

\footnotetext{
${ }^{14}$ Giorgio MazZANTI (éd), Basilio di Cesarea, Omelie sui Salmi e altre omelie esegetiche. Introduzione, commento e revizione G. MAZZANTI, traduzione e indici S. GIANI, Frankfurt am Main, etc., Peter Lang (coll. «Patrologia, Beiträge zum Studium der Kirchenväter», 37), 2017 ; 21,5 × 15, relié, 699 p. ISBN 978-3-63173826-9.

${ }^{15}$ Il aurait peut-être été utile de signaler la traduction anglaise d'A. C. WAY, Saint Basil. Exegetic Homilies, Washington DC (coll. « The Fathers of the Church. A New Translation » 46), 1963.
} 


\section{Basile de Césarée et Grégoire de Nysse}

L'ouvrage de Michael VÖLLSTADT ${ }^{16}$ est consacré aux deux frères cappadociens, Basile de Césarée et Grégoire de Nysse, et les aborde sous l'angle double du loisir ( $\sigma \chi 0 \lambda \eta ́)$ et de la contemplation $(\theta \varepsilon \omega \rho i ́ \alpha)$. Il s'agit d'une thèse de doctorat, soutenue à Fribourg en 2016 sous la direction de Thomas Böhm, au sein d'un programme de recherche plus large sur le loisir. L'ouvrage, très bien informé sur la bibliographie y compris récente ${ }^{17}$, et dans diverses langues, est construit en diptyque : sont successivement étudiés Basile, puis Grégoire. La première partie oppose œuvres exotériques et œuvres ascétiques, tandis que la seconde voit se succéder philosophie païenne et chrétienne, montée ininterrompue vers Dieu et descente de la vie active. Un excursus de moins de trente pages est consacré à la figure de Moïse chez les deux auteurs (et dans le discours de Grégoire de Nazianze sur Basile) ${ }^{18}$ et constitue l'articulation entre les deux parties. Enfin, une conclusion assez brève rapproche et compare les conceptions des deux auteurs. Le livre s'achève par quelques éléments statistiques, assez sommaires, sur l'usage des différentes racines sémantiques étudiées dans l'ouvrage, et par une bibliographie. Manque cruellement un index sinon des passages cités, du moins des passages étudiés, ce qui aurait été d'un grand secours pour l'utilisation du livre - car tous ne le liront pas du début à la fin.

Disons tout de suite que l'ouvrage a gardé un peu trop de la forme d'une thèse de doctorat, avec des notes souvent très longues, et qui alignent de longues listes de références aux œuvres de Basile et/ou de Grégoire, qui sont d'autant moins utiles qu'aucune aide n'est disponible pour se repérer dans l'ouvrage, hors son plan. On trouve aussi, pourtant, dans ces notes, des discussions ponctuelles ou plus larges, qui sont importantes. Les concepts qui sont au centre de l'enquête, de par leur caractère fondamental - surtout le second - conduisent M. Vollstädt à présenter, généralement de manière claire mais parfois un peu longue, presque toute la théologie des auteurs étudiés; sans doute était-ce difficilement évitable, mais cela risque de lasser un peu le lecteur. Au contraire, la comparaison des conceptions de Basile et de Grégoire est très resserrée ; elle se dégage certes à la lecture successive des deux corpus textuels et théologiques, mais peut-être aurait-elle pu être plus clairement articulée, surtout lorsque les positions sont relativement parallèles. Ce n'est certes pas le cas en tout point, comme le montre l'auteur, par exemple du fait de la prépondérance de $\theta \varepsilon \omega \rho i ́ \alpha$ chez Grégoire, en particulier en lien avec le domaine exégétique ${ }^{19}$, ou encore du rôle important qu'il accorde à l'à $\sigma \chi 0 \lambda i ́ \alpha$ - une telle conclusion rejoint la démonstration de M. Laird à propos de l'importance accordée au rôle joué par Moïse après la vision divine, dans sa redescente auprès de ses frères, rapprochement qui aurait mérité d'être souligné plus clairement. On notera également que M. Vollstädt met en évidence le rôle accordé à la figure d'Élie, dans les textes

\footnotetext{
${ }^{16}$ Michael VollstäDT, Muße und Kontemplation im östlichen Mönchtum. Eine Studie zu Basilius von Caesarea und Gregor von Nyssa, Freiburg, Basel, Wien, Herder (coll. « Freiburger theologische Studien » 184), 2018 ; $22 \times 14$, relié, 376 p. ISBN : 978-3-451-38067-9.

17 On notera cependant l'absence de toutes les publications récentes sur le Commentaire sur Isaïe, d'attribution disputée, en particulier l'ouvrage d'E. CATTANEO, Il commento a Isaia di Basilio di Cesarea. Attribuzione e studio teologico-letterario, Roma (coll. «Studia ephemeridis Augustinianum» 139), 2014, la recension importante de M. SIMONETTI, «Cattaneo E., Il Commento a Isaia di Basilio di Cesarea », Augustinianum 54, 2014, p. 561-567, et la réponse de l'auteur : E. CATTANEO, « Il commento a Isaia di Basilio di Cesarea. Una replica alla recensione di M. Simonetti », Augustinanum 55, 2015, p. 631-643.

${ }^{18}$ Sur la figure de Moïse et son rôle dans la représentation que Grégoire de Nysse donne de Basile, il aurait été utile de citer et d'utiliser l'article d'O. MunNICH, La Bible dans l'élaboration d'un modèle de sainteté : l'exemple de l'Éloge de Basile, dans M. CASSIN et H. GRELIER (éd), Grégoire de Nysse: la Bible dans la construction de son discours. Actes du colloque de Paris, 9-10 février 2007, Paris (coll. «Études augustiniennes, série antiquité »184), 2008, p. 191-212.

${ }^{19}$ On s'étonne d'ailleurs un peu que le Lexicon Gregorianum, si essentiel pour une telle enquête, soit certes cité en bibliographie, mais n'apparaisse jamais ou presque dans le corps de l'ouvrage ; la structuration de ses articles aurait mérité d'être soit présentée, soit discutée.
} 
de Basile, ou l'absence de lien entre loisir et contemplation dans les écrits ascétiques basiliens.

Toutes les conclusions de l'ouvrage ne sont pas neuves, et certaines pourront sûrement être discutées ou nuancées. Pour qui a le temps et le courage de suivre de bout en bout l'auteur, il y a beaucoup à tirer de ce volume, tant à propos des deux auteurs que de leur comparaison. On peut regretter, cependant, que l'auteur et l'éditeur n'aient pas facilité la tâche du lecteur en les privant de précieux instruments, en particulier d'un index des lieux cités et commentés, et en allégeant un peu l'appareil d'érudition de la thèse d'origine. Cependant, entre loisir et contemplation - si la traduction est adéquate pour $\theta \varepsilon \omega \rho i ́ \alpha$, ce qui n'est pas toujours le cas - ce livre nourrira la réflexion des lecteurs et des spécialistes des deux auteurs cappadociens.

\section{Grégoire de Nysse}

Deux études transversales sur Grégoire de Nysse figurent cette année dans le Bulletin, marquées l'une et l'autre par le choix d'un traitement chronologique des textes nysséens. Andrew RADDE-GALLWITZ poursuit ici un sillon qu'il avait déjà commencé à creuser il y a plusieurs années à propos de la notion de simplicité divine dans les écrits de Basile de Césarée et de son frère Grégoire, et qu'il n'a jamais abandonné depuis : l'étude des œuvres doctrinales de l'évêque de $\mathrm{Nysse}^{20}$. L'ouvrage qui est ici présenté propose en effet une étude d'ensemble des textes nysséens relatifs à la doctrine chrétienne, et plus particulièrement au cœur de la foi trinitaire et christologique. Comme à son habitude, l'auteur prête une attention particulière aux textes, à leurs circonstances de composition, à leurs destinataires et aux adversaires qu'ils réfutent et combattent. C'est en ce sens, principalement, qu'on doit comprendre le sous-titre de l'ouvrage (A Literary Study) : il ne faut pas en effet chercher dans ce livre une étude des formes littéraires des œuvres doctrinales de Grégoire, non plus qu'une étude des procédés littéraires à l'œuvre dans ces textes. En revanche, dans son étude des textes qu'il retient, A. Radde-Gallwitz prête toujours une grande attention aux modalités concrètes de la démonstration, aux formes qu'elle prend et aux images qui la soutiennent ou la constituent puisqu'une part non négligeable des développements théologiques de Grégoire prend la forme d'images, éventuellement enchaînées, plutôt que de démonstrations logiques ou bibliques. En outre, A. Radde-Gallwitz cherche toujours, dans la mesure du possible, à situer l'œuvre étudiée dans son contexte historique, ecclésial et doctrinal, à identifier les adversaires et les thèses en présence, l'objectif de l'auteur dans la rédaction de son œuvre. En effet, si l'auteur ne propose pas un examen exhaustif de chacune des œuvres doctrinales de l'évêque de Nysse en sa totalité - la tâche aurait dépassé, et de très loin, l'ampleur d'un seul livre - il en replace toujours les éléments étudiés dans la perspective d'ensemble du traité, de la lettre ou de l'homélie qu'il étudie ; quand le texte est assez court, A. Radde-Gallwitz cherche à le prendre en compte en totalité. L'ensemble de l'interprétation est guidé par quelques points nodaux, dont l'auteur montre bien l'importance dans la pensée de Grégoire et la portée qu'ils ont pu avoir; on retiendra en particulier la place du baptême et de sa formule-type (Mt 28, 19), l'attention portée à l'unicité de puissance et d'action de la Trinité ou encore le rôle du calendrier liturgique en formation dans la réflexion nysséenne, en particulier pour l'Incarnation. Dans cette perspective, on retrouve la finesse d'analyse théologique de l'auteur, qui sélectionne avec soin les textes, mais les remets aussi sans cesse en série, tant au sein de l'œuvre qu'il étudie qu'avec les autres traitements du même point ailleurs dans la production nysséenne. Grâce à cette patiente activité, A. Radde-Gallwitz concentre l'attention de son lecteur sur des aspects essentiels, dont on n'avait pas toujours mesuré l'importance et la

\footnotetext{
${ }^{20}$ A. RADDE-GAllwitz, Gregory of Nyssa's Doctrinal Works: A Literary Study, Oxford, New York, Oxford University Press (coll. « Oxford Early Christian Studies »), 2018 ; $24 \times 16$, relié, XVI + 307 p. ISBN : 978-0-19966897-7.
} 
portée, ou qui commencent tout juste à la retenir ; ainsi sur l'unité de puissance et d'opération, qui a fait l'objet d'une communication de X. Moralès lors du $14^{\mathrm{e}}$ colloque international Grégoire de Nysse (Paris, septembre 2018), ou encore sur les modalités de salut pour l'âme, par la plongée dans le baptême à l'imitation de la mort du Christ.

Voici, dans l'ordre où il les étudie, les textes de Grégoire qui sont présentés dans l'ouvrage, étant entendu que tous ne bénéficient pas d'un traitement aussi étendu : Sur le jour des lumières; Sur la divinité contre Évagre ; Ep. 5 et 24 ; À Eustathe sur la sainte Trinité ; Contre les macédoniens sur le Saint-Esprit; Contre Eunome I; Réfutation de la Profession de foi d'Eunome; $\grave{A}$ son frère Pierre sur la différence entre substance et hypostase ; $\grave{A}$ Ablabios qu'on ne dit pas trois dieux; Aux Grecs, à partir des notions communes ; Contre Eunome II ; À Simplicius, sur la foi ; Contre Eunome III ; Antirrhétique contre Apolinaire ; Ep. 3 ; Sur l'intervalle de trois jours entre la mort et la résurrection; Sur la divinité du Fils et de l'Esprit et sur Abraham; À Théophile contre les apolinaristes; Discours catéchétique; Sur le jour de la nativité ; Ep. 4. Et c'est sans doute ici qu'il faut faire l'unique mais essentielle réserve sur la démarche de l'auteur de ce livre si précieux par l'analyse des textes qu'il propose. En effet, A. Radde-Gallwitz a choisi d'organiser sa matière de manière chronologique ; on comprend bien l'intérêt d'une telle démarche, qui veut moins reconstituer la biographie intellectuelle d'un auteur ancien et son évolution intime que montrer comment ses positions théologiques et les manières de les défendre évoluent avec le temps et en fonction des circonstances qui les ont vu naître. C'est que l'auteur prête une grande attention - parfaitement justifiée, voire indispensable - aux circonstances qui ont présidé à la composition des textes doctrinaux de Grégoire, qui sont presque toujours écris en réaction, à un adversaire ou aux questions d'un allié. Mais c'est aussi là que le bât blesse : la chronologie des œuvres de l'évêque de Nysse, à l'exception de quelques rares points fixes, est pour l'essentielle flottante. Et pour le malheur de la recherche ultérieure, J. Daniélou a naguère fixé des dates, parfois au jour près, sur des critères faibles, pour ne pas dire plus ${ }^{21}$. Or dans la mesure où personne n'a, depuis, repris de manière systématique la chronologie des œuvres nysséennes - ce que l'on comprend aisément au vu de la difficulté de la tâche - on utilise largement la chronologie de Daniélou, tout en en rappelant les faiblesses ${ }^{22}$. Il faudrait d'ailleurs se souvenir que J. Daniélou a souvent varié luimême pour ces datations, au fur et à mesure de ses études nombreuses et dispersées, et que les deux articles cités sont loin de représenter le seul ou le dernier état de sa réflexion en la matière, ce qu'on oublie trop souvent. Or s'il prend avec précautions ces propositions, les complète et les corrige souvent par les études ultérieures, A. Radde-Gallwitz ne parvient pas toujours à s'en séparer et l'objet et la méthode de son enquête le conduisent souvent à les perpétuer; plus important encore, ces hypothèses conditionnent une part non négligeable de sa lecture des textes nysséens, comme un œil averti le reconnaîtra à la seule lecture de la liste ci-dessus, qui est, pour l'auteur, chronologique.

${ }^{21}$ Voir en particulier J. DANIELOU, «La chronologie des sermons de Grégoire de Nysse », Revue des Sciences religieuses 29, 1955, p. 346-372 ; J. DANIELOU, « La chronologie des œuvres de Grégoire de Nysse », Studia Patristica 7.1, 1966, p. 159-169.

${ }^{22}$ Le très utile article de P. MARAVAL, «Chronology of Works », dans G. MASPERO et L. F. MATEO-SECO (éd), The Brill Dictionnary of Gregory of Nyssa, Leiden, Boston (coll. « Supplements to Vigiliae christianae », 99), 2010, p. 153-169 (édition italienne 2007), propose une remarquable synthèse des données de la recherche, œuvre par œuvre. Cependant, lorsqu'aucune étude n'a été menée depuis les tentatives de J. Daniélou, il ne peut que reprendre les propositions de ce dernier. On signalera aussi l'étude de G. MAY, «Die Chronologie des Lebens und der Werke des Gregor von Nyssa », dans M. HARL (éd), Écriture et culture philosophique dans la pensée de Grégoire de Nysse. Actes du colloque de Chevetogne (22-26 septembre 1969), Leiden, 1971, p. 51-67, beaucoup plus prudente que les deux études de J. Daniélou et qui se refuse à donner une datation pour de nombreux textes ; mais de ce fait même, ses propositions n'ont pu remplacer celles de J. Daniélou, puisqu'elles les refusaient sans offrir une nouvelle solution. 
Or on sait que les datations avancées par J. Daniélou reposent souvent sur des critères pour le moins discutables; ainsi, pour le discours Sur l'intervalle de trois jours, voici les arguments avancés par Daniélou pour dater le texte de Pâques 382 : le discours fait une grande part aux figures bibliques, comme le sermon Sur le jour des lumières que Daniélou date de 383 ( «Ces deux sermons très remarquables montrent Grégoire orienté davantage vers l'Écriture, ce qui caractérise son évolution à cette époque $»^{23}$ ); alors que l'année 381 aurait été marquée par les controverses sur l'Esprit, l'année 382 serait marquée par les controverses sur la christologie, avec la composition de l'Antirrhétique contre Apolinaire et de la Lettre 3 (thème de la divinité restant liée, dans la mort, au corps et à l'âme ; même interprétation du Noli me tangere); en outre, ce dernier thème serait interprété autrement dans le Contre Eunome III, qui serait de l'hiver suivant. Je laisse le lecteur juge de la valeur de ces arguments; de mon point de vue, ils sont d'une faiblesse extrême - on notera en passant qu'A. Radde-Gallwitz date, lui, Contre Eunome III de 381-382, sans plus de preuve, sans doute pour le faire passer avant l'homélie et gommer ainsi le fâcheux aller-retour sur l'interprétation du verset johannique ${ }^{24}$. Un autre exemple, sans doute moins caricatural, aidera cependant à comprendre les problèmes posés : l'auteur choisit de situer le traité À Ablabios vers 381-382, reprenant ainsi la position de G. May. Cependant, cette datation s'appuie uniquement sur des parallèles thématiques et doctrinaux avec d'autres œuvres qu'il estime remonter à la même période, contre les études récentes sur ce texte.

C'est donc une question de méthode qu'il faut ici $\operatorname{poser}^{25}$ : peut-on considérer que des œuvres sont contemporaines parce qu'elles présentent non seulement un même thème ou une même approche (méthode de J. Daniélou), mais une même position doctrinale (méthode de J. Daniélou et d'A. Radde-Gallwitz) ? Peut-on considérer qu'il y a une progression linéaire des positions doctrinales de Grégoire de Nysse, d'une part, et une péremption de celles-ci ? Posée ainsi, la question pourrait sembler devoir rester matière à débat. Il me semble cependant avoir pu montrer de plusieurs manières que la balance penchait plutôt pour la négative : dans le domaine exégétique, pour les œuvres qu'on peut dater par des critères externes, il n'y a pas de développement linéaire de l'exégèse, mais des allers-et-retours, qui s'adaptent aux circonstances (ainsi pour l'interprétation de Pr 8, 22, dans Eun. I, Eun. III et Ref., dont l'ordre est assuré). D'autre part, Grégoire reprend, à près de dix ans de distance, des développements entiers, y compris doctrinaux et polémiques, non pas en simple écho mais sous la forme d'une citation remaniée, ainsi pour la naissance du Christ issu de la Vierge en Contre Eunome III (382-383) et dans les Homélies sur le Cantique (après 391) ou pour un passage de théologie trinitaire du Contre Eunome III repris dans les Homélies sur le Notre Père (années 385-390, probablement). Au vu de ces éléments, toute datation qui s'appuierait sur une proximité de position doctrinale coure donc le risque très sérieux de méconnaître la distance qui peut séparer deux œuvres. La méthode que j'ai commencé à mettre en place, et qui procède par repérage non pas d'échos, mais de reprise directe, de citation de ses œuvres antérieures par

\footnotetext{
${ }^{23}$ J. DANIELOU, « La chronologie des sermons », p. 361.

${ }^{24}$ On date en général ce livre d'entre 381 et 383 ; il est certain qu'une partie au moins du traité est achevée avant la rédaction de la Réfutation, qui en reprend des passages entiers ; de même, le discours Sur la divinité du Fils et de l'Esprit utilise des développements du Contre Eunome. Mais rien ne conduit à le dater d'avant Pâques 382, comme le propose A. Radde-Gallwitz sur la seule base d'un supposé développement doctrinal.

${ }^{25}$ De manière générale, la bibliographie sur laquelle s'appuie l'auteur est à jour et de grande qualité ; on signalera simplement pour mémoire que, avant l'importante démonstration de M. DelCogliano (2010) selon lequel Eunome ne dépend ni du Cratyle, ni des interprétations néoplatoniciennes de ce dialogue dans sa théorie du langage - contre la thèse de J. Daniélou - une position similaire, plus englobante mais moins développée, avait déjà été exprimée par G. M. DE DURAND, «Eunome », dans R. GOULET (éd), Dictionnaire des philosophes antiques, III, Paris, 2000, p. 324-333. Sur la question du baptême eunomien, on mentionnera l'étude importante de C. Spuntarelli, "In nome della morte di Cristo": la costruzione dell'identità cristiana nella formula battesimale eunomiana », Annali di storia dell'esegesi 21, 2004, p. 315-330.
} 
Grégoire lui-même - procédé fréquent dans son œuvre - oblige à prendre avec beaucoup de précautions les datations appuyées sur de tels parallèles thématiques ou doctrinaux, tout autant que l'hypothèse fondatrice d'un développement linéaire et univoque de la pensée de l'évêque de Nysse.

Est-ce à dire que ces remarques sapent les fondements mêmes de l'étude d'A. RaddeGallwitz? Non, bien loin de là. En effet, l'essentiel de son apport réside dans une lecture détaillée des textes et une étude serrée de la pensée théologique de Grégoire, au fil des textes où elle se formule; cet examen le conduit à attirer l'attention sur des aspects fondamentaux de la doctrine nysséenne qui avaient été peu étudiés. De ce point de vue, l'acquis est solide, et extrêmement précieux. Mais la forme choisie, qui cherche à reconstituer une trame chronologique et une biographie doctrinale (et intellectuelle), ne fait, me semble-t-il, qu'induire le lecteur en erreur, car nous n'avons pas encore les éléments objectifs non seulement pour dater précisément les œuvres, mais même pour les mettre toutes dans une série ordonnée. Aussi le lecteur devra-t-il bien garder à l'esprit que la trame et l'ordonnance qu'on lui présente ne sont qu'une hypothèse reposant sur des hypothèses. Cette réserve faite, il pourra bénéficier à plein de l'étude des textes, de la doctrine et de ses fondements exégétiques, qui est d'une très grande valeur et ouvre des perspectives nouvelles y compris sur des textes aussi travaillés que le Contre Eunome.

Raphael CADENHEAD éclaire, dans son ouvrage, une toute autre facette de la pensée et des écrits de Grégoire de Nysse ${ }^{26}$ : il s'agit de sa théologie ascétique, comme l'indique le soustitre de l'ouvrage. L'auteur reprend donc un domaine qui a été très souvent abordé ces dernières années, à propos de Grégoire comme pour bien d'autres auteurs, celui du corps, du désir, de la sexualité et du genre ${ }^{27}$, mais en cherchant à le traiter à travers la totalité des textes ascétiques nysséens. C'est bien l'originalité de cet ouvrage que de tenter de mettre en perspective les différents traitements du corps, du genre et des rapports entre les sexes que mit en œuvre l'évêque de Nysse pendant toute son activité de théologien et d'auteur. Cependant, comme pour l'ouvrage précédent - et plus encore peut-être - c'est la volonté même de l'auteur d'ordonner ces textes selon un parcours chronologique, qui coïncide pour lui avec une évolution, et plus précisément un progrès, de la pensée de Grégoire en la matière qui fragilise tout l'édifice. En effet, nombre de textes étudiés par R. Cadenhead soit sont de datation très discutée, soit sont situés par lui à une date qui a été remise en cause avec des arguments solides, par exemple pour les Homélies sur le Notre Père. En outre, l'auteur reprend la division de la vie de Grégoire en trois périodes qu'avait proposée J. Daniélou, alors même que cette division pose plus de problèmes qu'elle n'en résout, et conduit à la fois à séparer des œuvres pourtant proches dans le temps, et à rapprocher des œuvres éloignées par leur cadre d'écriture. En outre, les bornes de ces périodes (378 et 387 ) ne correspondent à aucune coupure réelle, en terme d'événement ou de changement net, dans la biographie de Grégoire telle qu'on peut la reconstituer. On peut surtout faire à l'ouvrage un second reproche majeur : toutes les divergences entre les œuvres nysséennes sont expliquées à travers le filtre du progrès intellectuel et théologique de l'auteur, supposé linéaire et constant; jamais les différences entre deux textes ne sont pensées en fonction du contexte de production de l'œuvre, de ses destinataires et de sa fonction. On trouve un bon exemple d'un tel procédé (p. 150-151) à propos de l'attribution des titres de 'père' et de 'mère' à Dieu : R. Cadenhead

\footnotetext{
${ }^{26}$ Raphael A. CADENHEAD, The Body and Desire: Gregory of Nyssa's Ascetical Theology, Oakland (CA), University of California Press (coll. «Christianity in Late Antiquity », 4), 2018, 23,5 × 16, relié, XII-267 p. ISBN 978-0-520-97010-6.

${ }^{27}$ L'ouvrage est paru trop tôt pour que l'auteur puisse tenir compte du dernier tome de l'ouvrage majeur de M. Foucault, Histoire de la sexualité. IV, Les aveux de la chair, Paris, 2018, auquel a été consacré en février 2018 un colloque international, « Foucault, les Pères et le sexe » (https://bnf.hypotheses.org/2264).
} 
oppose la lecture ancienne de Grégoire, dans le Contre Eunome (III.2), du prologue johannique qui écarte le nom de 'père', au progrès accompli lors de la rédaction des Homélies sur le Cantique, où Dieu peut être appelé 'mère' sans que cela pose de difficulté. L'auteur introduit un autre facteur, qui est la maturité des destinataires, qui ne permet pas une telle appellation dans le premier cas, mais l'autorise parfaitement dans le second : l'explication est déjà beaucoup plus satisfaisante, mais elle laisse encore de côté le contexte polémique de l'extrait du Contre Eunome et son rôle dans la réfutation de l'adversaire. De même, la part de la rhétorique, intimement liée à cette contextualisation, n'est presque jamais prise en compte dans l'analyse des formulations de Grégoire de Nysse, ainsi des variations nombreuses sur la mère ou l'origine des vices, formule que Grégoire adapte à sa cible du moment, ou encore des condamnations de vices féminins ou masculins, dont l'attribution varie en fonction des contextes d'énonciation. On trouve une approche semblable pour la mention de l'âge, qu'il s'agisse de celui de Grégoire ou de ses destinataires, qui est étrangement toujours prise au pied de la lettre. On notera enfin que la caractérisation du public de certaines œuvres est discutable ; ainsi de la Vie de Mö̈se, pour laquelle il est par trop réducteur, sur la base d'une phrase du prologue (I, 11, 4-5), d'identifier les destinataires avec des êtres spirituellement immatures : au vu de l'ensemble du texte, qui conduit jusqu'à la perfection, ou quasi (c'est d'ailleurs un élément fondamental du titre de l'œuvre, Sur la perfection en matière de vertu), une telle caractérisation est largement réductrice.

Le plan de l'ouvrage est construit sur ces trois phases supposées de la production nysséenne : I. Place du corps dans la vie vertueuse (371-378), où sont traités successivement mariage, célibat et pédérastie ; l'intégration des vertus et leurs liens réciproques (ainsi que des vices) ; l'émergence d'une théorie du désir ; II. Mélange ascétique et eschatologique de mâle et femelle (378-387) : vie mondaine de désir (mariage, enfants, argent et sexe); mort des proches ; controverses christologiques et trinitaires ; III. Intimité érotique avec le Christ et maturation du désir (387-394) : maturation spirituelle : virginité et récit du progrès ; mâle et femelle : échanges diachroniques. Même si l'auteur cherche à embrasser toute la production nysséenne et se réfère effectivement à de nombreuses œuvres de Grégoire, ce sont cependant quelques textes centraux pour son propos qui occupent la première place : Sur la virginité ; Vie de Moïse; Homélies sur le Cantique, mais aussi Sur la formation de l'homme.

Ces réserves mises à part, qui sont importantes il est vrai, le lecteur trouvera dans cet ouvrage matière à réflexion, à condition de tenir à distance le schéma d'interprétation chronologique (le progrès de la pensée nysséenne) que propose sans cesse l'auteur. R. Cadenhead est en particulier très attentif à ne pas transposer les présupposés modernes (et post-modernes) sur le genre à la théorie du désir, et en particulier du désir ascétique, de Grégoire. On relèvera en outre un acquis majeur, clairement exposé dans les derniers temps de l'ouvrage: les changements de genre relevés par la critique au cours de l'ascension de l'homme vers Dieu ne sont pas des fluctuations, mais des changements ordonnés, qui voient se succéder femme puis homme vertueux, pour aboutir finalement à la figure de la fiancée de l'Époux. En outre, l'auteur montre nettement que mâle et femelle présentent des traits caractéristiques qui diffèrent non seulement entre eux, mais aussi selon qu'ils sont pris dans le contexte du monde et du corps, ou de leur orientation vers Dieu. De même, R. Cadenhead montre comment Grégoire décrit un processus de maturation spirituelle au sein même du mariage, et non dans la seule virginité, processus qui comprend une purification progressive du désir. On notera encore l'attention de l'auteur à décrire les écarts entre la conception nysséenne de l'amour et de la fécondité spirituelle et la conception platonicienne de ces mêmes réalités, puisque c'est la femme, non l'homme, qui est chez Grégoire le modèle principal en la matière. Enfin, et sans doute est-ce l'un des accents principaux de cet ouvrage, R. Cadenhead montre de manière convaincante que le désir chez l'évêque de Nysse ne doit pas s'interpréter au sein d'un modèle homo- ou hétérosexuel, mais dans le cadre de sa 
transcendance par l'ascèse, lorsqu'il est orienté vers Dieu. Il met en outre en évidence la portée large du discours ascétique de Grégoire, qui ne concerne pas que des moines et moniales, des ascètes de profession, mais tout chrétien de bonne volonté.

Si la grande ombre de J. Daniélou plane donc sur cet ouvrage, de manière positive sans doute pour ce qui est de l'attention portée à l'itinéraire de l'âme vers Dieu dans la Vie de Moïse et les Homélies sur le Cantique, mais aussi de manière beaucoup plus discutable quand il s'agit de reprendre sa chronologie et sa conception de la production de Grégoire comme une progression intellectuelle continue et orientée, l'auteur intègre cette perspective dans un cadre conceptuel beaucoup plus anglo-saxon et discute avec justesse les interprétations antérieures, liées aux études féministes et de genre, de l'apport nysséen en matière de sexualité, de conception du corps et du genre. De ce point de vue, le livre de R. Cadenhead mérite donc une lecture très attentive.

Sans doute l'intérêt du recenseur pour Grégoire de Nysse n'est-il pas étranger à l'impression qu'il éprouve que les publications sur cet auteur paraissent à un rythme particulièrement soutenu, et ce depuis plusieurs années ${ }^{28}$. L'ouvrage ici présenté rassemble les contributions présentées lors d'un séminaire tenu à Oxford en 2016, sous la responsabilité conjointe d'une historienne de la philosophie, Anna MARMODORO, et d'un historien, Neil B. MCLYNN ${ }^{29}$. Il comporte onze contributions, après une brève introduction due aux deux éditeurs $^{30}$. Il n'est pas question de discuter en détail ici le contenu de chacune des études; on notera simplement quelques traits essentiels et les éléments saillants de telle ou telle contribution. On relèvera d'abord qu'il est l'œuvre de deux savants qui ne sont pas des spécialistes de Grégoire de Nysse, et que les contributeurs du volume se répartissent entre spécialistes et non spécialistes de cet auteur. Un tel choix apporte un regard renouvelé sur certains aspects de l'œuvre nysséenne, mais ne va pas non plus sans poser quelques difficultés $^{31}$. L'élément le plus important, cependant, est le point de départ de l'ouvrage, à savoir un sentiment de vive étrangeté né entre un historien et une philosophe lorsqu'ils parlaient pourtant d'un même auteur; une telle perspective de lecture paraît tout à fait prometteuse, et elle apparaît de manière nette dans un (trop) petit nombre de contributions, suscitant des approches neuves et fructueuses.

L'exposé liminaire de J. A. McGuckin, qui trace le portrait de Grégoire, retrace sa vie et présente son œuvre, dépend trop largement de la doxa établie depuis J. Daniélou et répétée

\footnotetext{
${ }^{28}$ Voir encore récemment: G. MASPERO, M. BRUGAROLAS et I. VigORELLI (éd.), Gregory of Nyssa: In Canticum Canticorum: Analytical and Supporting Studies. Proceedings of the 13th International Colloquium on Gregory of Nyssa (Rome, 17-20 September 2014), Leiden, Boston (coll. «Supplements to Vigiliae Christianae » 150), 2018.

${ }^{29}$ Anna MARMODORO et Neil B. MCLYNN (éd.), Exploring Gregory of Nyssa: Philosophical, Theological, and Historical Studies, Oxford, Oxford UP 2018 ; 24 × 16, relié, XI + 263 p. ISBN 978-0-19-882642-2.

${ }^{30}$ John MCGUCKIN, «Saint Gregory of Nyssa: Bishop, Philosopher, Exegete, Theologian », p. 7-28 ; Neil MCLYnN, «The Two Gregories: Towards Nyssen from Nazianzen », p. 29-48 ; Susanna Elm, «Dressing Moses: Reading Gregory of Nyssa's Life of Moses Literally », p. 49-73 ; Mark EDWARDS, « Origen and Gregory of Nyssa on the Song of Songs », p. 74-92; Christopher BEELEY, "Gregory of Nyssa's Christological Exegesis », p. 93-109; Ilaria RAMELLI, «Gregory of Nyssa on the Soul (and the Restoration): From Plato to Origen », p. 110-141 ; Johannes ZACHHUBER, « The Soul as Dynamis in Gregory of Nyssa's On the Soul and the Resurrection », p. 142-159; Morwenna LUDLOW, «Christian Formation and the Body-Soul Relationship in Gregory of Nyssa », p. 160-178 ; Sophie CARTWRIGHT, «Vulnerability as the Ground of Self-Determination in Gregory of Nyssa », p. 179-198; Andrew RADDE-GALLWITZ, «Gregory of Nyssa and the Three Gods Problem. Activity and Etymology in To Ablabius », p. 199-219; Anna MARMODORO, "Gregory of Nyssa on the Metaphysics of the Trinity (with Reference on his Letter To Ablabius) », p. 220-234.

${ }^{31}$ Ainsi dès l'introduction, où les éditeurs relèvent chez Grégoire une présence beaucoup moins nette que chez Basile et Grégoire de Nazianze, d'opposants déterminés et un moins grand sentiment d'urgence. Quand on sait la place qu'occupe la controverse avec Eunome, puis avec Apolinaire, dans l'œuvre de Grégoire, et les formes littéraires, oratoires et politiques que prend cette confrontation, la remarque laisse pour le moins dubitatif.
} 
encore récemment par A. Silvas, peignant un portrait assez lisse et pieux; les travaux de P. Maraval sur la vie et la chronologie de Grégoire auraient pu être mieux exploités ${ }^{32}$. De manière générale, cette contribution, qui aurait dû donner les clefs d'interprétation de la suite, est lourdement défaillante; il est vrai que la tâche était rude. L'étude de N. McLynn est beaucoup plus originale, qui cherche à décrire les relations entre les deux Grégoire, de Nazianze et de Nysse, en laissant pour une fois à l'écart, autant que faire se peut, la figure généralement centrale de Basile de Césarée. Tout aussi originale est l'étude de S. Elm sur le vêtement dans la Vie de Moïse, qui propose de resituer l'intérêt de Grégoire en ce domaine dans le cadre des débats sur le vêtement dans la société du temps, entre autres au contact des populations et troupes d'origine barbare. Si le texte de la Vie paraît servir un peu de prétexte plus que d'objet, et si bien des éléments restent hypothétiques, l'approche est intéressante et fructueuse. M. Edwards, comparant l'exégèse du Cantique par Origène et Grégoire, soutient la thèse un peu paradoxale que Grégoire est le plus platonicien des deux. L'étude de Ch. A. Beeley sur la christologie de l'évêque de Nysse en lien avec son exégèse, trace le tableau d'un auteur plus proche d'Antioche que les deux autres Cappadociens, même si l'unité du Christ est affirmée par lui plus clairement que chez un Diodore de Tarse ; mais de nouveau, plus que la conclusion, c'est ici la méthode qui importe, par laquelle l'auteur prête attention aux variations des énoncés christologiques en fonction du contexte, doctrinal, de controverse, exégétique, etc. I. Ramelli reprend une fois de plus - et longuement - le traité Sur l'âme et la résurrection et sa dépendance à Origène. Bien plus intéressante est la contribution de J. Zachhuber sur la même œuvre, qui parvient à des conclusions opposées et dégage une conception de l'âme comme dynamis, jusqu'ici largement passée inaperçue. M. Ludlow se penche sur la transformation de l'homme dans sa formation spirituelle à travers un groupe de traité bien moins étudiés que la moyenne (De perfectione; De professione christiana; De instituto christiano) ; elle éclaire entre autres les nuances dans les positions de Grégoire qui laissent entrevoir des destinataires moins férus de culture que ceux d'autres traités. On laissera le lecteur découvrir avec intérêt les autres acquis de cet article important. S. Cartwright reprend deux traités bien souvent étudiés, De opificio hominis et De anima et resurrectione, sous l'angle de la faiblesse humaine et de son rôle dans les choix fondamentaux de l'homme. L'étude d'A. Radde-Gallwitz sur l'Ad Ablabium provient de l'ouvrage présenté plus haut : nous n'y reviendrons pas ici. Enfin, A. Marmodoro se penche de nouveau sur ce bref texte, sans doute l'un de ceux de Grégoire qui a déjà fait couler le plus d'encre, sous l'angle du rapport entre unité et pluralité, qui y est effectivement centrale, et la traite dans le cadre d'une approche qui resitue la solution nysséenne dans l'histoire de la philosophie ancienne et de l'innovation chrétienne.

Voilà donc un riche ouvrage, nécessairement inégal comme tout recueil de ce genre, mais qui pourra cependant ouvrir des perspectives intéressantes au lecteur, à condition qu'il ne se fie pas aveuglément à toutes les affirmations du livre. Une meilleure prise en compte de l'ensemble des travaux sur Grégoire de Nysse aurait été utile, même si leur masse tend à décourager même le travailleur le plus acharné.

\footnotetext{
32 On notera aussi l'influence de la théorie d'I. Ramelli, qui fait d'Évagre le diacre de Grégoire de Nysse, et non de Grégoire de Nazianze, en reprenant une lecture isolée et erronée d'un état textuel de l'Histoire lausiaque. Le discours Sur la divinité du Fils et de l'Esprit, quoique non nommé (mais évoqué indirectement à travers le tableau des controverses doctrinales qui s'étendent jusqu'aux boutiquiers), semble placé à tort en 381 au lieu de 383. La date du discours In suam ordinationem retenue (394), proposée naguère par R. Staats en 1969, a été réfutée, et rétractée par celui-là même qui l'avait proposée (R. STAATS, Makarios-Symeon, Epistola Magna. Eine messalianische Mönchsregel und ihre Umschrift in Gregors von Nyssa “De instituto christiano”, Göttingen, 1984, p. 32 et n. 45). Le De instituto et la Grande Lettre du Pseudo-Macaire/Syméon ne sont pas évoquées, non plus que les travaux de R. Staats à ce sujet, alors même que l'auteur évoque l'influence du Pseudo-Macaire sur Grégoire. On pourrait multiplier à l'envie les éléments de telle nature.
} 
Issu d'une thèse de théologie patristique soutenue au Centre Sèvres en 2015, le livre de Franck DuBOIS est consacré à l'étude d'une théorie de la matière chez Grégoire de Nysse, dont l'auteur propose d'identifier la nature avec un concours de concepts ou de propriétés immatériels, faisant ainsi le pont entre Dieu et le monde matériel ${ }^{33}$. L'étude s'ouvre par l'examen d'une série de textes (Sur la virginité, Sur la création de l'homme, Sur l'âme et la résurrection, Sur l'Hexaemeron), puis d'œuvres liées à la controverse trinitaire, dont l'ordre d'étude n'est pas justifié. Une seconde partie présente successivement le lexique, les sources philosophiques et les sources patristiques. Une troisième et dernière partie prend plus de champ avec son objet, en présentant une vue d'ensemble sur la fonction de cette " théorie » chez Grégoire et sur sa portée contemporaine. Le grand intérêt de ce travail, qui se situe clairement au sein d'un regain d'intérêt pour la théologie de la création et l'anthropologie de l'évêque de Nysse, après des décennies où ce sont surtout sa théologie spirituelle et doctrinale et son exégèse qui ont été au centre de l'attention des chercheurs, est donc bien de concentrer le regard sur la relation entre créateur et créature, comme l'avait fait il y a peu Xavier Batllo dans le cadre des textes liés à la controverse trinitaire ${ }^{34}$, mais en plaçant cette fois l'accent sur le versant anthropologique et cosmologique. Par cette approche, le travail de F. Dubois offre donc une intéressante lecture de l'œuvre nysséenne.

Cependant, peut-être aurait-il fallu dire plus clairement que cette «théorie de la matière » non seulement n'était pas la seule que l'on trouvait chez Grégoire, mais qu'elle n'était probablement pas une théorie, au sens moderne du mot. Il y a là, toutefois, matière à discussion, si l'on peut dire. L'auteur de ces lignes, qui avait eu le plaisir de siéger au jury de cette thèse de doctorat, ne peut que regretter que les remarques qui avaient été faites par lui et par les autres membres du jury lors de cette soutenance n'aient été que très incomplètement prises en compte. Si une thèse de théologie, pour être validée, doit être publiée, il serait bon cependant que cette publication soit soumise à vérification. Or non seulement des titres fondamentaux manquent toujours dans la bibliographie, comme l'ouvrage de Ch. Köckert ${ }^{35}$, qui concerne pourtant directement le sujet, mais toutes les erreurs, normales dans un tel travail au stade de la soutenance, n'ont pas été corrigées pour la publication, même lorsqu'elles étaient ponctuelles. La chose est regrettable, non seulement pour le lecteur, mais aussi pour l'auteur lui-même, et ne permet pas de suivre avec toute la confiance voulue la démonstration pourtant intéressante de F. Dubois.

Depuis plusieurs années, Michel CORBIN consacre à divers ouvrages patristiques des sortes de commentaires suivis entremêlés avec une traduction partielle du texte étudié, souvent issus de cours qu'il a pu donner au Centre Sèvres. Deux volumes parus en 2018 portent sur des textes de Grégoire de Nysse, respectivement sur le Discours catéchétique ${ }^{36}$ et sur les Homélies sur le Cantique des cantiques ${ }^{37}$. Dans aucun des deux cas, il ne faut y chercher un commentaire scientifique, qu'il soit philologique ou patristique, de l'œuvre présentée, mais bien un parcours spirituel fondé sur une lecture personnelle de l'œuvre nysséenne, appuyée

\footnotetext{
${ }^{33}$ Franck DuBOIS, Le corps comme un syndrome : une théorie de la matière chez Grégoire de Nysse, Paris, Cerf (coll. « Cerf Patrimoines »), 2018 ; $23 \times 15,5,471$ p., $39 €$. ISBN 978-2-204-12070-8.

${ }^{34}$ X. BATLlo, Ontologie scalaire et polémique trinitaire : le subordinatianisme d'Eunome et la distinction

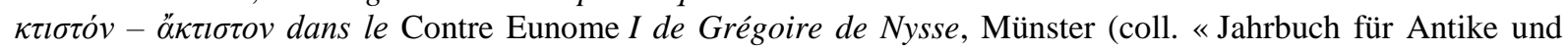
Christentum. Ergänzungsband. Kleine Reihe » 10), 2013.

35 Ch. KÖCKERT, Christliche Kosmologie und kaiserzeitliche Philosophie: die Auslegung des Schöpfungsberichtes bei Origenes, Basilius und Gregor von Nyssa vor dem Hintergrund kaiserzeitlicher Timaeus-Interpretationen, Tübingen (coll. «Studien und Texte zu Antike und Christentum » 56), 2009.

36 Michel CORBIN, Une catéchèse pascale de saint Grégoire de Nysse, Paris, Cerf (coll. «Cerf Patrimoines »), 2018 ; $23 \times 15,5,298$ p., $30 €$. ISBN : 978-2-204-10983-3.

37 Michel Corbin, Les homélies de Grégoire de Nysse sur le Cantique, Paris, Cerf (coll. «Cerf patrimoines »), $2018 ; 23 \times 15,5,467$ p., $34 €$. ISBN : 978-2-204-12283-2.
} 
sur de très larges citations de la traduction du texte, empruntée aux traductions disponibles en français (celle de R. Winling pour le Discours catéchétique, et celle d'Adelin Rousseau pour les Homélies sur le Cantique). Le lecteur familier des travaux sur Grégoire de Nysse peut être un peu décontenancé lorsqu'il voit présenter avec une tranquille certitude comme des vérités bien connues des hypothèses parfois même unanimement rejetées ; c'est trop peu dire que ces ouvrages ignorent tout des travaux récents sur l'évêque de Nysse, en particulier lorsqu'ils n'ont pas été publiés en langue française : même le Dictionnaire Grégoire de Nysse, paru en espagnol, en italien et en anglais ${ }^{38}$, n'est jamais cité, alors même que les articles de P. Maraval sur la vie de Grégoire et la chronologie de ses œuvres sont, à l'heure actuelle, la meilleure synthèse disponible sur le sujet. On n'y trouvera pas non plus mentionné les ouvrages essentiels pour l'étude de chacune des deux œuvres, par exemple l'étude de R. J. Kees sur le Discours catéchétique ${ }^{39}$ ou celles de F. Dünzl ou d'A. Cortesi sur les Homélies sur le Cantique ${ }^{40}$. On nous dira peut-être à bon droit que ce n'est pas l'objet du commentateur, qui propose un libre parcours interprétatif à partir de l'œuvre nysséenne. Il faudrait dans ce cas s'abstenir de donner des dates et des contextes, ou de faire de Grégoire «l'homme de confiance » de Théodose ; il faudrait aussi vérifier le contexte de composition des œuvres et leur objet : le Discours catéchétique n'est pas une catéchèse pascale - comme le veut le titre - mais un exemple, destiné à faire des catéchumènes, en donnant à ceux qui devaient amener à la foi païens (surtout) et juifs (secondairement) les moyens de les faire venir à la foi chrétienne, puis de leur en enseigner les rudiments.

Une fois ces choses dites, et si l'on ne cherche dans ces deux livres que leur lecture par Michel Corbin, dans le contexte ecclésial contemporain et à la lumière de la tradition théologique principalement occidentale - quelques auteurs anciens sont cités comme parallèles, mais c'est bien plus souvent à Anselme ou Thomas d'Aquin, ou même à Karl Barth, que recourt M. Corbin - les deux volumes valent la peine de la lecture. Pour qui veut se nourrir, à titre spirituel, à des œuvres patristiques de grande valeur, l'auteur fournit un guide agréable et intelligent; mais pour ceux qui y chercheraient une introduction ou un commentaire dans le cadre de travaux patristiques, il ne faudra les utiliser qu'avec une solide connaissance des travaux actuels sur ces œuvres et sur l'auteur et on ne peut que regretter que M. Corbin n'ait pas fait l'effort limité de mise à jour scientifique qui aurait évité de tels risques interprétatifs pour ses lecteurs non avertis. Peut-être la collection Cerf Patrimoine, où paraissent ces travaux, induit-elle aussi le lecteur en erreur: sans doute aurait-il mieux valu publier ces livres dans une collection de spiritualité.

\section{Titus de Bosra}

Après l'édition et la traduction du traité Contre les manichéens de Titus de Bosra ${ }^{41}$, l'équipe publie le dernier volet du triptyque consacré à cette œuvre, avec le volume de PaulHubert POIRIER et Timothy PeTTIPIECE sur les citations bibliques et manichéennes dans l'œuvre de Titus ${ }^{42}$. On ne reviendra pas sur la date et la nature du texte de l'évêque de Bosra,

\footnotetext{
${ }^{38}$ L. F. MATEO-SECO et G. MASPERo (éd.), The Brill Dictionary of Gregory of Nyssa, Leiden, Boston (coll. «Supplements to Vigiliae christianae»99), 2010, pour la version anglaise (Roma, 2007 pour la version italienne, et 2006 pour l'édition espagnole).

${ }^{39}$ R. J. KEES, Die Lehre von der Oikonomia Gottes in der « Oratio catechetica » Gregors von Nyssa, Leiden, New York (coll. « Supplements to Vigiliae Christianae » 30), 1995.

${ }^{40}$ Voir par exemple F. DüNZL, Braut und Bräutigam: die Auslegung des Canticum durch Gregor von Nyssa, Tübingen (coll. «Beiträge zur Geschichte der biblischen Exegese » 32), 1993 ; A. CORTESI, Le "Omelie sul Cantico dei cantici" di Gregorio di Nissa: Proposta di un itinerario di vita battesimale, Roma (coll. "Studia ephemeridis augustinianum »70), 2000.

${ }^{41}$ Sur cette dernière, voir « Bulletin de Patrologie », Rev. Sc. ph. th. 100, 2016, p. 475-476.

${ }^{42}$ Paul-Hubert PoIRIER et Timothy PeTtIPIECE, Biblical and Manichaean Citations in Titus of Bostra's Against the Manichaeans: An Annotated Inventory, Turnhout, Brepols (coll. «Instrumenta Patristica et Mediaevalia », 78), $2017 ; 24 \times 16$, relié, XXIV + 204 p. ISBN 978-2-503-57767-8.
} 
qui avait été rappelées en 2016, et la présentation ne portera que sur le contenu du présent volume ; il se divise en deux parties, répondant aux deux temps du titre : citations bibliques, citations manichéennes. Cependant, il ne faut pas se laisser tromper par la symétrie apparente ; en effet, si les citations bibliques peuvent être confrontées à un texte reçu et à une tradition manuscrite, y compris pour la version syriaque de l'œuvre de Titus, ce n'est bien évidemment pas le cas pour les citations manichéennes - terme qu'il faut d'ailleurs entendre en un sens beaucoup plus large que pour les citations bibliques, comme le précisent clairement les deux auteurs : tous les énoncés que l'auteur attribue à Mani ou à ses disciples qui peuvent au mieux être rapprochées de lieux parallèles chez d'autres auteurs. Le premier groupe comprend environ 205 citations (56 de l'Ancien Testament, 149 du Nouveau, ainsi qu'une citation non identifiée), le second, 120.

Pour l'Ancien Testament, l'analyse montre que le texte syriaque de Titus est le plus souvent très proche de celui de la Peshițta, sauf dans un certain nombre de cas où il semble refléter une traduction littérale du grec de Titus, ce que la partie conservée en grec permet de confirmer partiellement. Étant donné leur date (le manuscrit syriaque est daté de 411), ces citations constituent donc un témoignage important pour l'histoire du texte de la Peshița. Pour le Nouveau Testament, la situation est beaucoup moins unifiée pour la traduction syriaque; dans le cas des Évangiles et des Actes, on trouve tous les cas de figure (Peshitta, Vetus Syra, alignement sur le grec de Titus pour des variantes connues ou inconnues par ailleurs); la situation est équivalente pour le corpus paulinien, sans la Vetus Syra. Une présentation des études antérieures sur l'apport du traité de Titus à l'histoire du texte biblique est ensuite proposée, avant l'inventaire proprement dit, qui confronte systématiquement le texte de Titus aux textes édités en grec et en syriaque et commente les éventuels écarts.

La seconde partie, moitié moins longue, concerne les témoignages sur les textes manichéens. Le traitement de ce second corpus, dû à Th. Pettipiece, commence par une étude des modalités de citation biblique chez l'évêque de Bosra, afin de mettre en évidence la liberté qui est la sienne dans la reprise du texte sacré, et ce pour mieux comprendre la valeur à accorder à ses «citations » manichéennes. L'auteur rappelle en outre la difficulté qu'il y a à cerner la ou sans doute plutôt les sources manichéennes de Titus, qui n'étaient pas nécessairement toutes écrites, et ce d'autant plus que les doctrines manichéennes étaient ésotériques, comme le confirment l'absence presque totale dans les sources polémiques chrétiennes de nombreux éléments qui sont transmis par les rares écrits manichéens qui nous soient parvenus. Aussi les «citations » de Titus sont-elles bien moins des reproductions précises d'écrits que des souvenirs plus ou moins exacts des arguments manichéens. Ces «citations ", qui sont accompagnées de leur traduction anglaise, bénéficient d'un riche apparat de notes, lequel fournit les parallèles les plus éclairants et les plus significatifs.

On ne peut que féliciter les auteurs de l'ensemble du projet, qui avec ces trois livres ont fourni à la communauté scientifique non seulement un remarquable outil de travail, mais d'ores et déjà une première exploitation remarquable. Les trois volumes seront utiles, pour ne pas dire indispensables, à tous les spécialistes du christianisme ancien grec et syriaque tout comme aux spécialistes du manichéisme, mais aussi à ceux qui s'intéressent au texte biblique tant grec que syriaque.

\section{Gélase de Césarée}

Parmi les auteurs d'Histoire ecclésiastique de l'Antiquité tardive, Gélase de Césarée n'est sûrement pas le plus célèbre ; son œuvre a cependant joué un rôle important et la première édition critique de l'ensemble des fragments historiques et doctrinaux, que proposent Martin 
WALlRAFF, Jonathan STUTZ et Nicholas MARINIDES, constitue une avancée importante ${ }^{43}$. Presque l'exact contemporain de Grégoire de Nysse - le même synode constantinopolitain de 394 constitue pour l'un et pour l'autre le terminus post quem de leur mort, et l'on situe la naissance des deux évêques vers 335 - Gélase, neveu de Cyrille de Jérusalem, fut évêque de Césarée de Palestine. Sans qu'il atteigne la célébrité des grands historiens ecclésiastiques qui prirent la suite d'Eusèbe, la critique a accordé à son œuvre une place importante dans la reconstitution des sources perdues des historiens de l'Église. Le présent livre constitue donc l'aboutissement d'un processus de reconstruction commencé au début du XX $\mathrm{X}^{\mathrm{e}}$ siècle, et qui n'a que rarement été remis en cause en son ensemble ${ }^{44}$.

La situation de ce texte est en effet éminemment complexe : aucun fragment ne nous est parvenu directement, sans réécriture; la tradition la moins indirecte passe par l'Épitomé d'histoire ecclésiastique (Oxford, Bodleian Library, Barocci 142 ; Paris, BnF, grec 1555 ; Hagion Oros, Monè Batopediou, 286) et quelques rares citations explicitement attribuées. Les témoins utilisés pour la reconstitution sont cependant nombreux, et parfois fort célèbres, comme Rufin d'Aquilée, ou plus obscurs (Anonyme de Cyzique; Vie de Métrophane et d'Alexandre [BHG 1279]). La reconstruction a été menée avec soin, en se fondant soit sur les mentions explicites de l'auteur, soit sur le recoupement d'au moins deux témoins, rejetant donc dans l'ombre les passages dont la source est inconnue chez des auteurs qui ont utilisé Gélase - précaution nécessaire. Cependant, et comme les éditeurs le reconnaissent clairement, ce qui est présenté comme des fragments n'est dans la plupart des cas pas une reconstitution des mots mêmes de Gélase, qu'il est impossible d'atteindre à travers le filtre de ceux qui ont utilisé son œuvre, mais leur réécriture de son texte. L'Histoire de Gélase couvrait la période allant de la jeunesse de Constantin probablement jusqu'à la mort d'Athanase en 373, ou peu après. Le texte ne semble pas avoir jamais été divisé en livres. Enfin, les éditeurs font l'hypothèse et tentent de démontrer que nous avons conservé - sous la forme plus ou moins indirecte évoquée plus haut - plus de la moitié du texte de l'évêque de Césarée.

Après avoir présenté ce qu'on sait de l'auteur et l'histoire des recherches sur Gélase, les éditeurs présentent successivement les différentes sources utilisées pour la reconstitution du texte perdu. Photius est un témoin essentiel pour reconstruire l'œuvre de l'évêque de Césarée (en particulier Bibliothèque, 88-89 et 102). Mais c'est l'Histoire ecclésiastique de Rufin, et plus précisément son livre X, qui est l'une des sources essentielles des fragments ici édités. Socrate et Sozomène, dans une moindre mesure Théodoret, l'Anonyme de Cyzique, l'Épitomé mentionné plus haut, la Vie de Métrophane et d'Alexandre, évêques de Constantinople, la Vie d'Athanase (BHG 185) - seule source essentielle pour la présente édition pour laquelle une édition critique fasse défaut - la Chronique de Georges le Moine et divers textes hagiographiques contribuent à la reconstitution.

Les fragments doctrinaux sont plus réduits en nombre et surtout en ampleur. Ils avaient déjà été édités par Franz Diekamp en 1938 et dérivent pour l'essentiel du contexte des controverses christologiques. Ils sont conservés en grec ou en syriaque, le plus souvent dans des florilèges ou des recueils de citations doctrinales, entre autres chez Théodoret de Cyr, Sévère d'Antioche, Léonce de Byzance, la Doctrina Patrum ou encore Michel Glykas.

L'édition distingue entre Testimonia et Fragments - mais il faut garder en tête que les fragments ne reflètent pas forcément les mots mêmes de Gélase. Ils sont classés par ordre

\footnotetext{
${ }^{43}$ Martin WALlRAFF, Jonathan STUTZ et Nicholas MARINIDES, Gelasius of Caesarea. Ecclesiastical History: The Extant Fragments With an Appendix containing the Fragments from Dogmatic Writings, Berlin Boston, De Gruyter (coll. «Die griechischen christlichen Schriftsteller der ersten Jahrhunderte» N.F. 25), 2018; 24,5 × 17,5, relié, CXI + 294 p. ISBN : 978-3-11-047580-7.

44 Voir cependant P. VAN NUFFELEN, «Gélase de Césarée, un compilateur du cinquième siècle? ", Byzantinische Zeitschrift 95, 2002, p. 621-639, dont les positions sont discutées dans l'introduction du présent volume, p. XXVII-XXVIII.
} 
chronologique des événements qu'ils rapportent. Le texte dérive des éditions antérieures, dont l'apparat critique est repris ; il est complété par un apparat des parallèles (lieux bibliques et parallèles historiographiques), et un apparat qui fournit le texte des témoins secondaires. Les testimonia et fragments sont accompagnés d'une traduction anglaise et de notes. D'abondants index complètent le livre (Bible, auteurs anciens, manuscrits, noms propres), ainsi qu'une concordance avec la numérotation des fragments par Winkelmann.

Étant donné l'ampleur des textes et des sources utilisées, il est aisé de trouver des oublis ou des faiblesses secondaires, qui ne remettent en rien en cause la valeur d'ensemble de l'ouvrage et de l'édition; on en donnera cependant quelques exemples. Dans la discussion sur la date de mort de Gélase de Césarée, les auteurs se réfèrent au témoignage de la Vie de Porphyre de Gaza attribuée à Marc le diacre ; en effet, d'après ce texte, Jean de Césarée serait intervenu dans l'ordination de Porphyre, et cet évêque devrait être situé entre 395 et 400 . Il aurait été utile de se reporter à la nouvelle édition du texte par A. Lampadaridi, et à son étude d'ensemble de la Vie : elle montre sans conteste le caractère tardif du texte ${ }^{45}$; le témoignage sur l'existence d'un évêque de Césarée entre Gélase et Euloge est donc fragile, attesté qu'il est par la seule Vie de Porphyre, distante des événements de plusieurs décennies, voire d'un siècle ou plus. On regrettera que les manuscrits des différents textes utilisés ne soient mentionnés dans le corps de l'introduction que d'après leur sigle : une liste figure certes avant l'édition, mais la tâche du lecteur est ainsi compliquée. Pour les fragments doctrinaux, on mentionnera encore l'édition récemment parue de B. Daley pour Léonce de Byzance ${ }^{46}$.

Ce n'est pas le lieu d'entrer dans une discussion de la reconstruction du texte de Gélase : les spécialistes de l'historiographie ecclésiastique se pencheront de toute façon avec intérêt sur ce volume, mais aussi tous les spécialistes du $\mathrm{IV}^{\mathrm{e}}$ siècle. De même, tous ceux qui s'intéressent à l'édition de textes fragmentaires et à leur reconstruction pourront avec intérêt étudier la méthode proposée par les éditeurs, dont le travail constitue une avancée réelle dans le dossier Gélase.

\section{Jean Chrysostome}

L'édition des œuvres de Jean Chrysostome se poursuit lentement dans la collection des Sources chrétiennes; un nouveau volume, œuvre conjointe de Nathalie RAMBAULT et de Pauline ALLEN, apporte l'édition et traduction française annotée de cinq éloges de martyrs ${ }^{47}$ : Sur Juventin et Maximin (CPG 4349) ; Éloge de saint Romain (CPG 4353) ; Éloge de Julien, saint martyr (CPG 4360); Éloge de Barlaam, saint martyr (CPG 4361); Éloge des martyrs égyptiens (CPG 4363). Dans les cinq cas, il s'agit bien d'éloges, non de vies ou de discours funèbres : ce sont des pièces hautement rhétoriques, dans lesquelles les informations sur les martyrs qui font l'objet de la prédication sont rares, tout autant que les éléments sur le contexte dans lequel ils ont été prononcés. Les éditrices montrent que les cinq discours ont dû être prononcés à Antioche, avec certitude pour certains, avec forte présomption pour d'autres. Si la date calendaire est parfois connue avec une relative précision, il est en revanche

\footnotetext{
45 A. LAMPADARIDI, La conversion de Gaza au christianisme. La Vie de s. Porphyre de Gaza par Marc le Diacre (BHG 1570), Bruxelles (coll. «Subsidia hagiographica » 95), 2016, en particulier p. $24-25$; cependant, la date tardive de rédaction du texte (entre 445 et 556, selon l'auteur : voir p. 15-19) rend l'hypothèse précaire. L'éditeur a également montré clairement, contre les hypothèses de P. Peeters - repris dans le volume dirigé par M. Wallraff - qu'il n'y avait pas de Vie syriaque à la source de la Vie grecque, et que la Vie géorgienne était une traduction ad sensum du grec (voir en particulier p. 61-65).

${ }^{46}$ Voir «Bulletin de Patrologie », Rev. Sc. ph. et th. 102, 2018, p. 299-375, ici p. 337-339. On notera pour D4 l'omission (1. 11) de $\kappa \alpha \grave{~} \alpha \lambda \eta \theta \tilde{\eta} \pi \alpha ́ v \tau \alpha$ par les éditeurs, alors que l'expression figure bien dans le texte de Léonce (voir B. E. DALEY, Leontius of Byzantium: Complete Works, Oxford, New York, 2016, p. 226, 1), et est également attestée dans la citation syriaque de Sévère et donc dans la traduction anglaise des GCS, à la suite de l'édition de Diekamp.

${ }^{47}$ Nathalie Rambault et Pauline Allen, Jean Chrysostome, Panégyriques de martyrs, I, Paris, Cerf (coll. «Sources chrétiennes » 595), $2018 ; 19,5 \times 12,5,372$ p., $38 €$. ISBN : 978-2-204-12647-2.
} 
impossible, dans tous les cas, de déterminer l'année pendant laquelle ils ont été prononcés ; la localisation précise, à Antioche, se laisse parfois deviner. Les martyrs qui font 1'objet de ces prédications chrysostomiennes ont vécu à des époques assez variées, voire difficiles à situer : Juventin et Maximin ont été martyrisés sous Julien, le 29 janvier 363 ; Romain est, lui, une victime césaréenne martyrisée à Antioche en 303 ; de Julien et de Barlaam, on ne sait rien quant aux circonstances et à la période de leur martyr, de même que pour les martyrs égyptiens. On voit donc bien que l'intérêt de ces textes se situe davantage du côté du discours chrysostomien lui-même que du côté de son objet, les martyrs ; l'introduction du volume comporte d'ailleurs, après la présentation successive des cinq éloges, un chapitre sur le genre de l'éloge lui-même et son utilisation par Chrysostome.

Le texte grec des cinq éloges est accompagné d'une traduction française, due à Nathalie Rambault, qui se lit agréablement, et de notes, plus ou moins abondantes ${ }^{48}$, mais qui contribuent à situer le texte tant au sein de la rhétorique chrysostomienne que dans le cadre plus large des discours sur les martyrs et, éventuellement, de la situation géographique et historique évoquée. Quelques notes complémentaires plus longues complètent l'ouvrage ${ }^{49}$, suivies par un bref index scripturaire - un index des noms de personnes et de lieux aurait été utile.

Les cinq textes édités dans ce volume ont été transmis principalement par une famille de manuscrit dont les représentants les plus importants sont les Panegyrici chrysostomici naguère identifiés et étudiés par A. Ehrhard dans le cadre de son enquête sur les manuscrits hagiographico-liturgiques byzantins. Seul l'Éloge de Juventin et Maximin présente une tradition double, dont l'une des branches échappe à ce groupe dont le texte a été remanié et amélioré à l'époque byzantine et transmet, de ce fait, un texte plus lisse, trop honnête pour être original. La section de l'introduction qui concerne la tradition manuscrite et le classement des témoins n'est malheureusement pas à l'abri de reproches: les catalogues y sont inégalement cités, de même que l'étude fondamentale d'Ehrhard, souvent bien plus précise que certains catalogues ${ }^{50}$; certaines affirmations et généralisations sont discutables ${ }^{51}$, mais c'est surtout la méthode employée qui paraît problématique, au moins dans sa présentation, sinon dans ses résultats. Ainsi, le classement des témoins de l'éloge de Juventin et Maximin commence par l'affirmation que la double formulation du titre et de la doxologie «permettent de faire descendre les témoins de deux exemplaires différents » : si une telle divergence peut être un indice d'une telle dualité, elle n'en est en aucune façon une preuve, surtout quand on sait la variabilité des titres aux époques anciennes et médiévales. En deuxième lieu, toujours pour ce premier éloge, les éditrices montrent la cohérence de la famille $\beta$ à partir d'une série de fautes assez significatives, mais non la cohérence de la famille $\alpha\left(\mathrm{BJV}_{2}\right)$, qui présente toujours le bon texte. Dans cette même famille, la fin inachevée ou mutilée de l'Éloge dans $\mathrm{I}_{2}$ au bas d'un folio ne prouve pas que son modèle était mutilé, sauf à montrer qu'il n'y a pas de

\footnotetext{
${ }^{48}$ Elles auraient pu être parfois précisées ; ainsi, p. 182 n. 1, l'absence de nom propre de l'empereur ne relève sans doute pas principalement d'une damnatio memoriae, comme affirmé, mais plutôt de la pratique normale de la rhétorique oratoire, qui répugne aux noms propres et aux désignations trop précises.

${ }^{49}$ Décret De professoribus (Code Théodosien, XIII, 3, 6) ; Фı $\lambda \alpha v \theta \rho \omega \pi i ́ \alpha-\alpha ̉ \pi \alpha v \theta \rho \omega \pi i ́ \alpha$; Témoignages sur la clémence de l'empereur Julien ; Réprobation morale des spectacles.

${ }^{50}$ On notera aussi d'étranges formulations : ainsi «S. Spyridon-Eustratiades », comme auteur du catalogue de Lavra, au lieu du duo Spyridon Lauriotès (moine de Lavra) et Sophrone Eustratiadès. Ou encore (p. 106, n. 2), les liens supposés entre scriptoria du Stoudion, du Prodrome de Pétra et du Prodrome de Sozopolis monastères dont la période d'activité n'a que peu de recoupement et dont la qualification comme scriptoria reste problématique, sauf peut-être pour le premier. La circulation de manuscrits entre certains de ces monastères, dans des circonstances déterminées, évoquée par les articles cités dans la note, n'implique en aucune manière des liens réels pour la production de manuscrits, rendue impossible entre autres par l'absence de coïncidence chronologique.

${ }^{51}$ Ainsi, p. 90, l'affirmation que le nombre important de manuscrits des $\mathrm{XI}^{\mathrm{e}}-\mathrm{XII}{ }^{\mathrm{e}}$ siècles tient à «la prédilection croissante que porte l'église de l'époque aux vies de saints, de martyrs et aux récits de miracles ».
} 
perte de folio dans $I_{2}$, ce qui n'est pas fait ici. Enfin, le classement des témoins de $\beta$ est justifié par des rapprochements qui sont tantôt fondés sur des fautes, tantôt sur de bonnes leçons, ce qui est contraire à toute méthode d'édition critique des textes. On rencontre également plus loin quelques remarques déroutantes (p. 103-104) à propos des relations entre copie et modèle : jamais une copie n'est en tout identique à son modèle - dont on ne pourrait d'ailleurs la distinguer si elle n'avait des fautes propres. De tels soucis de méthode éditoriale jettent un doute certain tant sur les stemmas tracés par les éditrices que par le texte qu'elles proposent. Ce n'est pas le lieu dans ce bulletin de reprendre en détail le classement des manuscrits et l'établissement du texte, mais il est vivement souhaitable qu'une collection comme les Sources chrétiennes veille avec plus de soin sur la méthode des éditions qu'elle propose.

Malgré ces critiques, il demeure que ce volume sera utile tant aux spécialistes de Chrysostome qu'à ceux qui s'intéressent aux éloges tardo-antiques et aux formes littéraires liées au culte des saints - peut-être moins directement aux spécialistes des saints, cependant.

Alors que bien des textes de Jean Chrysostome attendent encore une édition critique et une traduction dans une langue moderne, d'autres ont fait, ces dernières décennies, l'objet de plusieurs éditions et de plusieurs traductions. C'est par exemple le cas du Commentaire sur Job (CPG 4443), dont Lucio CoCO vient de donner une traduction italienne ${ }^{52}$. C'est ici l'édition de H. Sorlin, parue dans la collection Sources chrétiennes en deux volumes en 1988 $\left(\mathrm{n}^{\text {os }} 346\right.$ et 348), et non celle de D. et U. Hagedorn (Patristische Texte und Studien 35, 1990), éminents spécialistes des commentaires anciens sur Job, qui est utilisée, sans qu'aucune justification en soit donnée. Ce texte chrysostomien, tardivement redécouvert par Angelo Maria Bandini dans son catalogue des manuscrits de la Biblioteca Medicea Laurenziana de Florence (1764) et qui avait échappé aux grandes entreprises éditoriales consacrées à l'évêque de Constantinople, tant celle d'Henry Savile que celle de Bernard de Montfaucon, resta inédit jusqu'à l'édition de H. Sorlin. On a soulevé des doutes assez sérieux sur sa paternité, du fait de sa forme littéraire, en particulier : le commentaire est assez fragmenté et manque de ligne directrice ; cependant, aucun argument définitif n'a été apporté.

Le présent volume offre donc la première traduction italienne de ce texte chrysostomien, qui propose un commentaire suivi de l'ensemble du livre de Job. L'introduction présente brièvement l'auteur, les circonstances d'édition du texte et son contenu ; comme de règle dans cette collection, les notes sont très restreintes et se contentent de fournir les éléments minimaux pour comprendre le texte, sans chercher à le situer dans la tradition patristique d'explication du livre de Job. On sait l'importance de ce livre biblique pour la question du mal et du rapport de l'homme à Dieu : l'interprétation chrysostomienne, si proche du texte et tournée vers un sens moral qu'elle soit, présente donc un intérêt réel pour qui voudrait mieux comprendre $J o b$, mais aussi pour qui s'intéresse à l'exégèse chrysostomienne de l'Ancien Testament. Le livre est complété par un index biblique et un index des noms propres.

Outre le Commentaire sur Job, la collection Testi patristici a publié en 2018 une autre traduction de Jean Chrysostome, due cette fois à Domenico CiARLO, pour le traité sur les cohabitations suspectes $(C P G 4311-4312)^{53}$. Ce traité double avait fait l'objet dès 1955 d'une édition critique par J. Dumortier, qui est ici utilisée. Il porte condamnation de la cohabitation entre moines ou ascètes, d'une part, et vierges, d'autre part, qui sont respectivement les cibles des deux traités; dans les deux cas, il s'agit de diatribes, au sens qu'a ce genre dans la

\footnotetext{
${ }^{52}$ Lucio Coco, Giovanni Crisostomo, Commento a Giobe, Roma, Città Nuova (coll. « Testi patristici », 256), $2018 ; 20 \times 13,5,261$ p., $30 €$. ISBN 978-88-311-8256-0.

53 Domenico Ciarlo, Giovanni Crisostomo, Le coabitazioni, Roma, Città Nuova (coll. « Testi patristici », 254), $2018 ; 20 \times 13,5,133$ p., $20 €$. ISBN 978-88-311-8254-6.
} 
littérature antique, bien à sa place pour un tel sujet qui concerne au premier chef la conduite de la vie, ce que la théologie classique appellerait la morale. La date de ces traités n'est pas assurée, non plus que leur contexte de production, et les témoignages anciens à ce sujet demeurent contradictoires; le traducteur soutient une datation au début de l'activité de Chrysostome, pendant la période du diaconat - donc à Antioche - et considère qu'il appartient de plein droit au corpus ascétique de l'auteur, tel qu'il est constitué dans la tradition manuscrite. Les arguments pour justifier cette datation, du moins tels qu'ils sont exposés brièvement dans l'introduction, sont cependant assez faibles et ténus. L'essentiel de l'introduction est cependant consacré à un panorama sur la question des cohabitations suspectes, envisagées d'ailleurs sous leurs différentes appellations ( $\sigma v v \varepsilon i ́ \sigma \alpha \kappa \tau o 1$, subintroductae, agapetae), depuis les textes pauliniens (1 Co en particulier) jusqu'aux différents textes d'époque patristique, dont bon nombre sont d'attribution discutée ${ }^{54}$ et plus encore de datation incertaine ${ }^{55}$, et aux textes conciliaires jusqu'à la fin du $5^{\mathrm{e}}$ siècle.

Après cette mise en perspective, l'analyse du texte lui-même est en revanche réduite et plutôt rejetée dans les notes de la traduction, un peu plus abondantes dans ce volume que dans les autres livres de la même collection présentés cette année. Une traduction italienne d'un tel texte est, quoi qu'il en soit, une bonne nouvelle, et on ne peut que saluer l'inlassable activité des collègues italiens et des directeurs de cette collection, au service de la recherche et d'une plus large connaissance des textes patristiques.

\section{Cyrille d'Alexandrie}

Nombreuses sont encore les cuvres de Cyrille d'Alexandrie pour lesquelles on ne bénéficie encore ni d'une édition critique véritable, ni d'une traduction en langue moderne. C'était également le cas de son monumental Commentaire sur Jean, en douze livres; le premier volume (livre I) vient de paraître dans la collection Sources chrétiennes, dans une édition et traduction dues à Bernard MEUNIER ${ }^{56}$, précédent titulaire de ce Bulletin. Cet épais volume comprend à la fois l'introduction générale à l'édition du commentaire, qui sera l'œuvre de plusieurs auteurs, l'introduction du premier livre, son édition et sa traduction, accompagnées de notes, ainsi que quelques notes complémentaires en fin d'ouvrage et un index scripturaire. L'introduction présente d'abord les éléments de contexte et d'approche globale de ce commentaire, qui remonte assez haut dans la production de Cyrille et est situé par l'auteur à la période qui lui est traditionnellement attribuée, à savoir entre 425 et 428/429, soit entre la Lettre festale de 424, qui marquerait la nouveauté de l'intérêt cyrillien pour le débat avec Eunome, et les débuts de la controverse nestorienne. Si ces critères sont faibles et tout de vraisemblance, on ne dispose pas à ce jour d'éléments plus probants. L'exégèse de Cyrille dans ce commentaire, et en particulier dans ce premier livre, est essentiellement doctrinale - l'éditeur écrit systématiquement «dogmatique »; au contraire des discours, les sections narratives sont traitées par Cyrille beaucoup plus rapidement.

\footnotetext{
${ }^{54}$ Pour la paternité du traité De la véritable intégrité dans la virginité, il faut au moins signaler, aux côtés de l'article classique de F. Cavallera, l'ouvrage d'A. BURGSMüLlER, Die Askeseschrift des Pseudo-Basilius, Untersuchungen zum Brief Über die wahre Reinheit in der Jungfräulichkeit, Tübingen (coll. « Studien und Texte zu Antike und Christentum » 28), 2005, qui, s'il ne résoud pas définitivement la question d'attribution, montre cependant la grande fragilité de l'attribution à Basile d'Ancyre proposée naguère par F. Cavallera.

55 Ainsi, pour le traité Sur la virginité de Grégoire de Nysse, il serait bon de ne pas présenter comme parfaitement assurée la datation proposée naguère par M. Aubineau mais discutée ensuite, sur des bases solides, tant par J. GRIBOMONT, «Le panégyrique de la virginité, œuvre de jeunesse de Grégoire de Nysse », Revue d'ascétique et de mystique 43, 1967, p. 249-266, que par R. STAATS, « Messalianism and Antimessalianism in Gregory of Nyssa's De virginitate », Patristic and Byzantine Review 2, 1983, p. 27-44; IDEM, «Basilius als lebende Mönchsregel in Gregors von Nyssa De Virginitate », Vigiliae Christianae 39, 1985, p. 228-255.

56 Bernard Meunier, Cyrille d'Alexandrie, Commentaire sur Jean. I, Livre I. Texte grec, introduction, traduction, notes et index, Paris, Cerf (coll. «Sources chrétiennes », 600), $2018 ; 19,5 \times 12,5,634$ p., $59 €$. ISBN : 978-2-204-13156-8.
} 
Ce premier livre couvre Jn 1, 1-28; le traitement de ces premiers versets permet d'évoquer successivement des positions adoptianistes, monarchianistes, ariennes, eunomiennes ${ }^{57}$, polythéistes, mais aussi peut-être origénistes, à propos de la préexistence des âmes, tout autant que contre les positions anthropomorphites. Ce résumé ne rend cependant qu'imparfaitement compte d'une exégèse qui traite également de christologie, bien sûr, mais aussi de l'Esprit, ou encore de Moïse au regard de ceux qui l'ont suivi, jusques et y compris au regard du Christ.

L'introduction rassemble bien des études ponctuelles intéressantes. On relèvera par exemple le cas de l'emploi de l'adverbe $\delta i \eta \eta \mu \alpha \tau \iota \kappa \tilde{\omega} \varsigma$ pour introduire des raisonnements syllogistiques, qui laisse perplexe, comme le souligne l'auteur ${ }^{58}$. On signalera également l'intéressante question des thèses, voire des citations, attribuées à Eunome ou à ses disciples, qui occupent une place non négligeable dans la discussion cyrilienne, et qui avaient été laissées de côté par R. P. Vaggione dans son édition des œuvres eunomiennes - au contraire des éléments de même type qui sont présents dans le Thesaurus. Ces matériaux, qui présentent parfois des positions eunomiennes qui ne sont pas attestées par ailleurs, demanderaient, comme le dit l'auteur lui-même, un traitement particulier, qui devrait les mettre en série avec les autres éléments du même type dont témoigne Cyrille. En revanche, d'autres dossiers sont traités de manière cursive, mais avec des omissions un peu surprenantes; ainsi pour l'usage du syllogisme en théologie : après Théodoret, B. Meunier passe au $12^{\mathrm{e}}$ siècle, avant d'évoquer brièvement Jean Damascène puis de revenir au $13^{\mathrm{e}}$ siècle, laissant ainsi de côté l'essentiel de la période qui voit l'utilisation importante de ce mode de raisonnement, précisément dans les controverses christologiques. Il est vrai que la matière couverte est déjà très vaste pour une introduction.

L'édition du texte repose sur quatre manuscrits, répartis en deux branches (B [Città del Vaticano, BAV, Barb. gr. 504], d'une part, et M [Venezia, Bibl. Nazionale Marciana, gr. Z 121], D [Città del Vaticano, BAV, Vat. gr. 592] et E [Vat. gr. 593] d'autre part). L'éditeur a consulté et relevé une abondante tradition indirecte, mais l'a pour l'essentiel écartée; d'ailleurs, plutôt que des listes d'occurrences dans l'introduction, le lecteur aurait apprécié de disposer d'un apparat de la tradition indirecte sous le texte, qui aurait permis de mieux voir les passages qui ont retenu l'attention des lecteurs anciens. Les jugements portés sur l'absence de valeur éditoriale des florilèges et des chaînes exégétiques surprennent un peu, au vu de ce qu'on sait d'autres textes anciens; il est d'ailleurs réducteur d'opposer citations exactes des florilèges aux réécritures des chaînes : dans les deux formes littéraires, on peut trouver tant l'une que l'autre situation. Qu'on permette d'autre part au recenseur, qui est l'un des administrateurs de la base de données Pinakes (http://pinakes.irht.cnrs.fr), mentionnée de manière peu flatteuse dans l'ouvrage, quelques rectifications factuelles : les données de cet outil, qui paraît pourtant être de quelque utilité à la communauté scientifique, proviennent des catalogues, et ne sont qu'exceptionnellement vérifiées sur les manuscrits ou à travers d'autres sources. Aussi l'erreur sur le contenu du manuscrit Milano, Bibl. Ambrosiana, A 184 sup. (cité p. 129), remonte-t-elle au catalogue de Martini et Bassi, qui identifie le texte comme Commentaire de Cyrille, avec des divergences par rapport à l'édition, sans y reconnaître une chaîne. Il en va de même pour le ms. Hagion Oros, Monè Stavronikita, 77 (catalogue de S. Lampros). Pour le ms. Sankt-Peterburg, Rossijskaja Nacional'naja biblioteka (RNB), Ф. № 573, 72, l'indication est claire dans Pinakes : il y a plusieurs textes d'auteurs divers sur les

\footnotetext{
${ }^{57}$ L'auteur reprend la reconstitution traditionnelle qui fait des positions d'Eunome la suite de l'arianisme, voire un nouvel arianisme; on tend à nuancer aujourd'hui de telles filiations hérésiologiques, d'autant qu'Eunome ne se réclame jamais d'Arius ni des textes «ariens » de la première moitié du $\mathrm{IV}^{\mathrm{e}}$ siècle, et que Basile de Césarée comme Grégoire de Nysse n'établissent jamais nettement de filiation explicite qui rattacherait Eunome à Arius.

${ }^{58}$ Voir p. 69-70 ; aux références citées, on serait tenté d'ajouter des exemples rhétoriques, en particulier AnONyme de Seguier, Art rhétorique, 112, 9 ; PSEUdo-Hermogene, De l'invention, IV, 8, qui confirment le sens de mode narratif, par opposition à d'autres modes rhétoriques.
} 
ff. 1-25, situation signalée par le double tiret ${ }^{59}$; c'était l'ancienne manière de mentionner chaînes et florilèges, utilisée pour toutes les données insérées à Toronto, avant 1995, et encore un peu après. Il en va de même pour le ms. Firenze, Biblioteca Medicea Laurenzian, plut. 86.8. Pour les citations ultérieures, on signalera l'édition de B. Daley pour Léonce de Byzance, sans doute parue trop tard pour être utile à l'auteur ${ }^{60}$. On se demande également si c'est volontairement que l'auteur s'en est tenu, dans sa liste des témoins secondaires, aux florilèges doctrinaux et a laissé de côté les florilèges spirituels, dans lesquels on trouve également des citations du Commentaire ${ }^{61}$. Le recenseur se demande également si les citations de Pierre de Callinique, conservées il est vrai uniquement en syriaque, ne pourraient avoir une valeur importante pour l'étude du texte, étant donné leur date et leur importance pour l'édition d'autres traités ; elles semblent avoir été écartées par l'éditeur.

Le texte grec présente peu de différences par rapport à l'édition antérieure de Pusey ; l'éditeur en recense une trentaine. Il est cependant établi avec plus de sûreté, même si on aimerait pouvoir mieux mesurer la forme des citations anciennes. La traduction est claire et fidèle, et permet de prendre aisément connaissance de cette vaste œuvre, qui présente des richesses d'ordres très divers. On relèvera en passant que le commentaire présente une division en chapitres, qui remonte à Cyrille lui-même et est annoncée dans le prologue ; ces chapitres confirment la teneur majoritairement doctrinale du commentaire. Les notes sont maintenues dans des dimensions raisonnables, mais fournissent cependant des matériaux utiles à la lecture et à l'interprétation; elles sont complétées par quelques notes de fin, plus amples. On proposera ici quelques compléments, y compris pour l'introduction. La variante

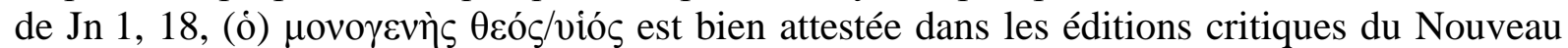
Testament, contrairement à ce qu'affirme l'auteur ${ }^{62}$. Le traité Aduersus Arium et Sabellium (CPG 3141) n'est plus depuis longtemps attribué à Grégoire de Nysse. Pour un répertoire des mentions d'Aristote chez les Pères, on consultera, plutôt que l'article vieilli de J. de Ghellinck, l'étude de D. T. Runia ${ }^{63}$; on notera d'ailleurs à ce propos (voir p. 64-65) que les accusations tournées contre Eunome de recourir à la technologie et au syllogisme paraissent polémiques, comme l'ont montré les études récentes sur le Contre Eunome de Grégoire de Nysse - au contraire de son maître Aèce, dont le Syntagmation est à cet égard caractéristique. On relèvera aussi que l'interprétation anti-hérétique du «prologue» johannique, destiné par avance à réfuter les hérétiques, se trouve déjà dans le Contre Eunome III.2.16-27 de Grégoire de Nysse, livre dont Cyrille a manifestement connaissance, et qui pourrait l'avoir inspiré sur ce point; Grégoire y montre en effet comment le prologue réfute par avance la position d'Eunome, par une affirmation claire et pédagogique de la foi, ce qui n'est pas sans rappeler la lecture cyrillienne.

Qu'on excuse la longueur des remarques sur le présent ouvrage : cette ampleur n'indique pas un défaut du livre, mais bien l'intérêt que l'auteur de ces pages a pris à lire le travail de B. Meunier, qui a ainsi rendu un service signalé à la communauté scientifique, en rendant aisément accessible le texte de Cyrille. Il ne reste plus qu'à souhaiter bon courage aux

\footnotetext{
${ }^{59}$ Voir https://pinakes.irht.cnrs.fr/mode-d-emploi.html.

${ }^{60}$ Voir «Bulletin de patrologie », Rev. Sc. ph. et th. 102, 2018, p. 299-375, ici p. 337-339 (édition parue en 2016).

${ }^{61}$ On signalera aussi que Jean VI Cantacuzène figure à deux reprises (p. 146 et 149), comme deux auteurs différents, répondant tantôt au patriarche latin de Constantinople, tantôt à celui de Jérusalem : seule la première localisation patriarcale est juste. Pour Scholarios, il aurait mieux valu utiliser, pour identifier les citations éventuelles, l'édition des CEuvres complètes dirigée par L. Petit, X. Sidéridès et M. Jugie, 1928-1936, plutôt que la $P G$.

${ }^{62}$ Voir E. et E. NestLe, B. et K. Aland et alii, Nouum Testamentum Graece, Stuttgart, $2001^{27}$.

${ }^{63}$ D. T. RUNIA, «Festugière revisited : Aristotle in Greek Patres », Vigiliae Christianae 43, 1989, p. 1-34. Voir aussi l'ouvrage tout récent de M. J. EDWARDS, Aristotle and Early Christian Thought, 2019.
} 
différents savants, dont B. Meunier, qui ont en charge les autres livres, car c'est une entreprise de longue haleine qui les attend, et dont tous espèrent voir les fruits.

Qu'on permette au recenseur d'ajouter, au milieu des épais ouvrages ici présentés, un petit volume sur lequel on a bien voulu attirer son attention. Il réunit quelques-unes des publications - et des inédits - de Jean-Marie LABELLE ${ }^{64}$, qui a longtemps enseigné à 1'Université de Strasbourg, d'abord en sa faculté de théologie catholique puis en Sciences de l'éducation. La présence de ce petit volume dans ce bulletin tient à ce qu'il contient la nouvelle édition d'un long article en deux parties, que l'auteur avait consacré à Cyrille d'Alexandrie, dans la Revue des sciences religieuses, en 1978 et $1979^{65}$. Il y étudiait les rapports de Cyrille avec la philosophie de son temps. Cet article est complété par un inédit, «Cyrille et l'unité des chrétiens », qui est constitué pour l'essentiel par une traduction et un commentaire d'un passage du Commentaire sur Jean de Cyrille (XI, 11). Les deux textes sont précédés d'un entretien avec Françoise Vinel, professeur émérite de la même Université et spécialiste de patristique. Ces deux textes seront sans doute utiles aux spécialistes de Cyrille, même si certains aspects en sont nécessairement dépassés - on pense en particulier aux progrès des connaissances sur le néoplatonisme tant athénien qu'alexandrin, aussi bien que sur ses phases plus anciennes. Mais la présentation d'ensemble de la vie et de la carrière de J.M. Labelle, par lui-même et par l'éditeur du volume, offrent également un réel intérêt dans le domaine de l'histoire de l'Église de France et plus particulièrement de sa frange intellectuelle et enseignante. Histoire somme toute classique d'un enfant tôt destiné au séminaire, ordonné et se tournant vers les études théologiques, et qui, après mai 68 et le grand vent de renouveau du Concile, quitte l'état clérical, se marie, et se voit retirer par Rome sa licentia docendi; d'où une réorientation subie d'abord, réappropriée ensuite, vers les sciences de l'éducation. Avec ce petit volume, la faculté de théologie reconnaît ainsi, à quelques décennies de distance, sa dette envers J.-M. Labelle, tout en offrant au lecteur un livre touchant et intéressant.

\section{Cyrille d'Alexandrie et Théodore de Mopsueste : exégèse}

Deux exégètes dont on a coutume de dire que tout les oppose, Théodore de Mopsueste et Cyrille d'Alexandrie, forment l'objet du livre de Hauna T. ONDREY ${ }^{66}$ : il s'agit d'une version remaniée de sa thèse de doctorat de l'Université de St Andrews. L'ouvrage compare l'interprétation que les deux auteurs donnent du corpus des douze prophètes (ou petits prophètes) dans leur commentaire respectif. Cependant, et c'est ce qui fait l'originalité du livre, l'auteur choisit non de comparer ponctuellement leur exégèse, verset par verset ou prophète par prophète, mais d'en dégager les fondements herméneutiques et l'orientation générale. Partant de caractérisations reçues des deux exégèses de l'Ancient Testament - celle de Théodore serait infra-chrétienne, rejetant toute lecture messianique et christologique de l'Ancient Testament, quand celle de Cyrille serait christocentrique et verrait dans l'Ancien Testament une série de prophéties du Christ - H. T. Ondrey examine de près leurs commentaires des Douze afin de préciser l'image générale, voire de la rectifier; elle y parvient assez bien, mettant en lumière une complexité plus grande que la réduction précédente et faisant voir comment l'attitude des deux auteurs varie en fonction des passages

\footnotetext{
${ }^{64}$ Jean-Marie LABELLE, Croire et penser. Approches théologiques, éd. Marc FEIX, Strasbourg, ERCAL Publications (coll. «Histoire contemporaine du catholicisme en Alsace », 25), 2019 ; 20,5 × 14,5, 268 p., $15 €$. ISBN : 9782905919243.

65 J.-M. LABELLE, «Saint Cyrille d'Alexandrie, témoin de la langue et de la pensée philosophiques au $\mathrm{V}^{\mathrm{e}}$ siècle », Revue des sciences religieuses 196 et 199, 1978 et 1979, p. 135-158 et 23-42.

${ }^{66}$ Hauna T. ONDREY, The Minor Prophets as Christian Scripture in the Commentaries of Theodore of Mopsuestia and Cyril of Alexandria, Oxford, New York, Oxford University Press (coll. « Oxford Early Christian Studies »), $2018 ; 22,5 \times 14,5$, relié, XI + 268 p. ISBN 978-0-19-882453-4.
} 
considérés, si bien que toute généralisation telle que celle qui a été rappelée ci-dessus fausse clairement la perspective.

La question qui sous-tend le livre est, au-delà des deux auteurs considérés, celle de l'opposition supposée entre école exégétique d'Antioche et école exégétique d'Alexandrie ; l'auteur consacre d'ailleurs une part significative de son assez longue introduction à cette dichotomie, à ses limites et aux critiques qui lui ont été de longtemps adressées, ainsi qu'aux solutions qui ont été proposées pour la remplacer. Elle retient en particulier les suggestions de Lewis Ayres (grammatical et figural - avec une distinction supplémentaire en figural et bad figural) et de Peter Martens (literal et nonliteral - subdivisé à son tour en better and worse nonliteral), parmi lesquelles la première a sa préférence. Cependant, d'une manière assez déconcertante, cet exposé liminaire, qui présente un réel intérêt ne serait-ce que pour la synthèse des discussions qu'il propose, ne conditionne pas vraiment la suite du livre : l'auteur reprend en effet largement par la suite l'opposition entre école d'Antioche et école d'Alexandrie, entre lecture historique et typologique, et allégorie, sans faire un usage autre qu'anecdotique des catégories d'analyse qu'elle a elle-même présentées. Le lecteur le regrettera un peu, dans la mesure où une telle reprise des catégories anciennes affaiblit l'exposé et en limite parfois la finesse d'interprétation.

L'ouvrage est construit en quatre parties successives ; la première, qui comporte un unique chapitre, étudie les commentaires de Théodore et de Cyrille sur les douze en les comparant à ceux de Didyme d'Alexandrie et de Jérôme de Stridon, sous l'angle du rapport à l'histoire, afin de montrer que les deux auteurs qui sont l'objet du présent livre prêtent une attention réelle à l'histoire : selon $\mathrm{H}$. T. Ondrey, Théodore et Cyrille, s'ils n'abordent certes pas le texte dans une perspective historico-critique, comme on le leur reproche parfois de manière anachronique, cherchent cependant à montrer que les prophéties des Douze correspondent à des événements réels et témoignent de l'action salvifique de Dieu dans l'histoire, non seulement par la prophétie mais par sa réalisation dans l'histoire d'Israël. La seconde partie, qui aborde en deux chapitres successifs Théodore puis Cyrille, s'intéresse à la compréhension qu'ont les deux exégètes du rôle des prophéties des Douze au sein de l'histoire d'Israël. L'auteur montre que Théodore souligne l'importance des Douze dans la prédiction d'événements pour le peuple hébreu et dans la formation de ce dernier pour qu'il connaisse le Dieu unique ; la relation des Douze à l'annonce messianique est plus limitée, dans la mesure où l'auteur voit surtout ce corpus comme incitant Israël à l'attente du Messie, plus qu'il n'annonce explicitement le Christ, sa vie et sa mort. Cyrille, au contraire, met l'accent sur le rôle d'éducation à la Loi que jouent les Douze, secondairement à la connaissance de la nature divine ; s'il voit dans le corpus des annonces du Christ, elles ne sont cependant clairement accessibles qu'après l'Incarnation, la Passion et la Résurrection. La troisième partie s'attache à la lecture des petits prophètes lorsqu'ils sont considérés comme Écriture chrétienne, et non plus au sein du seul judaïsme. H. T. Ondrey montre comment Théodore dégage des correspondances dans l'action salvifique de Dieu entre Ancien et Nouveau Testaments, qui démontrent la continuité de son action et de sa volonté de Salut dans l'histoire. Cyrille mettrait au contraire l'accent sur la définition d'une identité chrétienne, distincte de celles des juifs et des païens, et sur la victoire sur Satan. Leurs deux lectures sont caractérisées, de manière synthétique, comme téléologique pour Théodore, typologique pour Cyrille. La dernière partie forme conclusion et compare de manière synthétique les approches des deux auteurs, tout en les mettant en perspective au sein de leur réception par l'Église, à travers en particulier la condamnation de Théodore et son élévation en Orient.

L'intérêt de l'auteur porte nettement sur l'étude comparée des deux commentaires au plan théologique et exégétique ; il ne faut pas y chercher d'avancées dans le domaine historique rien de neuf pour la datation des deux Commentaires; acceptation sans discussion d'une thèse toujours surprenante, et pourtant admise, qui accorde à Cyrille d'Alexandrie une connaissance 
directe des commentaires exégétiques de Jérôme, ce qui supposerait soit que Cyrille lisait le latin, soit qu'il y ait eu une traduction intégrale de ces commentaires en grec ; affirmation qu'Origène est le premier à produire un commentaire chrétien de l'Écriture, sans que mention ne soit faite d'Hippolyte. En revanche, l'ouvrage fourmille de remarques d'un grand intérêt, par exemple sur l'absence de spiritualisation progressive du culte à l'époque des prophètes, selon Cyrille, pour lequel la transformation se ferait d'un coup, à la venue du Christ, ou encore sur la distinction, dans l'exégèse de Théodore, entre la présence de prophéties vétérotestamentaires du Christ (en nombre limité) mais le refus d'une lecture typologique rétrospective.

L'ouvrage de H. T. Ondrey offre donc une lecture stimulante des deux commentaires sur les Douze prophètes de Théodore de Mopsueste et Cyrille; s'il n'en constitue pas un commentaire suivi, non plus qu'une comparaison systématique de leurs exégèses, il en propose cependant une lecture comparée synthétique et thématique, qui en dégage bien les enjeux et en affine la caractérisation, réhabilitant par là-même l'interprétation de Théodore sans en nier les limites et l'orientation propre. La lecture du livre sera utile non seulement aux spécialistes des deux auteurs, mais aussi à tous ceux qui étudient l'exégèse de l'Ancien Testament, car les angles d'approche retenus peuvent éclairer l'étude que l'on fera de l'interprétation de bien d'autres livres bibliques.

\section{Théodoret de Cyr}

Théodoret, évêque de Cyr, actif au $5^{\mathrm{e}}$ siècle de notre ère, a reçu une attention relativement soutenue pendant les dernières décennies, en particulier pour ses positions dans les débats christologiques mais aussi pour sa correspondance, assez abondante. Les études de son œuvre exégétiques sont un peu plus rares, mis à part les travaux et éditions fondamentaux de JeanNoël Guinot. Le volume d'Agnès LORRAIN ${ }^{67}$ vient combler un peu ce déficit relatif et annonce surtout une édition à venir du Commentaire des épîtres pauliniennes, point très important étant donné le déficit d'éditions critiques pour les œuvres exégétiques de Théodoret. Issue d'une thèse de doctorat soutenue en décembre 2015 à Sorbonne Université, cette double entreprise d'étude et d'édition permet donc à l'auteur de proposer un traitement d'ensemble, dans un premier temps, du Commentaire sur l'Épître aux Romains. En attendant l'édition du texte, annoncée dans la collection des Griechischen Christlichen Schriftsteller, A. Lorrain propose dans ce volume une étude d'ensemble de ce premier volet du commentaire paulinien de Théodoret. La principale difficulté pour aborder ce texte, comme l'auteur le souligne elle-même, consiste non tant dans la complexité et l'élaboration de l'exégèse de Théodoret que dans son caractère lisse et paraphrastique, au moins en première approche. Aussi, plutôt que d'en proposer une étude linéaire ou même thématique, A. Lorrain a préféré aborder le texte à travers le plan suivant: introduction; langue de Théodoret; prologue général de l'In epistulas Pauli; rapport de l'exégèse de Théodoret à celle de Jean Chrysostome ; rapports entre exégèse et polémique dans le Commentaire sur Romains. Le deuxième chapitre, consacré à différents traits de la langue, et en particulier du vocabulaire, du commentaire, est sans doute l'élément le moins bien intégré du présent volume, dans la mesure où cette série de courtes fiches sert à la fois à l'édition du texte grec et à divers points du commentaire présenté dans ce volume. Si sa lecture séparée est donc en soi intéressante, elle laisse cependant le lecteur quelque peu sur sa faim. L'étude sur les sources de Théodoret dans son commentaire a été volontairement limitée au seul Chrysostome, laissant de côté, par exemple, Origène ou Théodore de Mopsueste, pour de bonnes raisons - écart interprétatif, transmission extrêmement fragmentaire - mais une comparaison avec les autres

\footnotetext{
${ }^{67}$ Agnès LORRAIN, Le Commentaire de Théodoret de Cyr sur l'Épître aux Romains. Études philologiques et historiques, Berlin, Boston, Walter de Gruyter (coll. «Texte und Untersuchungen zur Geschichte der altchristlichen Literatur », 179), 2018 ; 24,5 × 17,5, relié, XV + 392 p. ISBN 978-3-11-053788-8.
} 
interprétations aurait cependant été éclairante pour mieux saisir l'originalité de Théodoret. L'auteur conclut également à l'impossibilité, en l'état, de dater ce commentaire, même relativement par rapport aux autres œuvres de Théodoret. On notera aussi, dans le chapitre premier, une intéressante réflexion sur le rapport au texte biblique commenté, même si les catégories employées ne semblent pas toujours adéquates, en particulier lorsque la juxtaposition des lemmes, isolés du commentaire, est lue comme une «marque de respect pour la littéralité du texte »(p.15): on penserait plus volontiers à une simple pratique scolaire.

Le chapitre deuxième, qui porte sur la langue et les expressions, est sans aucun doute le plus discutable, au moins dans sa forme et sa position actuelle. L'auteur a choisi de s'appuyer largement sur le $T L G$, ce qui est sans doute la meilleure méthode, mais encore aurait-il fallu ne pas se fier aux datations et attributions de cet outil. Ainsi des références à Éphrem, qui sont présentées comme datant du $4^{\mathrm{e}}$ siècle et attribuées à Éphrem le Syrien, alors qu'on sait combien les attributions sont problématiques dans ce corpus et les datations complexes à établir $^{68}$. On pourrait d'ailleurs multiplier les exemples de ce genre, avec des attributions fautives à Grégoire de Nysse ${ }^{69}$ ou plus encore à Jean Chrysostome. Or le lecteur n'a souvent pas le détail des références aux textes, mais seulement à l'auteur. On peut aussi se demander s'il était pertinent de limiter au $5^{\mathrm{e}}$ siècle les références retenues, ce qui empêche toute perspective et toute vision d'une postérité de ces expressions. Enfin, il n'y a malheureusement pas de pondération du nombre d'occurrences par rapport à la taille des corpus d'auteurs considérés. Malgré ces réserves, ces fiches de vocabulaire et de style sont loin d'être sans intérêt; l'auteur parvient même à mettre en évidence une expression caractéristique de cette

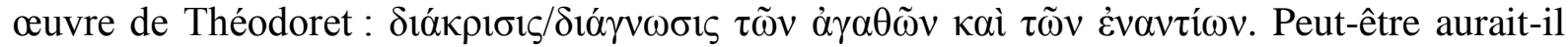
cependant mieux valu les présenter en annexe, plutôt que de risquer de décourager le lecteur au seuil même de l'ouvrage.

Dans le chapitre trois, l'étude du prologue porte à la fois sur la rhétorique de Théodoret et sur son apport à l'interprétation du corpus paulinien, en particulier la reconstitution qu'il donne de l'ordre de rédaction des épîtres et de leur localisation. On aurait aimé également quA. Lorrain confronte les conclusions de Théodoret aux conclusions auxquelles on parvient aujourd'hui, afin d'évaluer la valeur de ces raisonnements, et non pas seulement de les décrire. Le chapitre quatre concerne les rapports à Jean Chrysostome ; A. Lorrain étudie avec beaucoup de soin ces rapports complexes. En effet, si la dépendance de l'évêque de Cyr à Jean est certaine, elle se manifeste de manière très irrégulière et parfois volontairement décalée, et surtout elle n'apparaît qu'à travers des réécritures de forme variée (abrégement, amplification, prolongement, etc.). Si les hypothèses proposées pour expliquer ces modifications - et en particulier l'usage de gloses chrysostomiennes plusieurs fois répétées dans le manuscrit de Théodoret, à des endroits différents - n'emporte pas toujours l'adhésion, l'approche d'ensemble est intéressante et permet à A. Lorrain de mettre en évidence les

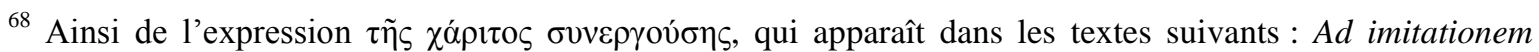
prouerbiorum (CPG 3910); De compunctione (CPG 3916); De uirtute ad nouitium monachum (CPG 3930); In illud: Attende tibi ipsi (CPG 3932) ; Capita centum. Quomodo quis humilitatem sibi comparet (CPG 3936); Epistula ad Ioannem monachum de patientia (CPG 3943); Sermones paraenetici ad monachos Aegypti (CPG 3942); De abstinendo ab omni consuetudine perniciosa (CPG 4000), qui sont tous rangés dans les «compositions et remaniements de basse époque » par D. HEMMERDINGER-ILIADOU, «Éphrem grec », Dictionnaire de spiritualité 26-27, 1959, col. 800-815, sauf CPG 3916 (pièces métriques). Ou encore pour le verbe $\pi \alpha \rho \alpha \kappa v i \zeta \omega$, dont la première occurrence ne se trouve pas chez Éphrem (In sanctam Parasceuen et in crucem et latronem [CPG 4062]), qui entre dans la même catégorie que les œuvres évoquées précédemment, mais bien chez Jean Chrysostome.

${ }^{69}$ Ainsi des textes Inuentio imaginis in Camulianis (CPG 3224), texte hagiographique sûrement plus tardif que le $4^{\mathrm{e}}$ ou le $5^{\mathrm{e}}$ siècle, ou Ad imaginem dei et ad similitudinem (CPG 3218), œuvre qui revient en fait à Anastase le Sinaïte.
} 
infléchissements importants que propose Théodoret : mise en arrière-plan de l'actualisation moralisante et des interprétation violemment anti-judaïques, utilisation très inégale des diverses homélies de Chrysostome, emprunts à d'autres œuvres, etc. Le cinquième et dernier chapitre envisage successivement plusieurs adversaires : les juifs, qui sont des adversaires davantage historiques et littéraires que directs, et que Théodoret traite avec une certaine modération; Marcion, Valentin et les manichéens, parmi lesquels Marcion constitue un adversaire structurant du commentaire, sans pour autant qu'il y ait de confrontation directe avec des marcionites - A. Lorrain note en outre que les versets débattus ne sont pas nécessairement ceux qui l'étaient chez les auteurs précédents; controverses trinitaires et christologiques, qui ne sont pas réellement distinguées et parcourent tout le commentaire, dont elles constituent un fil directeur souvent masqué, sans pour autant former la matière privilégiée de l'exégèse, bien au contraire.

Cette étude d'importance sur le Commentaire sur Romains de Théodoret, qui en prépare l'édition critique - et, espérons-le, la traduction - est donc très bienvenue. Elle met cependant en valeur le caractère lisse, en apparence anodin, voire paraphrastique, de l'exégèse paulinienne de l'évêque de Cyr. Il est d'autant plus important, dans ce contexte, de disposer d'une étude aussi attentive aux détails du texte et à son écriture, qui seule parvient à en faire émerger des éléments plus intéressants, en particulier dans le domaine des controverses doctrinales et des infléchissements par rapport à ses prédécesseurs.

\section{Adrien}

Dans une liste des grands exégètes de l'Antiquité chrétienne, rares seraient les savants qui mentionneraient un certain Adrien, dont la seule œuvre conservée est une Introduction aux divines Écritures, dont la dernière édition remontait à la fin du $\mathrm{XIX}^{\mathrm{e}}$ siècle. C'est ce texte rare et précieux dont Peter MARTENS nous propose une nouvelle édition critique accompagnée d'une traduction et d'abondantes notes ${ }^{70}$. L'auteur, Adrien, est inconnu par ailleurs et son œuvre très rarement mentionnée : l'éditeur relève en particulier une mention chez Cassiodore, dans les Institutions, qui fournirait une possible indication de date $\left(2^{\mathrm{e}}\right.$ quart du $\mathrm{V}^{\mathrm{e}} \mathrm{s}$. $)$ du fait de la position de l'Introduction d'Adrien parmi les autres introductions citées, si l'ordre de citation est bien chronologique. Photius lui consacre une notice de deux lignes (Bibliothèque, 2). Enfin, on a voulu rapprocher de l'Adrien auteur de l'Introduction trois lettres de la correspondance attribuée à Nil d'Ancyre (II, 60 ; III, 118 ; 266) adressées à un certain Adrien et dont la première traite de la lecture attentive de l'Écriture. P. Martens tend à considérer ce rapprochement comme probant et y voit une confirmation de la date et du milieu d'exercice d'Adrien. Il écarte un peu trop rapidement, me semble-t-il, les très lourds doutes qui ont été soulevés à propos de la «correspondance »de « Nil » ${ }^{71}$, lesquels conduisent d'ailleurs à écarter les deux arguments qui font pencher l'opinion de l'auteur en faveur de l'identification des deux Adrien : la proximité chronologique de Nil et Adrien, et le contexte philo-antiochien et plus précisément chrysostomien. En revanche, on peut tout à fait envisager que le nom d'Adrien ait été choisi pour le destinataire des «lettres » en raison même de l'existence de l'auteur de l'Introduction. Un point plus assuré pour la datation et le contexte exégétique est constitué par la dépendance à Théodore de Mopsueste, ce qui conduit à situer la rédaction

70 Peter W. MARTENS, Adrian's Introduction to the Divine Scriptures: An Antiochene Handbook for Scriptural Interpretation, Oxford, New York, Oxford UP (coll. «Oxford Early Christian Texts »), 2017 ; $24 \times 16$, relié, XV + 344 p. ISBN : 978-0-19-870362-4.

${ }^{71}$ Voir en dernier lieu L. BossinA, «Il carteggio di Nilo di Ancira con il generale Gainas è un falso », dans A. Rigo, A. BABUIN et M. Trizio (éd), Vie per Bisanzio. VII Congresso Nazionale dell' Associazione Italiana di Studi Bizantini (Venezia, 25-28 novembre 2009), 2, Bari 2013, p. 215-249 ; L. BossinA, « Nilo, Crisostomo e altre lettere false », dans F. P. BARONE, C. MACE et P. A. UBIERNA (éd), Philologie, herméneutique et histoire des textes entre Orient et Occident. Mélanges en hommage à Sever J. Voicu (Instrumenta Patristica et Mediaevalia 73), Turnhout 2017, p. 823-849. 
après 380 et confirme bien l'appartenance au milieu antiochien. L'œuvre d'Adrien est à resituer dans le genre antique de l'introduction. Elle traite du style de l'Écriture, de ses particularités et du style hébreu, en se plaçant à trois niveaux : message, diction, syntaxe. Le corps du traité est suivi de divers appendices (§ 73-79). Tout l'ouvrage comporte un grand nombre d'exemples et de citations bibliques, dont plus de la moitié sont pris aux Psaumes. On relèvera aussi plusieurs catalogues et listes.

Le texte a été très largement négligé, tant au plan des éditions qu'à celui de l'interprétation. L'editio princeps est due à David Hoeschel en 1602, et a été suivie par une autre édition, en 1887, par Friedrich Goessling, avec traduction allemande. L'éditeur mentionne ensuite quelques rares articles et mentions rapides de l'œuvre. La tradition manuscrite est complexe : il existe au moins deux recensions, dont seule la première a été éditée, et est conservée intégralement. Elle est transmise par 13 manuscrits, qui descendent tous de L (Firenze, Bibl. Medicea Laurenziana, Conventi Soppressi 39). La seconde recension est connue uniquement de manière fragmentaire : 3 manuscrits du $16^{\mathrm{e}}$ siècle transmettent deux longs extraits, et plusieurs fragments figurent dans les chaînes exégétiques. Cependant, les chaînes transmettent aussi des traces d'un troisième état $\left(\mathrm{R}_{\mathrm{a}}\right)$, qui serait la source commune des deux recensions connues plus largement. P. Martens propose une étude détaillée des manuscrits, avec d'amples références bibliographiques ; parfois, la datation des témoins aurait pu être affinée grâce aux filigranes pour les manuscrits de papier (par exemple Città del Vaticano, BAV, Ottob. gr. 194, 270, etc. , tous des témoins du $16^{\mathrm{e}}$ siècle examinés sur place). On notera aussi que le Vat. gr. 1269, de la même bibliothèque, n'a pas été endommagé par l'eau, mais par une encre corrosive, phénomène fréquent à cette époque ${ }^{72}$.

Cependant, si l'introduction sur la tradition manuscrite retient l'attention, le cœur du livre et son apport essentiel est constitué par l'édition du texte, soit de la première recension seule, soit des deux recensions lorsqu'elles sont accessibles, avec une présentation synoptique en colonnes. L'édition est accompagnée d'une traduction richement annotée, qui fournit en fait un commentaire abondant et présente en particulier les parallèles avec les sources ou équivalents du texte d'Adrien, en particulier chez Théodore de Mopsueste. À la suite figure l'édition d'une quarantaine de fragments tirés des chaînes aux Psaumes (sauf un qui provient des chaînes sur Job), avec un bref commentaire sur leur authenticité, leur rapport avec le texte connu en tradition directe et leur transmission. Il est probable que d'autres fragments figurent encore dans les chaînes, mais il faudra attendre l'édition de ces recueils si complexes pour pouvoir les isoler aisément. Un index scripturaire, mais malheureusement pas d'index des manuscrits ni surtout des textes cités ou mentionnés, complètent le livre.

On ne peut qu'être extrêmement reconnaissants à Peter Martens d'avoir mené à bien ce difficile travail d'édition, de traduction et d'interprétation d'un texte peu connu et quelque peu aride. Si sa forme et son contenu même expliquent qu'il n'ait que peu retenu l'attention jusqu'à présent, on peut espérer que le livre ici présenté, qui le rend aisément accessible, en facilitera la connaissance et l'usage. Sans doute une étude clairement délimitée du type de texte biblique dont témoignent les très nombreuses citations d'Adrien aurait-elle déjà été utile au lecteur dans le cadre de cet ouvrage, mais elle viendra sans doute ailleurs par la suite.

\section{Maxime le Confesseur}

Les œuvres de Maxime le Confesseur sont sans doute celles qui ont reçu l'attention la plus suivie au sein de la Series graeca du Corpus christianorum - si l'on excepte les versions orientales de Grégoire de Nazianze, réunies dans une sous-collection spécifique. Cette précieuse série d'édition s'enrichit encore avec le volume de Katrien LEVRIE ${ }^{73}$, issu de sa

\footnotetext{
${ }^{72}$ Voir les images disponibles en ligne : https://digi.vatlib.it/view/MSS Vat.gr.1269.

73 Katrien LEVRIE, Maximi Confessoris Capita de duabus Christi naturis, necnon Pseudo-Maximi Confessoris Capita gnostica, Turnhout, Brepols (coll. «Corpus Christianorum, series Graeca »11), 2017 ; $25 \times 16$, relié, $279 * 99$ p. ISBN 978-2-503-57425-7.
} 
thèse de doctorat soutenue à Leuven sous la direction de Peter Van Deun et Reinhart Ceulemans. L'ouvrage propose la première édition critique de deux séries de kephalaia de nature très différente l'une de l'autre: le De duabus Christi naturis (CPG 7697.13) est authentiquement maximien, très court (10 chapitres, 79 lignes de texte) et transmis par un assez grand nombre de manuscrits (77 manuscrits, plus la tradition indirecte) ; les Capita gnostica (CPG 7707.11) sont probablement pseudépigraphes, ou plutôt deutéro-maximien - si l'on peut reprendre les formulations de la critique biblique - le texte est plus long (100 chapitres, 56 pages) sans pour autant atteindre la taille des grandes œuvres de Maxime, la tradition manuscrite extrêmement réduite (cinq manuscrits). Le livre comporte une assez longue introduction qui concerne essentiellement la tradition manuscrite, après une très brève présentation de l'auteur et des deux œuvres concernées. Si la discussion sur le De duabus Christi naturis pouvait être brève, dans la mesure où elle ne présente aucune complexité particulière, ni pour son contenu christologique (mise en parallèle des hérésies trinitaires et des hérésies christologiques de Nestorios et d'Eutychès), ni pour sa forme, la deuxième œuvre requérait une discussion plus poussée. En effet, les Capita gnostica sont de paternité discutée : ils reprennent d'une part 10 chapitres des Capita XV (CPG 7695), œuvre a priori authentique de Maxime qui se retrouve également en son entier dans les Diuersa capita ( $C P G$ 7715), collection de chapitres qui est, elle, inauthentique ; ils présentent également des liens assez étroits avec nombre d'œuvres maximiennes, sans qu'il s'agisse pour autant de citations directes, à l'exception des chapitres mentionnés ci-dessus. L'auteur conclut non à une paternité maximienne mais plutôt à l'œuvre d'un disciple ou imitateur de Maxime le Confesseur, qui aurait puisé à diverses œuvres pour composer un «à la manière de »; on aurait attendu, dans ce contexte, que soit au moins mentionné l'auteur du texte d'inspiration maximienne qui figurent dans les Chaînes des trois Pères sur les livres salomoniens et qu'il aurait peut-être été utile de comparer aux chapitres ici étudiés. La datation du texte reste très incertaine et repose uniquement sur le premier témoin indirect, la Chaîne sur l'Épître aux Hébreux de Nicétas (actif à la fin du $11^{\mathrm{e}}$ et au début du $12^{\mathrm{e}}$ siècle), et sur le plus ancien manuscrit conservé (Firenze, Bibl. Medicea Laurenziana, plut. 8.20, $10^{\mathrm{e}}-11^{\mathrm{e}}$ siècle). Contrairement au premier texte, l'analyse du contenu et de la structure de l'œuvre est en revanche absente et doit être cherchée dans un article antérieur de l'auteur ${ }^{74}$, ce qui est peu pratique.

On signalera ici une petite découverte dont la lecture de cette édition a été l'occasion : aux chapitres 18-31 des Capita gnostica, on trouve en effet un commentaire suivi du Ps 108, 23b31 , où chaque chapitre est introduit par le stique du psaume qui y est commenté. La chose ressemble fort à un commentaire du psautier sous formes de scholies ou chapitres, tel que l'a mis en évidence récemment $\mathrm{E}$. Rapa, dans un mémoire de master 2 soutenu sous la direction de Ch. Boudignon ${ }^{75}$. Or ces chapitres se retrouvent, sous une forme légèrement récrite, et sous le sigle Maxime, dans la Chaîne de Nicétas sur les Psaumes (CPG C 21). Qui plus est, ils ne sont pas isolés ; comme l'avait souligné de manière partielle G. Dorival, à partir des psaumes qui avaient fait l'objet de son sondage, la Chaîne sur les Psaumes de Nicétas comprend de nombreux extraits attribués à Maxime le Confesseur ${ }^{76}$. Un rapide sondage dans l'un des manuscrits (Torino, BNU, B.I.5) a montré qu'autour du groupe de scholies sur Ps 108, 23b-31 reprises dans les Capita gnostica, on trouve de manière continue d'autres scholies attribuées à

\footnotetext{
${ }^{74}$ Byzantion 84, 2014, p. 241-256, voir en particulier p. 245 le tableau synthétique, qui met bien en valeur les fils successifs, commentaire du Ps 108, du Discours 11 de Grégoire de Nazianze, de deux passages des Juges et de sections de Genèse.

${ }^{75}$ Traduction des Commentarii in Psalmos de Maxime le Confesseur, Aix-Marseille Université, 2018.

${ }^{76}$ Voir en dernier lieu G. DoRIVAL, Les chaînes exégétiques grecques sur les Psaumes. Contribution à l'étude d'une forme littéraire, V, Louvain (coll. « Spicilegium Sacrum Lovaniense » 54), 2018, p. 362-366, avec la présentation de cet ouvrage, infra, p. *******.
} 
Maxime avant et après celles-ci. Il semblerait donc qu'il faille y voir un commentaire complet du psautier, sous forme de chapitres ou scholies, qui doit être attribué dans sa forme actuelle soit à Maxime le Confesseur, soit à l'un de ses disciples - et qui ne nous est accessible, dans la Chaîne de Nicétas, que sous une forme récrite. L'hypothèse d'E. Rapa se trouve donc confirmée : il aurait bien existé un commentaire complet de Maxime sur le psautier, dont les Quaestiones et dubia conservent des extraits, dont le Commentaire sur le Psaume 59 est une partie ou une hypostase, et dont la Chaîne de Nicétas sur les Psaumes est un témoin essentiel, tandis que les Capita gnostica n'en donnent à connaître que quelques extraits supplémentaires.

Le corps du volume est constitué par l'édition critique des deux séries de chapitres, accompagnée d'un apparat des sources et des lieux parallèles, volontairement réduit pour le De duabus, d'un apparat critique et d'un apparat des marginalia. Le texte édité est clair et paraît solide ; on aurait cependant apprécié de bénéficier d'une liste des variantes par rapport aux éditions précédentes, afin de mieux mesurer le progrès accompli. Divers index ferment le volume : lieux bibliques, sources et parallèles, manuscrits.

L'essentiel du livre, cependant, est constitué par la justification de l'édition critique : présentation des manuscrits, de la tradition indirecte, classement des témoins. Pour la première œuvre, du fait de la brièveté du texte et du faible nombre de fautes véritables, $\mathrm{K}$. Levrie ne peut aboutir qu'à des regroupements de quelques manuscrits, qui s'appuient largement sur les conclusions des éditeurs d'autres œuvres de Maxime présentes dans les mêmes manuscrits ; c'est déjà un résultat louable, mais qui montre bien les limites de cette entreprise d'édition isolée d'un texte aussi bref. Les conclusions relatives aux Capita gnostica sont beaucoup plus nettes et l'éditrice parvient à un stemma d'ensemble pour les cinq manuscrits ; on restera cependant plus dubitatif sur le classement du modèle utilisé par la Chaîne de Nicétas, dans la mesure où les seuls accords relevés avec $\mathrm{F}$ portent sur de bonnes leçons, et non sur des fautes. C'est sans doute cette partie de l'introduction consacrée à la tradition manuscrite qui attirera le plus de critique, du fait de diverses faiblesses qui ne sont pas rédhibitoires, mais diminuent la confiance du lecteur. Ainsi des confusions entre édition proprement dite, comme celle de Combefis, et leur reprise dans la Patrologia graeca - ce n'est d'ailleurs probablement pas l'éditeur de la Patrologie qui aurait eu recours à un manuscrit de la famille $\mathrm{Af}, \mathrm{Bg}, \mathrm{Br}$, mais bien plus probablement Combefis ; celle, beaucoup plus gênante, entre manuscrits de contenu mêlé (miscellanées) et manuscrits formés de plusieurs unités codicologiques, voire volumes composites formés tardivement de plusieurs fragments de manuscrits; l'étrange équivalence posée entre Fettaugenmode et Perlschrift, écritures que deux siècles séparent, et la caractérisation de la première par des tracés arrondis de certaines lettres, quand ces tracés sont en fait grossis - formant comme des yeux dans le bouillon de l'écriture, d'où son nom; et l'on pourrait allonger encore la liste. Le contenu des manuscrits n'est pas décrit en totalité, ce que l'on comprend parfaitement - même si quelques approximations dans les formules laissent sceptiques, ainsi de l'attribution à Anastase le Sinaïte de «textes canoniques » (il s'agit en fait d'un extrait du Viae dux); seuls les textes maximiens sont décrits, en totalité, et ce même quand d'autres éditeurs de Maxime ont déjà donné ce contenu. Peut-être aurait-il été plus économique de se contenter des textes proches de l'œuvre éditée, dans les manuscrits décrits. L'histoire récente des manuscrits, lorsqu'elle est connue, est traitée de manière relativement détaillée ; cependant, elle n'est que très rarement utilisée pour le classement des manuscrits. Il faut dire enfin que, d'une manière surprenante pour une publication dans une collection aussi prestigieuse, la langue de l'introduction est gravement déficiente et fourmille de fautes ; il revenait aux éditeurs de faire revoir le Français avant publication.

Ces remarques périphériques mis à part, la communauté scientifique ne pourra que se réjouir de voir ainsi publiés deux nouveaux textes de Maxime le Confesseur, ou à lui 
attribués ; sans doute sont-ce les Capita gnostica qui ouvrent le plus de voies à de futures recherches, pour déterminer en particulier leur auteur ou du moins les modalités et le milieu de leur composition.

Les Questions à Thalassios de Maxime le Confesseur viennent de faire l'objet d'une traduction anglaise, due à Maximos ConsTAS ${ }^{77}$, qui avait déjà traduit il y a peu les Ambigua du même Maxime. En outre, les Questions à Thalassios, dont l'édition est parue en deux volumes en 1980 et 1990, a également fait l'objet récemment d'une traduction française par Françoise Vinel, dans la collection Sources chrétiennes (529, 554, 569 : 2010-2015). Les lecteurs disposent donc maintenant d'outils de travail bienvenus pour étudier cette œuvre ample, sous forme de soixante-cinq questions et réponses sur des difficultés de l'Écriture. Ces questions seraient celles de Thalassios le Libyen, higoumène destinataire de plusieurs autres œuvres de Maxime, et également l'auteur de quatre Centuries sur la charité, la tempérance et la vie spirituelle. Les réponses portent sur 28 passages de l'Ancien Testament et 53 du Nouveau (certaines réponses concernent plus d'un passage); deux seulement traitent de contradictions apparentes entre Ancien et Nouveau Testaments, mais beaucoup plus nombreuses sont les sections qui portent sur des contradictions internes au Nouveau Testament, rejoignant ainsi la tradition majoritaire de ce genre littéraire des Questions et réponses sur l'Écriture, tel que l'a illustré, par exemple, Eusèbe de Césarée.

Une assez longue introduction présente très brièvement l'auteur, puis traite plus en détail de l'œuvre et de son contenu. En effet, si le texte maximien part de l'Écriture, il ne s'agit pas pour autant d'un traité exégétique, mais bien d'un exposé théologique d'ampleur beaucoup plus vaste; c'est que Maxime résout les difficultés scripturaires en passant à une contemplation plus profonde de l'Écriture, qui ne s'arrête pas au sens littéral mais la comprend dans un cadre anthropologique, cosmologique et salvifique beaucoup plus large. $\mathrm{M}$. Constas relève à juste titre que la construction d'ensemble de l'œuvre ne se laisse pas aisément dégager ; pas de plan ou de progression nette dans ce texte formé de pièces séparées, mais en revanche des ensembles de niveau plus réduit, une construction par petites unités, par constellations réduites et enchaînements limités. On retrouve donc là les modalités mêmes de l'écriture en chapitres, telle que l'a analysée par exemple Paul Géhin à propos des œuvres d'Évagre le Pontique ${ }^{78}$. L'introduction envisage ensuite un certain nombre de thèmes de l'œuvre, de manière nécessairement un peu fragmentée. M. Constas présente également le dossier complexe des scholies aux Questions à Thalassios : Maxime indique lui-même, dans le prologue, avoir pourvu son œuvre, à la relecture, de compléments et corrections, et ces scholies se retrouvent tant dans la tradition manuscrite grecque que dans la traduction latine de Jean Scot Érigène - avec quelques différences. La difficulté vient ensuite, lorsqu'il s'agit de déterminer quelles scholies sont de Maxime, et lesquelles ne lui reviennent pas. Ces scholies sont traduites à la suite de chaque Réponse. Un tel phénomène, qui montre l'auteur à l'œuvre de manière continuée sur son propre texte, et qui trouve un parallèle significatif chez Anastase le Sinaïte, demanderait encore une étude littéraire approfondie.

La traduction, dont on laissera l'évaluation aux collègues anglophones ${ }^{79}$, comporte une annotation assez abondante et critique, qui reprend - et discute parfois - les acquis des

\footnotetext{
${ }^{77}$ Maximos Constas, St. Maximos the Confessor, On Difficulties in Sacred Scripture: The Responses to Thalassios, Washington D.C., The Catholic University of America Press (coll. «The Fathers of the Church, A New Translation », 136) 2018 ; $22 \times 14$, relié, XX + 583 p. ISBN 978-0-8132-3031-3.

${ }^{78}$ Voir plus largement P. GEHIN, «Les collections de kephalaia monastiques. Naissance et succès d'un genre entre création originale, plagiat et florilège », dans A. RIGO (éd), Theologica minora. The minor Genres of Byzantine Theological Literature, Turnhout (coll. «Byzantios. Studies in Byzantine History and Civilization », 8), 2013, p. 1-50.

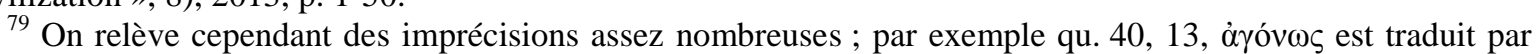
« in ignorance », contre « sans être fécondée » (F. Vinel) ou infecunde (Érigène) ; qu. 40, 14, $\tau \tilde{\omega} v \mu \varepsilon \lambda \lambda o ́ v \tau \omega v$ est
} 
volumes parus dans la collection Sources chrétiennes, où l'introduction et les notes étaient dues à J.-C. Larchet. M. Constas propose également d'assez nombreux rapprochements tant avec le reste de l'œuvre de Maxime qu'avec les textes d'autres auteurs. Trois indices (général, biblique, mots grecs) complètent cet épais volume.

Les lecteurs disposent donc désormais d'une seconde traduction en langue moderne des Questions à Thalassios, qui permettra, à n'en pas douter, un accès plus aisé à ce texte riche et touffu, dont on est encore loin d'avoir épuisé toute la sève.

Outre l'édition et la traduction qui viennent d'être présentés, il convient encore de mentionner un troisième livre sur Maxime le Confesseur, œuvre de Raffaele COPPI ${ }^{80}$. Ce bel et intéressant ouvrage traite de la question du modèle et de l'imitation du modèle dans la théologie de Maxime le Confesseur. L'introduction présente le sujet avec une certaine liberté, en partant principalement d'une analyse de la Lettre 11 de Maxime ; elle situe également l'approche par rapport à l'ouvrage de M. Mira (Apostolado y filiación divina. La relación interpersonal en Máximo el Confesor, 2011), dont l'auteur montre les limites et de l'interprétation duquel il s'écarte souvent. La démonstration s'organise ensuite en deux parties, consacrées successivement au Christ, sauveur et modèle de l'homme, et au croyant, modèle de perfection et médiateur pour le salut de ses frères. L'enquête s'appuie largement sur les textes de Maxime, qui sont souvent et longuement cités et commentés ; cependant, l'enquête est bien systématique et ne se limite pas au commentaire juxtaposé de lieux pertinents pour le propos. R. Coppi construit une approche systématique de l'œuvre de Maxime, pour en dégager l'apport théologique dans le domaine essentiel des rapports du croyant, du Christ et des autres fidèles. Le dialogue de l'auteur est constant non seulement avec les textes maximiens eux-mêmes, mais aussi avec la littérature critique sur Maxime. On

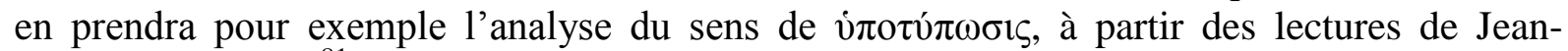
Miguel Garrigues ${ }^{81}$ et de Marcel Doucet: R. Coppi élargit le corpus et procède par comparaison des emplois du terme débattu dans des couples ou des triplets, afin d'en éclairer le sens. C'est donc une étude de théologie patristique, mais qui s'appuie sur un examen précis des textes et de leur langue. L'auteur ne recule pas non plus devant la recherche des sources de Maxime, ainsi à propos d'Ambigua ad Ioannem, 10, 1117B-C (Moïse) : écartant Grégoire de Nysse et le pseudo-Denys, R. Coppi propose de voir chez Philon d'Alexandrie une source plus essentielle de l'interprétation de Maxime - nous laisserons aux spécialistes de ces auteurs le soin d'évaluer la connaissance directe de Philon par Maxime.

Les notes, très abondantes - et parfois trop, au point de ne plus laisser qu'un peu de texte en haut de page - témoignent du soin mis à l'enquête. On pourrait bien sûr la compléter sur tel ou tel point, par exemple pour le passage de la Brève explication du Notre Père, étudié p. 249-250, avec l'affirmation paradoxale selon laquelle l'homme se fait le modèle de Dieu en remettant les dettes, afin que Dieu lui pardonne à son tour. La source du passage, passée ici sous silence, est à chercher dans les Homélies sur le Notre Père de Grégoire de Nysse, dont

traduit par «good things of the future », contre «l'avenir » (F. Vinel) ou futurorum (Érigène); qu. 40, 24, $\pi \rho \tilde{\alpha} \xi_{1 v}$ est traduit par «the practice of the virtues », contre «praxis » (F. Vinel) ou actionem (Érigène) : il s'agit certes de la 'pratique', une des parties du système ascétique évagrien, mais il paraît trop réducteur de traduire le terme par «pratique des vertus ». Dans la formulation de la question 44, on notera aussi la traduction d'ov̉ $\sigma i ́ \alpha$ par «nature », ce qui risque pour le moins d'induire le lecteur en erreur.

${ }^{80}$ Raffaele COPPI, Discepolo e modello. Il credente in relazione con Cristo e gli uomini nella teologia di Massimo il Confessore, Roma, Institutum Patristicum Augustinianum (coll. «Studia Ephemeridis Augustinianum »152), $2018 ; 24,5 \times 17$, relié, 346 p. ISBN : 978-88-7961-124-4.

${ }^{81}$ Cet auteur, installé depuis longtemps en France et qui a publié pour l'essentiel en français, du moins sur Maxime le Confesseur, est nommé sous son prénom espagnol (Juan-Miguel) et l'auteur se réfère à lui comme «le théologien espagnol », sans doute pour le distinguer de Marcel Doucet: formule qui pourrait troubler le lecteur français. 
P. Van Deun avait déjà signalé, dans son édition, le rôle fondamental pour l'explication de Maxime, et dont $\mathrm{Ch}$. Boudignon a récemment montré de manière détaillée l'importance, y compris pour ce passage précis. La bibliographie pourrait être ici ou là complétée ${ }^{82}$, mais elle est assez riche pour son objet.

Voilà donc un intéressant livre, qui conduit le lecteur à travers un intéressante parcours dans la pensée de Maxime le Confesseur et met en avant une lecture dynamique de sa christologie et surtout de sa sotériologie. Ce mouvement est présent de bout en bout du livre, et lui donne son souffle. Les spécialistes de Maxime apprécieront mieux que le présent lecteur la valeur de l'ouvrage au regard de l'état des travaux sur cet auteur; en l'état, cependant, la lecture de ce livre est intéressante, riche et stimulante.

\section{Sacra parallela}

Les Sacra ou Hiéra sont l'un des plus importants florilèges patristiques grecs ; cependant, malgré de nombreuses et importantes études, cette collection ne nous était jusqu'alors accessible qu'à travers l'édition très défectueuse de Michel Le Quien (1712), reprise par la Patrologia graeca, et qui présente une recension dérivée et dégradée du texte original. On doit à José DECLERCK, qui travaille depuis longtemps sur ce texte, et à Tobias THuM, la première édition des deux principales recensions du livre II $^{83}$. Généralement considéré, à la suite d'une bonne part de la tradition manuscrite, comme l'œuvre de Jean Damascène, le recueil serait en fait à attribuer à un moine Jean, actif en Palestine et peut-être à la Laure de Saint-Sabas dans le premier quart du VII ${ }^{\mathrm{e}}$ siècle, d'après les travaux de J. Declerck ${ }^{84}$. Les quatre volumes monumentaux ici publiés (en tout plus de 2700 pages), en attendant le cinquième volume de ce premier groupe, qui présentera des textes supplémentaires, une étude d'ensemble de la composition du livre II et tous les index nécessaires à son utilisation - le volume est paru en juillet 2019 - offrent au lecteur, et surtout à l'utilisateur, l'édition du texte grec, pourvu de nombreux apparats critiques, ainsi que deux longues introductions. La première présente d'abord l'œuvre en son ensemble assez brièvement (37 p.), puis la tradition manuscrite de la première recension du livre II et les principes de son édition ; la seconde

\footnotetext{
${ }^{82}$ Par exemple, il aurait été bon de citer, au côté du premier article de G. Bunge sur hénade et monade chez Évagre (1989), le second du même sur le même sujet : «Encore une fois : Hénade ou Monade ? Au sujet de deux notions-clés de la terminologie technique d'Évagre le Pontique », Adamantius 15, 2009, p. 9-42. Pour la Foi orthodoxe, de Jean Damascène, les volumes de Sources chrétiennes sont une traduction (avec le texte grec paru dans les Patristische Texte und Studien), non une édition ; pour Platon, on citera plutôt la nouvelle édition des Oxford Classical Text quand elle existe (E. A. DuKE et alii, 1995, et S. R. SLINGS [Respublica], 2003), plutôt que la vieille édition de Burnet dans la même collection. Toujours dans le domaine philosophique, les éditions de la collection Loeb ne sont pas les éditions de référence pour Aristote. Mais on voit que nous sommes là dans les à-côtés du sujet principal.

${ }^{83}$ Tobias THUM, Die Schriften des Johannes von Damaskos. VIII/4, Iohannis monachi (VII saeculo ineunte) Sacra, olim Iohanni Damasceno attributa. Liber II, De rerum humanarum natura et statu. Erste Rezension. Ertser Halbband, A-E (II 1-1000), Berlin, Boston, de Gruyter (coll. «Patristische Texte und Studien », 74) 2018 ; 23,5 × 16, relié, CXLIII + 586 p. ISBN 978-3-11-055578-3. Tobias THUM, Die Schriften des Johannes von Damaskos. VIII/5, Iohannis monachi (VII saeculo ineunte) Sacra, olim Iohanni Damasceno attributa. Liber II, De rerum humanarum natura et statu. Erste Rezension. Zweiter Halbband, Z- $\Omega$ (II 1001-2293), Berlin, Boston, de Gruyter (coll. «Patristische Texte und Studien », 75) 2018 ; 23,5 × 16, relié, IX + p. 587-1194. ISBN 978-311-055579-0. José DECLERCK, Die Schriften des Johannes von Damaskos. VIII/6, Iohannis monachi (VII saeculo ineunte) Sacra, olim Iohanni Damasceno attributa. Liber II, De rerum humanarum natura et statu, Zweite Rezension. Erster Halbband, $A-E\left(* I I^{2} 1-1592\right)$, Berlin, Boston, de Gruyter (coll. « Patristische Texte und Studien », 76), 2018 ; 23,5 × 16, relié, CXI + 730 p. ISBN 978-3-11-055580-6. José DECLERCK, Die Schriften des Johannes von Damaskos. VIII/6, Iohannis monachi (VII saeculo ineunte) Sacra, olim Iohanni Damasceno attributa. Liber II, De rerum humanarum natura et statu, Zweite Rezension. Zweiter Halbband, Z- $\Omega\left(* I I^{2} 1593-\right.$ 2907), Berlin, Boston, de Gruyter (coll. «Patristische Texte und Studien », 77), 2018; 23,5 × 16, relié, IX + p. 731-1295. ISBN 978-3-11-055581-3.

${ }^{84}$ J. DECLERCK, «Les Sacra Parallela nettement antérieurs à Jean Damascène », Byzantion 85, 2015, p. 27 65.
} 
présente les mêmes éléments pour la seconde rédaction. La difficulté principale pour l'édition de ce florilège monumental vient de ce qu'aucun manuscrit ne nous a transmis en son intégrité la totalité du florilège, qui doit être reconstruit à partir de témoins partiels et/ou dérivés, qui constituent eux-mêmes des collections séparées dotées d'une histoire textuelle propre.

Connu et exploité depuis longtemps soit à travers l'édition de Le Quien, soit directement à partir de la tradition manuscrite, ce florilège qui rassemble de manière thématique des citations de l'Ancien et du Nouveau Testaments, complétées par des extraits patristiques ainsi que par d'autres empruntés à Philon d'Alexandrie et à Flavius Josèphe (dans cet ordre), est d'une richesse exceptionnelle et a déjà permis à bien des savants de faire remonter à la lumière des textes par ailleurs perdus. L'enquête a en particulier été menée pour des auteurs pré-nicéens, parmi lesquels Irénée de Lyon, ou encore tout récemment, avec la collaboration de José Declerck, pour le Contre les manichéens de Titus de Bosra ${ }^{85}$. Cependant, étant donné la variété des auteurs utilisés et la longueur parfois conséquente des extraits cités, cette collection est également d'un intérêt considérable pour l'édition des textes même lorsqu'ils sont conservés en tradition directe, par le témoignage qu'elle apporte. Les trois livres, qui sont chacun organisés en chapitres thématiques dotés d'un titre, portent respectivement sur Dieu (I), l'homme et tout ce qui le concerne (II) et vices et vertus (III) ; seul ce dernier livre est construit sur le principe des parallèles, qui a donné son nom courant (Sacra parallela) à tout le florilège ; les thèmes ou vertus sont classés par ordre alphabétique. Les tables initiales des titres sont accompagnées de $\pi \alpha \rho \alpha \pi$ $\mu \pi \alpha i$ (livres I et II), qui offrent des renvois supplémentaires vers les titres principaux des sections, pour des thèmes secondaires; des scholia, dues à l'auteur, complètent également les extraits.

Sans entrer dans les détails de la reconstruction des deux recensions, on présentera cependant quelques éléments qui donneront au lecteur une idée de la complexité du dossier. La première recension est transmise par deux témoins majeurs, appelés Florilège $K$ et Florilegium Vaticanum; de ce dernier dérivent six autres florilèges. Aucun des deux florilèges principaux ne contient la totalité de l'œuvre d'origine, au vu de la table des chapitres, et ils ne se complètent l'un l'autre qu'imparfaitement. Quant à la deuxième recension, elle n'est jamais transmise à l'état séparé et doit être reconstruite à partir de florilèges dérivés, par élimination des éléments qui proviennent des livres I et III du florilège d'origine.

Le texte grec est accompagné de nombreux apparats : le premier indique les références des citations présentes dans les titres de chapitres, et les extraits ainsi que les parallèles éventuels des extraits dans d'autres florilèges ; le deuxième identifie la source, biblique ou patristique, de l'extrait; le troisième précise les témoins qui transmettent l'extrait, ainsi que sa numérotation et sa position dans les principaux témoins; le quatrième traite de l'attribution de l'extrait, tandis que le cinquième est l'apparat critique proprement dit, qui comprend également une comparaison avec la tradition indirecte de l'extrait, lorsqu'elle existe. Enfin, lorsqu'un titre de chapitre apparaît, un apparat supplémentaire lui est consacré.

Ce n'est pas le lieu de dresser ici la liste de tous les auteurs transmis, des plus courants, comme la Bible, Jean Chrysostome ou Grégoire de Nazianze, à des figures beaucoup moins connues, comme Gennade de Constantinople ou Antipater de Bosra. Le dernier volume de l'édition monumentale de ce livre II, paru en juillet 2019, donnera tous les index nécessaires à l'exploitation par les éditeurs de texte et ceux qui s'intéressent à la transmission de tel ou tel auteur. Mais le lecteur peut déjà se plonger dans la lecture, complète ou sélective, de ce remarquable florilège qui a joué un rôle si important à Byzance. C'est donc l'un des grands projets d'édition de Marcel Richard, qui avait fait de ce florilège le premier élément de son

\footnotetext{
${ }^{85}$ Sur l'auteur et les publications liées à son traité, voir dans ce Bulletin, p. ***_***.
} 
article de référence sur les Florilèges spirituels grecs ${ }^{86}$ et lui avait consacré d'importants travaux préparatoires, malheureusement restés inaboutis, qui voit ainsi une première réalisation magistrale. Elle ne devra en aucun cas être négligée par les éditeurs de texte.

\section{Métrophane de Smyrne}

Les hasards de la transmission des textes et de l'histoire de l'érudition font présenter ici une traduction d'un Commentaire sur l'Ecclésiaste, due à Vincenzo LOMBRINO, et dont la paternité a été longuement débattue ${ }^{87}$, alors même qu'il relève pleinement de la période byzantine et non de l'époque patristique. Il n'en reste pas moins étonnant que le traducteur ait choisi de le présenter sous l'un de ces noms d'emprunt, plutôt que sous celui de son véritable auteur, dont l'identité est maintenant connue grâce aux travaux de Peter Van Deun, à savoir Métrophane de Smyrne, actif dans la $2^{\text {nde }}$ moitié du $9^{\mathrm{e}}$ siècle et mort vers $912^{88}$. Ce texte a en effet circulé dans la tradition manuscrite soit anonyme, soit sous le patronage de Grégoire de Nysse, et a été attribué à l'époque moderne à Grégoire d'Agrigente (fin $6^{\mathrm{e}}$-début $7^{\mathrm{e}} \mathrm{s}$.), évêque surtout connu par l'intermédiaire d'une Vie très romancée. Sans doute est-ce la collection dans laquelle paraît la traduction, et qui est consacrée aux textes patristiques, qui explique qu'on ait conservé cette attribution problématique, plutôt que de rendre le commentaire à son véritable auteur; mais ce n'est pas rendre service aux lecteurs.

Il est vrai que l'histoire du texte est complexe et que ses éminents éditeurs dans la Series Graeca du Corpus christianorum, Jacques Noret et Gerard H. Ettlinger, avaient fini par publier le texte sans parvenir à en identifier l'auteur. Mais depuis, l'attribution a été largement démontrée par Peter Van Deun, entre autres par comparaison avec la traduction géorgienne, qui a, elle, conservé l'attribution à Métrophane de Smyrne. L'état de l'annotation du volume reflète d'ailleurs assez cet état de choses : on y cherchera en vain, le plus souvent, tout parallèle byzantin et la mise en contexte des interprétations de Métrophane est très limitée. On sait combien le commentaire d'un commentaire exégétique est chose complexe, en particulier $\mathrm{du}$ fait des pertes multiples de textes patristiques. Peut-être aurait-on pu souhaiter que l'auteur développe davantage cette mise en perspective, non seulement patristique mais aussi byzantine. Cependant, l'essentiel du volume n'est pas là : V. Lombrino offre la première traduction du Commentaire sur l'Ecclésiaste de Métrophane de Smyrne dans une langue moderne, et il faut lui en savoir gré. Là est le prix de ce livre ; la collection dans laquelle il a paru ne cherche d'ailleurs pas à donner un apparat développé aux textes qu'elle rend accessible. L'introduction, assez riche, donne déjà un bon aperçu du contenu et des enjeux du texte.

Il n'aurait pas été inutile, cependant, de corriger quelques approximations. Ainsi (p. 252), à propos du commentaire de Qo 10, 14-15, et de la mention explicite d'Eunome et d'Aèce par Métrophane, le renvoi fait en note aux Homélies sur l'Ecclésiaste de Grégoire de Nysse devrait être nuancé, dans la mesure où Grégoire ne commente pas ce passage, puisque ses homélies s'arrêtent dans le courant de Qo 3. En outre, il n'y a aucune mention nominale d'Eunome ou d'Aèce dans les Homélies sur l'Ecclésiaste, non plus qu'un exposé en bonne et due forme sur le sujet de la connaissance de la substance divine ou de la création. Le développement de Métrophane contre Eunome suppose plutôt une connaissance directe (ou non) des réfutations d'Eunome par Basile et Grégoire, ou à tout le moins d'une notice hérésiologique sur Aèce et Eunome. C'est dans ce sens qu'il aurait été bon de mener l'enquête

\footnotetext{
${ }^{86}$ M. RICHARD, «Florilèges spirituels grecs », Dictionnaire de spiritualité 33-34, 1962, col. 475-512 [= IDEM, Opera minora, Turnhout, 1976, $\left.\mathrm{n}^{\circ} 1\right]$.

${ }^{87}$ Vincenzo Lombino, Pseudo-Gregorio di Agrigento, Commentario all'Ecclesiaste, Roma, Città Nuova (coll. « Testi patristici », 255), 2018 ; $20 \times 13,5,318$ p., $33 €$. ISBN 978-88-311-8255-3.

${ }^{88}$ Voir au premier chef P. VAN DEUN, « La chasse aux trésors : la découverte de plusieurs œuvres inconnues de Métrophane de Smyrne (IX ${ }^{\mathrm{e}}-\mathrm{X}^{\mathrm{e}}$ siècle) », Byzantion 78, 2008, p. 346-367.
} 
et d'orienter le lecteur. On ajoutera aussi quelques éléments bibliographiques récents sur Métrophane et ses œuvres, qui ont sans doute paru trop tard pour être pris en compte ${ }^{89}$.

Encore une fois, l'essentiel n'est pas là : les lecteurs ne peuvent que se féliciter de disposer maintenant d'une traduction italienne de ce riche - et long - commentaire, qui ne pourra qu'en faciliter l'étude.

\section{Auteurs latins à partir du IV siècle \\ Jérôme de Stridon}

Les commentaires exégétiques anciens sur les Psaumes sont importants par leur taille, leur nombre et leur contenu; si la redécouverte d'une série d'Homélies sur les Psaumes d'Origène a donné une impulsion renouvelée à l'étude de ces corpus ${ }^{90}$, d'autres travaux moins spectaculaires n'en sont pas moins importants. C'est le cas de la traduction annotée des Tractatus in Psalmos de Jérôme, qu'Alessandro CAPONE vient de publier ${ }^{91}$. Les deux épais volumes proposent, comme de coutume dans la précieuse collection des Opere di Girolamo, le texte de l'édition Morin de 1958, face à une traduction italienne pourvue de notes précieuses.

Dans sa brève introduction, A. Capone retrace avec clarté les étapes des discussions qui ont accompagné ces Tractatus depuis leur redécouverte par G. Morin à partir de 1895 : leur attribution à Jérôme, tout d'abord, puis, suite aux travaux de V. Peri en 1980, la question de leur dépendance totale ou partielle à Origène - s'agissait-il d'une traduction d'homélies origéniennes, légèrement complétée par Jérôme, ou bien d'homélies de Jérôme, fondées en tout ou partie sur des textes d'Origène ? - avant de revenir à une paternité hiéronymienne claire, qui reconnaît cependant les apports origéniens. Les homélies d'Origène sur les Psaumes redécouvertes à Munich viennent confirmer cette dernière reconstitution, qui s'impose. L'influence d'Origène sur l'exégèse des Psaumes par Jérôme est nette, mais non univoque : le traducteur relève plusieurs interprétations qui s'opposent, explicitement ou non, au maître alexandrin, ainsi qu'une dépendance plus large à la tradition alexandrine, en particulier à Philon et Didyme. Cependant, l'exégèse hiéronymienne présente des facettes multiples et ne se réduit pas à l'interprétation d'Origène ou à sa réfutation; elle inclut également une nette dimension polémique. A. Capone, s'appuyant sur plusieurs de ses travaux antérieurs, montre également qu'il ne s'agit pas d'une série d'homélies cohérente, composée à un moment et dans un contexte donnés, mais d'homélies de date et de contexte divers, qui ont été réunies par la suite. Aussi leur datation ne peut-elle être établie de manière globale, sinon à travers une attribution large au séjour à Bethléem (389-après 410).

Les deux volumes contiennent les textes suivants: I, Homélies sur les Ps 1, 5, 7, 9 (brève), 14 (et Homélie aux néophytes sur le Ps 14), 41, 66, 67, 74-78, 80-48, 86, 89-91, 93, 95-98, 100-111, 114, 115 ; II, Homélies sur les Ps. 119, 127, 128, 131-133, 135-137, 139-143, 145149 ; Seconde série d'Homélies sur les Ps 10, 15, 82-84, 87-93 (avec un autre fragment sur le Ps 93), 95, 96. Des index (biblique, auteurs anciens, noms propres) et des errata du volume I complètent ce riche ensemble. Les notes éclairent le texte principalement dans son lien avec

\footnotetext{
${ }^{89}$ Voir en particulier P. VAN DEUN, « Le "Liber de cognitione Dei” de Métrophane de Smyrne (CPG 3223$)$. Un bilan des fragments conservés », Medioevo greco 17, 2017, p. 241-280 ; P. VAN DEUN, « Le commentaire de Métrophane de Smyrne sur la Première Épître de Pierre (chapitre I, versets 1-23) », Travaux et Mémoires 21.2, 2017, p. 389-417.

${ }^{90}$ Voir « Bulletin de Patrologie », Rev. Sc. ph. et th. 100, 2016, p. 459-515, ici p. 459-462.

${ }^{91}$ Alessandro CAPONE, Girolamo, 59 Omelie sui Salmi (1-115). Omelia sul Salmo 41 Ai Neofiti, Roma, Città Nuova (coll. «Opera Omnia di San Girolamo », 9.1), 2018 ; 23,5 × 15, relié, 526 p., $80 €$. ISBN : 978-88-3119858-5. Alessandro CAPONE, Girolamo, 59 Omelie sui Salmi (119-149). Omelie sui Salmi, seconda serie, Roma, Città Nuova (coll. «Opera Omnia di San Girolamo », 9.2), 2018 ; 23,5 × 15, relié, 433 p., $78 €$. ISBN : 978-88311-9859-2.
} 
le reste des œuvres de Jérôme, secondairement mais fréquemment dans ses rapports avec l'exégèse d'Origène, plus rarement dans ses relations avec les autres exégètes anciens. Il est vrai qu'une bonne part de ces textes ne sont encore accessibles que dans des éditions anciennes et problématiques, dérivées de manière peu critique des chaînes exégétiques. Ce très vaste chantier attend encore, après les travaux de G. Dorival évoqués à la fin de ce Bulletin, une relève courageuse qui permettra à terme de mieux mettre en perspective les interprétations des différents auteurs. Mais les deux volumes d'A. Capone sont une précieuse contribution à cette étude de l'exégèse ancienne des Psaumes, qui vient remplacer la précédente traduction italienne due à G. Coppa (1993).

Parmi les multiples productions écrites de Jérôme, dont un grand nombre est lié directement au texte biblique, il faut faire une place spéciale à un groupe un peu particulier, qui est constitué par les préfaces que l'auteur a donné à ses différentes traductions des livres bibliques tant vétéro- que néo-testamentaires. Ce sont ces préfaces qui font l'objet d'un volume de traduction et de commentaire, œuvre collective dirigée par Aline CANELLIS dans la collection Sources chrétiennes ${ }^{92}$. Fruit d'un travail collectif en séminaire commencé en $2007^{93}$, à la suite du séminaire d'Yves-Marie Duval, le présent volume offre une riche moisson autour de petits textes qui ne sont en rien anodins et sont très différents des argumenta ou préfaces aux livres bibliques dans la tradition grecque. En effet, ces préfaces portent très nettement la marque de leur auteur, de ses préoccupations et de ses combats. Elles précédaient tant des traductions effectuées depuis l'hébreu que depuis le grec. Généralement pourvues d'une dédicace et répondant aux canons informels de la préface antique, ces courts textes sont marqués par le lien amical ou de patronage avec les dédicataires, mais aussi par les controverses vives qui ont accompagné les traductions hiéronymiennes et le choix d'abandonner le modèle grec pour l'Ancien Testament, au profit d'un retour à l'hébreu - avec la formule fameuse de l'hebraica ueritas, présente à plusieurs reprises dans ces textes. On y rencontre encore de fréquentes objurgations aux copistes, priés de prêter une attention suffisante au texte qu'ils reproduisent, en particulier pour les noms propres, tant dans leur graphie que dans la séparation des mots.

La longue introduction qui, si l'on compte la bibliographie, occupe presque les trois cinquièmes du volume, dresse un tableau d'ensemble du rapport de Jérôme aux différents états et langues du texte biblique - principalement Ancien Testament, puisque c'est là que se pose la question du choix de la langue de référence, grec ou hébreu, mais aussi Nouveau Testament, puisque Jérôme a révisé également les traductions des évangiles. Les auteurs y sont particulièrement attentifs aux fluctuations de Jérôme et à son évolution ; ainsi du texte de la Septante, d'abord perçu comme une traduction unique, à la suite de la légende des 70 traducteurs, puis conçu comme une pluralité de traduction produite par ces mêmes septante juifs à Alexandrie, dont la divergence a encore été accentuée par la faute des copistes. Au contraire, le texte hébraïque est perçu par Jérôme comme unique et unifié, référence stable sinon tout à fait immuable - l'affirmation serait d'ailleurs à nuancer au vu des commentaires de Jérôme ${ }^{94}$. Si ces textes ne peuvent être isolés du reste de l'œuvre de Jérôme - et les

\footnotetext{
92 Aline CANellis (dir.), Jérôme, Préfaces aux Livres de la Bible. Textes latins des éditions de R. Weber et R. Gryson et de l'Abbaye Saint-Jérôme (Rome), revus et corrigés ; Introduction, traductions et notes réalisées en séminaire sous la direction d'Aline CANELLIS, Paris, Éditions du Cerf (coll. « Sources chrétiennes », 592), 2017. $19,5 \times 12,5,530$ p., $54 €$. ISBN : 978-2-204-12618-2.

${ }_{93}$ Participation de : Agnès Bastit, Carole Bouchara, Aline Canellis, Régis Courtray, Michel Cozic, Benoît Gain, Jean-Louis Gourdain, Pierre Jay, Benoît Jeanjean, Patrick Laurence, Laurence Mellerin, Marc Milhau, Benoît Mounier, Francesco Pieri, Clive Sweeting, Delphine Viellard.

${ }^{94}$ Voir par exemple JeROME, Commentaire sur Habacuc (éd. S. MANTELLI [CCSL LXXVI-LXXVIA bis]), I, 2, 19-20, 1. 1260-1261: Praeterea sciendum in quibusdam Hebraicis uoluminibus non esse additum omnis, sed absolute spiritum legi. Voir infra pour la présentation de cette édition.
} 
traducteurs ont pris soin de fournir en abondance des parallèles avec d'autres textes hiéronymiens - ils offrent comme un condensé de son approche des livres bibliques. Les préfaces sont présentées non dans l'ordre chronologique de rédaction, dont la reconstitution reste pour une part hypothétique, en particulier pour l'ordre exact des livres, mais dans l'ordre biblique. Plusieurs tableaux aident cependant à prendre une vue d'ensemble des hypothèses chronologiques qui ont été émises, même si le lecteur ne dispose pas, dans ce volume, de la totalité du dossier sur les datations et des arguments, qui auraient occupé une place trop grande.

Les auteurs retracent également rapidement l'histoire de la circulation de ces textes, qui ont d'une part été inclus dans les manuscrits bibliques, et en particulier rassemblées à partir de la constitution, à la période carolingienne, de pandectes; cependant, ces préfaces ont également circulé à l'état séparé ou par petits groupes, dans des manuscrits de contenu varié. Si leur fonction principale, introduire à une traduction hiéronymienne donnée, leur est ici retirée par la nature même du livre qui les rassemble, leur mise en série permet en revanche au lecteur d'en percevoir la portée dans la carrière intellectuelle de Jérôme et dans ses combats. Le volume comporte également la traduction de préfaces qui ne sont pas de Jérôme mais figurent dans les éditions de la Vulgate : Siracide, Épitres pauliniennes, ainsi que la traduction latine de la Lettre à Carpien d'Eusèbe de Césarée, qui introduit à l'usage des canons pour les évangiles (deux planches couleur donnent d'ailleurs un aperçu de ces tables et des signes qui y correspondent dans les marges). Un index scripturaire clôt le volume ; vu l'abondance de textes de Jérôme et d'autres auteurs chrétiens qui sont cités dans le livre, un index des auteurs anciens aurait été profitable. La bibliographie, abondante, est étrangement redoublée d'une longue liste des abréviations qui comprend également une part de la bibliographie et fait quelque peu double usage.

Mais ce ne sont que détails et les lecteurs francophones disposent, avec ce volume, sinon d'une somme sur le rapport de Jérôme au texte biblique et à ses traductions - celles qui lui préexistaient et celles qu'il a produites - du moins d'un très utile manuel, au sens d'un livre maniable, qui constitue plus qu'une porte d'entrée dans cet univers foisonnant, qui débouche tant sur la critique textuelle et l'exégèse biblique que sur les polémiques chrétiennes de la fin $\mathrm{du} \mathrm{IV}^{\mathrm{e}}$ et du début du $\mathrm{V}^{\mathrm{e}}$ siècles, ou encore sur les discussions antiques sur les méthodes de traduction.

Si le volume des Sources chrétiennes qui vient d'être présenté rassemblait la traduction de petites pièces couvrant la presque totalité du corpus biblique, le volume de Sincero MANTELLI offre l'édition critique du commentaire de l'un des Douze prophètes, Habacuc ${ }^{95}$. Il vient remplacer l'une des parties de l'édition de M. Adriaen, parue en 1969 dans la même collection et qui ne constituait pas une véritable édition critique, mais plutôt une reprise améliorée d'éditions antérieures. Le texte de Jérôme, réparti en deux livres et un prologue, occupe environ 2500 lignes dans la nouvelle édition ; son établissement a été mené à partir de 14 manuscrits, sélectionnés parmi les témoins datés au plus tard du XII ${ }^{\mathrm{e}}$ siècle, parmi la centaine de manuscrits conservés et identifiés ; l'un d'eux, parmi les plus anciens (Paris, BnF, lat. 10600) contient un épitomé, d'utilisation difficile pour l'édition. Les autres témoins ont été évalués au moyen de sondages, dont les résultats ne sont pas fournis ici. L'éditeur distingue classiquement deux branches dans la tradition, et quelques sous-groupes à l'intérieur de ces branches. Après la justification rapide du classement des témoins, une dernière section de l'introduction est consacrée aux éditions antérieures. Une liste des divergences avec l'édition précédente aurait été utile.

\footnotetext{
${ }^{95}$ Sincero Mantelli, S. Hieronymi presbyteri Opera. Commentarii in Prophetas minores. Commentarius in Abacuc, Turnhout, Brepols (coll. «Corpus Christianorum Series Latina », 76-76Abis 1 ; S. Hieronymi Presbyteri opera. I, Opera exegetica 6, editio altera), 2018 ; 25 × 16, relié, CXXI + 114 p. ISBN : 978-2-503-57955-9.
} 
Cependant, l'essentiel de l'introduction porte sur l'exégèse par Jérôme du texte d'Habacuc, après une brève section sur la datation du texte, situé vers 393. L'éditeur met en effet en lumière les différents aspects du rapport hiéronymien au texte biblique, grec et latin, la forme littéraire du commentaire suivi, mais également les traits propres à l'explication d'Habacuc, ainsi que son rapport à ses prédécesseurs, juifs et surtout chrétiens. Parmi ceux-ci figure au premier chef Origène, mais $S$. Mantelli cherche à montrer qu'il n'est pas la source unique de Jérôme et ajoute par exemple Didyme. L'éditeur s'arrête en particulier sur l'interprétation d'Ha 3, 2a et les problèmes d'établissement du texte de ce passage, en lien avec l'exégèse d'Origène et sa réception. On notera qu'il formule également de sérieuses réserves sur la possible connaissance des textes de Jérôme par Cyrille d'Alexandrie et reste extrêmement prudent en ce domaine, contrairement à d'autres études récentes.

Le texte est pourvu d'un apparat critique et d'un apparat biblique, et très ponctuellement d'un apparat des sources profanes ou des parallèles chez Jérôme. Cependant, on ne trouve pas d'appart des sources proprement dit, non plus que des parallèles. Un index biblique et un très court index des auteurs et œuvres cités complètent l'ensemble.

Si l'introduction fournit déjà un parcours interprétatif au sein de l'œuvre, il faudra sans doute attendre les traductions nouvelles fondées sur cette édition pour que le texte soit complètement exploité. On dispose maintenant, grâce au travail de S. Mantelli, d'une base beaucoup plus solide pour étudier ce texte, et l'on ne peut qu'espérer que les autres commentaires aux Douze suivront rapidement, même si l'absence de transmission conjointe de ces textes à date haute fait que la présente édition ne facilitera pas forcément la tâche pour la publication des autres commentaires.

Les publications sur Jérôme sont abondantes cette année; outre les trois volumes déjà présentés, on signalera également la traduction de Douze homélies sur des sujets divers par Jean-Louis GoURDAIN ${ }^{96}$. Ces textes, redécouverts et réattribués à Jérôme, pour l'essentiel, par Dom Germain Morin à la fin du XIX ${ }^{\mathrm{e}}$ siècle, sont des homélies liées aux fêtes de l'année liturgique (Noël, Épiphanie, Pâques), ou liées à ce cycle (carême), trois commentaires de péricopes bibliques (Mt 18, 7-9 ; Lc 16, 19-31 ; Jn 1, 1-14), ainsi que deux homélies sur la vie chrétienne et plus particulièrement monastique. La question de l'authenticité et de l'attribution hiéronymienne, qui est considérée comme acquise, n'est pas reprise ici, non plus que l'établissement du texte - qui bénéficie simplement de quelques corrections typographiques, et de l'apport d'une contribution de R. Courtray, pour l'Homélie sur Lazare et le riche. L'introduction, assez brève, dégage les grands thèmes des homélies, qui sont cependant assez diverses: théologie mariale, baptême, interprétation de l'Écriture, controverse doctrinale - qui reste cependant largement au second plan. La traduction est accompagnée de notes très réduites, et complétée par un index scripturaire.

La majorité de ces homélies est constituée par un commentaire de texte biblique, Nouveau Testament ou Psaumes, texte qui est suivi ligne à ligne et commenté presque mot à mot, avec une reprise constante des lemmes bibliques qui structurent l'exposé. Sans doute ces explications de texte gagneraient-elles à être mise en série ou du moins en rapport avec l'exégèse grecque et latine sur ces passages, parfois très souvent commenté, comme le Ps 117, en contexte pascal. Cet utile petit volume facilite donc l'accès à ces homélies de Jérôme, dont la lecture intéressera tant les spécialistes de l'auteur que tout lecteur cultivé.

96 Jean-Louis GourdaIn, Jérôme, Douze homélies sur des sujets divers. Texte G. Morin (CCSL 78), introduction, traduction et notes J.-L. GourdaIN, Paris, Cerf (coll. «Sources chrétiennes », 593), 2018 ; $19,5 \times 12,5,234$ p., $29 €$. ISBN : 978-2-204-12479-9. 


\section{Ambrosiaster}

Après Jérôme, venons-en à l'un de ses adversaires directs. Les auteurs restés pour nous anonymes sont nombreux dans l'Antiquité, y compris chrétienne; certaines figures sont cependant d'une importance plus grande et ont suscité la curiosité des savants et des hypothèses nombreuses sur leur identité. C'est le cas de l'Ambrosiaster, probablement un prêtre actif à Rome ou plutôt dans ses environs immédiats dans le dernier quart du IV siècle. Il est l'auteur d'une assez importante œuvre exégétique, et Théodore DE BRUYN a publié la traduction de son Commentaire sur l'Épître aux Romains ${ }^{97}$. Ce volume s'inscrit dans un projet plus large, mené en collaboration avec Stephen A. COOPER et David G. HuNTER, qui ont collaboré à l'introduction du présent livre et ont en charge les commentaires sur le reste du corpus paulinien - les trois traducteurs ont travaillé de concert pour harmoniser, autant que possible, l'ensemble.

Le volume s'ouvre par une ample introduction, qui semble valoir pour tout le corpus, et non pour la seule épître aux Romains. Elle présente d'abord ce qu'on peut savoir de l'auteur et du contexte de production, avec un bref rappel des hypothèses qui ont pu être émises. Elle s'attarde ensuite plus longuement sur la transmission du texte de l'Ambrosiaster, qui est particulièrement complexe: en effet, non seulement l'œuvre est transmise de manière pseudépigraphe, mais elle existe en outre en plusieurs recensions ( 3 pour Romains et quelques autres textes, mais le plus souvent 2 seulement), qui paraissent remonter dans leur ensemble à un travail de révision de l'auteur lui-même. On notera d'ailleurs la longue litanie des éditeurs qui furent en charge de son édition pour le CSEL, et dont plusieurs sont morts à la tâche sans avoir pu l'achever. Le texte biblique de l'Ambrosiaster, vieux-latin, est présenté brièvement, avant des présentations beaucoup plus développées de l'exégèse, de la théologie et des aspects polémiques des commentaires. L'exégèse de l'auteur est marquée par une prépondérance de la paraphrase explicative, qui n'est pas très éloignée de la méthode antiochienne pour le corpus paulinien. Enfin, une section présente le témoignage de l'auteur sur la vie religieuse à Rome à son époque et étudie ses prises de position en la matière, par exemple sur la hiérarchie interne du clergé et les rôles des différents ministères - il défend vigoureusement la place des prêtres (presbytres, auxquels il applique le terme de sacerdos), dont il fait probablement partie. Les auteurs ont également relevé la question des femmes ou ses réserves sur l'ascétisme pour les laïcs, contre les positions de Jérôme.

La traduction, qui est accompagnée de notes assez abondantes, n'est pas présentée avec le texte latin; les auteurs s'en expliquent en arguant de la complexité de la transmission : le CSEL présente le texte en colonnes synoptiques pour les différentes recensions. Mais dans la mesure où la traduction proposée est celle de la recension $\gamma$, qui est supposée être la plus aboutie et la dernière, il n'aurait pas été difficile de retenir ce texte, quitte à fournir en note non seulement la traduction des écarts significatifs avec les autres recensions, comme le propose le présent volume, mais aussi le texte latin de ces divergences entre recensions. Il est vrai que le volume du livre en aurait encore augmenté, mais le lecteur aurait été mieux pourvu. L'annotation est très largement constituée par les mentions de ces divergences, ainsi que par quelques éléments d'explication, de contexte et de repérage des sources éventuelles. Une bibliographie et divers index (biblique, auteurs et textes anciens, manuscrits, auteurs modernes, sujets) complètent utilement le livre.

On laissera aux spécialistes de l'exégèse latin le jugement sur l'acuité de la traduction et de l'appareil scientifique fourni; s'il existait une traduction italienne des commentaires pour nombre des épîtres dans la Collana di testi Patristici de Città Nuova, et une traduction anglaise

${ }^{97}$ Theodore S. DE BRUYN, Stephen A. COOPER et David G. HUNTER, Ambrosiaster's Commentary on the Pauline Epistles: Romans, trad. et notes Theodore S. DE BRUYN, intro. Theodore S. DE BRUYN, Stephen A. CoOPER et David G. HunTER, Atlanta, SBL Press (coll. «Writings from the Greco-Roman World 41), $2017 ; 23 \times 15,5$, CXXX + 319 p. ISBN : 978-1-62837-195-6. 
récente (G. L. Bray, 2009), ce riche volume, et ceux qui ne manqueront pas de le suivre, faciliteront sûrement l'étude de ces textes et leur meilleure prise en compte, au-delà du cercle restreint des spécialistes de l'exégèse patristique de langue latine.

Arator

Au sein de la poésie chrétienne antique, un petit nombre d'œuvres se présente comme des paraphrases en vers de l'Écriture ou comme des exégèses en vers. L'Histoire apostolique d'Arator, dont Bruno BUREAU et Paul-Augustin DEPROOST ont fait paraître une édition critique traduite et amplement introduite et annotée ${ }^{98}$, est une épopée biblique, fondant panégyrique des apôtres Pierre et Paul, récit de la matière fournie par le livre néotestamentaire des Actes des Apôtres, et exégèse de ce texte. Arator, né en Ligurie vers 490, est formé par Ennode de Pavie puis par Deutérius à Milan ; il occupe un rang élevé à la cour de Ravenne (comes domesticorum puis comes rerum priuatarum), puis revient à Rome vers 537-538 et devient clerc - il est connu avec le titre de sous-diacre. Il avait composé une œuvre, poétique et peut-être en prose, assez significative, mais seul le dossier relatif à l'Histoire apostolique nous est parvenu. Son poème est remis solennellement au pape Vigile le 6 avril 544, et une recitatio a lieu à Saint-Pierre-aux-liens à partir du 13 avril ; Arator meut vers la fin des années 540 ou le début des années 550 .

Le poème est formé de deux chants, comportant respectivement 1076 et 1250 vers; il est précédé d'une Lettre au pape Vigile et accompagné de deux autres lettres, à Florian, abbé probablement du monastère de Romainmôtier - et à son condisciple Parthénius. Il comporte deux séries de capitulationes (une pour chaque livre), qui fournissent une sorte de table des chapitres; les éditeurs ont rejeté en fin d'ouvrage les tituli en prose, insérés dans les manuscrits (en deux rédactions) dans le corps du poème et qui fournissent des résumés en prose du passage des actes traité dans le poème. Enfin, une relatio qui narre l'histoire de la présentation de l'œuvre et de ses lectures ferme l'ensemble.

L'introduction offre une étude fouillée sur l'auteur, le contexte de production de l'œuvre mais surtout sa nature littéraire et ses modalités d'écriture, y compris au plan prosodique ; les deux éditeurs s'appuient pour cela sur leurs nombreux travaux antérieurs sur Arator. La seconde moitié de l'introduction est consacrée à une étude de la tradition manuscrite, qui est très abondante : parmi les cent trois manuscrits connus, les éditeurs n'ont retenu que ceux qui étaient antérieurs $\mathrm{au} \mathrm{XI}{ }^{\mathrm{e}}$ siècle et fondent leur édition sur vingt-six manuscrits, dont certains sont très fragmentaires. Au sein de cet ensemble, ils dégagent deux phases, qui voient successivement la constitution d'une vulgate carolingienne, puis la diffusion et la modification de celle-ci. S'appuyant sur les nombreux travaux antérieurs, ils aboutissent à un stemma extrêmement complexe (voir p. CLXV), témoin de l'abondance des travaux érudits sur ce texte dès l'époque carolingienne. On laissera aux spécialistes du domaine la discussion de cette reconstitution textuelle et historique. Deux éditions assez récentes, dues à A. P. McKinlay (1950) et A. P. Orbán (2006), avaient déjà préparé amplement le travail ; on trouvera à la fin de l'introduction une liste des 124 écarts textuels avec le texte établi par ces deux prédécesseurs. La traduction, précise, ne cherche pas à rendre la versification latine et est disposée à pleine page ; elle est accompagnée par 280 pages de notes, rejetées en fin de volume - ce qui laisse de larges espaces blancs en bas de page gauche et déséquilibre malheureusement la composition d'ensemble du volume, puisqu'en belle page, on trouve un abondant apparat critique, négatif, sous le texte latin. Les notes sont pour l'essentiel philologiques et une part considérable d'entre elles vise à éclairer l'intertexte du poème, au plan des mots, des images et des modèles poétiques, ou, dans une moindre mesure, à justifier

\footnotetext{
98 Bruno Bureau et Paul-Augustin DePRoOst, Arator, Histoire apostolique, Paris, Belles Lettres (coll. «Collection des Universités de France, série latine »), 2017 ; 19,2 × 12,5, CXCII + 494 p. (dont 185 doubles), $89 €$, ISBN 978-2-251-01478-4.
} 
les choix textuels - et parfois les deux à la fois. Quelques notes, plus rares, situent l'orientation théologique et exégétique de la réécriture d'Arator.

Si l'intérêt poétique du texte est évident, il ne faut pas non plus en négliger l'intérêt théologique ; non qu'il faille y chercher une élaboration doctrinale originale ou significative, mais le poème d'Arator développe une lecture des Actes qui n'est pas neutre. Si le déplacement de la polémique contre les juifs vers une attaque contre tous les ennemis du christianisme est assez clair, l'interprétation politique et ecclésiastique actualisante proposée par les auteurs voient dans l'œuvre d'Arator une pièce en faveur de la position de l'Église romaine, garante de la foi au milieu des vicissitudes du temps et des attaques des ennemis de la vraie foi. Cette lecture s'appuie également sur une conception de l'ecclésiologie fondée sur les Actes et sur une morale relativement ascétique. Cependant, l'analyse littéraire n'est pas moins intéressante, tant dans les phénomènes de sélection - la totalité des Actes n'est pas reprise - que dans les procédés de réécriture mis en œuvre, ainsi que dans les inflexions qu'ils dessinent.

C'est donc un important volume qui est proposé aux lecteurs, et que son insertion dans la Collection des Universités de France ne devra pas faire négliger aux spécialistes du christianisme ancien, même si le phénomène est plus courant pour les auteurs latins que pour les auteurs grecs. Si la forme poétique du texte peut obscurcir au premier abord le rôle actif de l'auteur dans l'interprétation des Actes, elle ne doit pas laisser penser que le poème ne vaut que par sa seule virtuosité : outre le plaisir du lecteur savant, sa lecture ne pourra que profiter aussi au spécialiste de littérature et d'histoire du christianisme, ne serait-ce que par l'exemple significatif d'épopée biblique qu'il fournit.

\section{Martin de Braga}

Guy SABBAH et Jean-François BERTHET ont fait paraître, dans la collection Sources chrétiennes, une traduction française des œuvres de Martin de Braga, annotée avec la collaboration de Laurent ANGLIVIEL DE LA BEAUMELLE, et pourvue d'un texte latin révisé 99 . Martin, né en Pannonie sans doute vers 510-520, acheva sa vie comme évêque de Braga en Galice, où il mourut en 579. À en croire les historiens ses contemporains, et en particulier Grégoire de Tours, il aurait fait un long voyage dans l'Orient monastique ; aucune source externe ne le confirme, cependant. Il aurait ensuite séjourné à Constantinople où il aurait consolidé sa formation grecque. L'auteur a laissé un petit corpus de textes moraux et pastoraux (Pour repousser la jactance, De l'orgueil, De la colère, Règle de la vie vertueuse, Exhortation de l'humilité, Réformer les paysans, De la triple immersion, De la Pâque), ainsi que trois brefs poèmes, à l'origine des inscriptions. Les œuvres ici traduites ne laissent rien paraître d'une telle connaissance des sources orientales, tout imprégnées qu'elles sont de la Bible, mais aussi de Sénèque - dont l'auteur s'inspire longuement et directement - de Césaire d'Arles ou encore de Jean Cassien. Les liens supposés avec l'Orient transparaissent ailleurs que dans les textes ici traduits : on prête en effet à Martin la paternité d'une traduction des Sentences des Pères égyptiens, c'est-à-dire des Apophtegmes (avec son disciple Pascase de Dumio), ainsi qu'un compendium des canons des conciles orientaux (Capitula Martini). Mais les auteurs du présent livre se sont concentrés sur les œuvres propres à l'évêque de Braga, et qui reflètent au mieux son rôle en Galice, rôle d'évêque et de pasteur que révèlent des textes tôt constitués en corpus, peut-être à l'initiative même de leur auteur. Si l'auteur n'est pas un écrivain de premier plan, cette série de textes mérite cependant une lecture attentive et la riche annotation du volume en déploie les sources et les enjeux.

\footnotetext{
${ }^{99}$ Guy SABBAH et Jean-François Berthet, Martin de Braga, Euvres pastorales et morales, intro., texte et trad. Guy SABBAH et Jean-François BeRTHET, notes Guy SABBAH, Jean-François BeRTHET et Laurent ANGLIVIEL DE la BeAuMElle, Paris, Cerf (coll. «Sources chrétiennes » 594), 2018 ; 19,5 × 12,5, 370 p., $42 €$. ISBN 978-2-204-12789-9.
} 


\section{Cassiodore}

On ne présentera que fort brièvement la traduction du traité De l'âme de Cassiodore qu'a publiée Alain GALONNIER dans la même collection Sources chrétiennes ${ }^{100}$. Le traité, première œuvre du savant fondateur de Vivarium, homme politique retiré des affaires dont il marque le changement d'orientation, après les Variae, a été souvent traduit dans les diverses langues européennes, comme le rappelle la bibliographie du présent volume. L'épaisse introduction présente l'homme et son œuvre, et plus particulièrement le De anima, ainsi que sa postérité. La traduction suit, moyennant une vingtaine de corrections, le texte édité par J. W. Halporn dans le Corpus christianorum en 1973; elle s'accompagne de notes assez abondantes. Cassiodore est un personnage complexe, et un traité de l'âme, composé à la fin de l'Antiquité - on le date généralement de 538/539 - implique nécessairement une grande richesse doxographique et des sources multiples; A. Galonnier maîtrise sans aucun doute ces différents aspects, mais le moins qu'on puisse dire est que le livre tel qu'il a été publié n'en facilite pas l'accès aux lecteurs, même de bonne volonté. Les redites sont nombreuses et l'exposé manque souvent de netteté, sinon de clarté ; bien des points restent imprécis, pour être trop vite évoqués ou trop élégamment formulés : dates, sources, adversaires, etc. D'autres avant nous ont été plus virulents sur la valeur de l'ouvrage, y compris pour la traduction ${ }^{101}$; nous n'entrerons pas dans une telle approche, mais regrettons simplement qu'un texte si riche et d'abord si complexe n'ait pas été servi par plus de pédagogie et d'économie.

\section{Conceptions de la langue et du langage}

La langue et le langage sont au centre de l'épais volume Ideas on Language in Early Latin Christianity, issu d'une thèse de doctorat soutenue à la KU Leuven en 2015 par Tim DENNECKER $^{102}$ : il ne s'agit pas, cependant, d'une étude de la langue latine, moins encore de la langue latine chrétienne, mais des perceptions et des conceptions de la langue et du langage chez les auteurs latins chrétiens, depuis Tertullien jusqu'à Isidore de Séville. L'approche choisie par l'auteur est systématique : trois parties traitent successivement de l'histoire du langage et des langues, de la diversité des langues, puis de la description du langage et des langues - le terme anglais language permet à l'auteur de jouer de ces deux acceptions, plus aisément qu'en français. Chacune des parties est structurée de manière progressive, depuis la perspective la plus surplombante jusqu'au plus petit détail ; sont ainsi étudiées l'origine et la nature du langage, la situation originelle (avant Babel), l'origine de la multiplicité des langues (Babel) ; l'évaluation et les usages de la diversité des langues, l'évaluation et les usages du multilinguisme, les interprétations et les usages des situations surnaturelles qui conduisent au multilinguisme (Pentecôte, surtout, mais aussi langage des anges et situations hagiographiques); les quatre derniers chapitres, qui forment la dernière partie, portent successivement sur la description des niveaux du langage, de la phrase, du mot et des lettres. $\mathrm{Au}$ sein de chaque chapitre, l'approche est soit thématique, soit chronologique, soit une combinaison des deux. L'auteur cherche en effet moins à dégager une position chrétienne, qu'à montrer la diversité de ces positions et leur évolution progressive, ainsi que les écarts par rapport à une éventuelle ligne majoritaire. T. Dennecker traite des différents auteurs, Augustin, bien sûr, ou Isidore, mais aussi l'Ambrosiaster, Jérôme, Philastre de Brescia et bien

\footnotetext{
${ }^{100}$ Alain Galonnier, Cassiodore, De l'âme. Texte de l'édition de J. W. Halporn, Introduction, traduction et notes d'A. GALONNIER, Paris, Cerf (coll. « Sources chrétiennes » 585), $2017 ; 19,5 \times 12,5,425$ p., $45 €$. ISBN : 978-2-204-11759-3.

101 Voir P. MATTEI, «Bulletin de patristique latine », Recherches de science religieuse 106, 2018, p. 611645, ici p. 634-635.

102 Tim DeNECKER, Ideas on Language in Early Latin Christianity from Tertullian to Isidore of Seville, Leiden, Boston, Brill (coll. «Supplements to Vigiliae Christianae », 142), 2017 ; 24,5 × 16, relié, XV + 497 p. ISBN : 978-90-04-34987-2.
} 
d'autres, sans chercher à les hiérarchiser, mais en dégageant les relations entre eux et les évolutions d'ensemble.

Il n'est pas question d'évoquer, dans l'espace restreint de ce bulletin, la totalité des questions et des textes abordés par ce riche ouvrage - dont on regrettera seulement qu'il ne donne presque jamais le texte latin des extraits cités et commentés, mais seulement une traduction farcie de quelques mots latins. Il sort par trop du champ de compétence du recenseur pour que celui-ci se risque à un jugement de fonds. Quelques grandes lignes se dégagent cependant : presque toutes ces discussions sur le langage et les langues interviennent dans des cadres argumentatifs et discursifs dans lesquels elles ne sont pas l'objet premier; c'est à l'occasion d'un point d'exégèse ou d'une controverse doctrinale qu'apparaissent les textes ici commentés. Comme l'auteur le reconnaît lui-même, cette particularité tient en grande partie au fait qu'il a exclu de son enquête les manuels et traités techniques sur la langue ; l'objet de son étude est constitué uniquement - et la tâche est déjà ample - par les textes chrétiens qui traitent du langage, chrétiens non seulement par leur auteur mais aussi par leur contenu. L'auteur dégage également quelques réseaux intellectuels et des filiations qui ne révèlent pas de surprise particulière, de même que la prépondérance à long terme des solutions augustiniennes, à travers divers relais, ou encore le rôle fondamental du traducteur et philologue que fut Jérôme. C'est sans doute moins dans ces conclusions générales que dans les discussions de détail que réside cependant l'intérêt du livre, et dans la confrontation des points de vue sur chacun des sujets étudiés. D'utiles index et une très épaisse bibliographique complètent cet ouvrage et en facilitent grandement l'utilisation.

\section{Monachismes et ascèses}

Plusieurs volumes parmi ceux qui sont recensés cette année sont consacrés à la littérature ascétique, et plus particulièrement aux écrits du désert égyptien. Le premier d'entre eux est celui de Zachary B. SMITH, qui porte pour l'essentiel sur le corpus des Apophtegmes des Pères, et plus particulièrement sur la collection alphabétique ${ }^{103}$. Après une longue introduction, qui couvre près d'un cinquième du livre et présente le corpus, son contexte de formation et de diffusion ainsi que son contenu et sa forme littéraire, l'ouvrage est bâti en deux parties qui étudient successivement la question de l'autorité dans la littérature chrétienne antique à propos de l'Égypte, par comparaison avec le tableau qu'en donnent les Apophtegmes, puis le souci de soi (self-care) dans les Apophtegmes, par comparaison avec la philosophie antique et tardo-antique. Plusieurs appendices rassemblent pour l'essentiel des listes d'occurrences commentées, qui constituent les soubassements des deux parties principales ; ils ne remplacent malheureusement pas un index des lieux cités, qui est absent on trouve en revanche un index des personnes et textes (sans indication des passages concernés) et un autre des sujets.

Écrit avec une certaine érudition, le livre garde cependant une relative fraîcheur dans la présence de son auteur, qui n'hésite pas à s'appuyer sur les modalités de compréhension du monde de ses enfants ou à décrire les lieux où il écrivit l'ouvrage (des cafés américains), pour mieux éclairer son propos ; la chose ne manquera pas de surprendre un lectorat européen peu habitué à ces procédés, mais il ne doit pas conduire à juger négativement l'ouvrage pour autant. Z. B. Smith présente d'abord un état des lieux fort intéressant des travaux sur les Apophtegmes, intégrant en particulier à la fois leur contexte d'origine (l'Égypte) et leur contexte de rédaction finale et d'usage (la Palestine); sans doute est-ce sur ce point que le

103 Zachary B. SMITH, Philosopher-Monks, Episcopal Authority, and the Care of the Self. The Apophthegmata Patrum in Fifth-Century Palestine, Turnhout, Brepols (coll. «Instrumenta Patristica et Mediaevalia » 80) 2017 ; $24 \times 16$, relié, 327 p. ISBN 978-2-503-57888-0. 
lecteur reste le plus sur sa fin, comme l'a déjà relevé $\mathrm{Ph}$. Rousseau ${ }^{104}$. Si le grand nombre de textes étudiés par l'auteur ne pourra que retenir l'attention du lecteur patient, il n'est pas sûr que son interprétation d'ensemble, qui voit dans les Apophtegmes une sorte de manifeste en faveur de la séparation des ascètes par rapport aux autorités ecclésiales, en particulier pour se protéger des conflits internes à l'Église, emporte l'adhésion.

Qu'en est-il de l'apport de l'auteur dans les trois sphères qu'il envisage successivement? L'introduction sur les Apophtegmes est une utile mise au point qui ne doit pas être négligée. La section sur les rapports d'autorité, si elle rassemble une intéressante collection de cas et de textes, est cependant discutable dans l'interprétation qu'elle donne de ces textes, en particulier parce qu'elle s'appuie trop facilement sur le silence ou la distance pour en conclure à une hostilité ou à une opposition. La différence des charismes et des fonctions entre clergé ordonné et ascètes - deux catégories qui ne sont d'ailleurs pas sans recoupements en des points, les moines ordonnés prêtres pour leur communauté, en particulier, qui auraient mérité un examen plus systématique et plus poussé - indique bien l'existence de deux sphères, mais non une nécessaire hiérarchisation de ces deux groupes. Que Théophile soit inférieur aux anciens du désert comme ascète n'implique pas qu'il leur soit inférieur comme évêque. S'il faut retenir un point des analyses de l'auteur, il semble bien que ce soit la tentative de maintenir une sphère ascétique séparée, qui ne refuse pas tout rôle à la hiérarchie ordonnée, en particulier aux prêtres, mais tend à cantonner ces derniers à leur rôle eucharistique, et à ne reconnaître une légitimité aux évêques que dans les domaines qui ne touchent pas au désert et à ses pratiques. Peut-être aurait-il été plus utile au lecteur non de parcourir les textes par auteur, mais de les rassembler en fonction des questions traitées, ce qui aurait évité bien des redites. La dernière section fait le choix volontaire du vocabulaire de Michel Foucault (souci de soi) contre celui de Pierre Hadot (exercices spirituels); la lecture des textes de ce dernier auteur est d'ailleurs assez réductrice - ainsi des exercices spirituels réduits presque uniquement à la préparation à la mort. Il n'aurait d'ailleurs pas été inutile de citer plus largement les travaux d'André-Jean Festugière en ce domaine ${ }^{105}$. Pour point de comparaison avec les Apophtegmes, Z. B. Smith retient Cicéron, Sénèque et Plutarque ; sans doute aurait-il été utile de prendre en compte aussi des néoplatoniciens, et au premier chef Plotin. Mais la principale difficulté causée par cette section n'est pas dans ces détails : comparer le souci de soi dans les Apophtegmes directement avec les textes philosophiques, c'est occulter totalement le rôle d'autres auteurs chrétiens, qui ont joué un rôle essentiel dans le processus d'élaboration, comme Origène ou les Cappadociens, ou encore Évagre. L'auteur donne ainsi la fausse impression d'un emprunt direct de la spiritualité du désert à la philosophie profane et risque d'induire le lecteur en erreur. Bien des développements sur les visions, la vie angélique, etc. ne sont pas sans intérêt, mais ce cinquième chapitre tend à présenter davantage la vie quotidienne des moines que la place et les modalités propres du souci de soi dans l'ascétisme égyptien. En outre, le cadre interprétatif historique très clairement mis en place dans l'introduction n'est ici d'aucune utilité : l'auteur ne fait pas usage de la distinction entre contexte égyptien d'origine et adaptation palestinienne, non plus qu'il ne relève les traits propres à ce dernier contexte.

L'auteur a visiblement une très faible connaissance de la transmission manuscrite d'un texte grec et des particularités des Apophtegmes en ce domaine ; il dépend ici en tout de J.C. Guy, qu'il reprend parfois avec des formules surprenantes. En outre, on ne trouve pas un mot sur les traductions anciennes du texte et leur rôle dans la reconstruction du texte d'origine

${ }^{104}$ P. RousSEAU, «Philosopher-Monks, Episcopal Authority, and the Care of the Self: The Apophthegmata Patrum in Fifth-Century Palestine. By Zachary B. Smith. Turnhout: Brepols, 2017 », Church History 87, 2018, p. $1178-1180$.

${ }^{105}$ En particulier A.-J. FestugIERE, La révélation d'Hermès Trismégiste, Paris (coll. «Collection d'études anciennes, série grecque » 75), $2006\left(1949-1954^{1}\right)$. 
ou de son histoire. Sa bibliographie n'est pas non plus sans lacune, comme l'avait relevé Ph. Rousseau; on pourrait ajouter des titres à cette litanie, par exemple les études de G. Bunge sur les Chapitres sur la prière d'Évagre, qui auraient pu utilement éclairer la discussion des débats origénistes autour de Théophile ${ }^{106}$. On trouve aussi des formulations ou approches quelque peu naïves dans le domaine littéraire : ainsi du genre protreptique, qui ne se saurait se réduire à la persuasion, et qui n'est pas caractéristique de l'Antiquité tardive - il aurait d'ailleurs été utile de renvoyer aux études en ce domaine, par exemple à l'excellent ouvrage de S. van der Meeren ${ }^{107}$; ou encore (p. 55) de la surprenante lapalissade qui relève que le genre littéraire des Apophtegmes est marqué par l'intentionnalité et cherche à influencer son lecteur - comme tout genre littéraire, semble-t-il. On est également surpris que Pacôme et la littérature qui lui est liée tienne aussi peu de place dans l'ouvrage, ne serait-ce qu'à titre de comparaison; il ne figure pas dans l'index des personnes et ce corpus essentiel n'est évoqué qu'une fois, comme en passant (p. 117-118). Plusieurs points des analyses textuelles sont discutables; ainsi de l'interprétation de Vita Antonii, 16, 1 (p. 78-82), qui veut

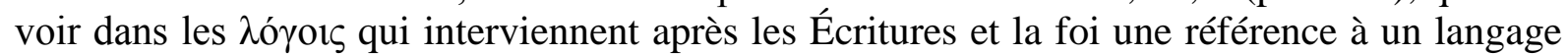
liturgique ou au credo - d'autant que la traduction par words induit sans doute en erreur ${ }^{108}:$ il s'agit bien plutôt de discours, et ce d'autant plus que la phrase introduit précisément le début des discours d'Antoine aux frères. Plus gênante encore est la traduction de $\pi v \varepsilon v \mu \alpha \tau o \varphi o ́ \rho o \varsigma$ par spiritborn. On trouve également des conclusions forcées (p. 113) à propos des cas problématiques de moines estimant pouvoir se passer de l'eucharistie, ou d'anges remplissant le rôle de prêtres : c'est oublier que, dans le premier cas, il s'agit d'un moine condamné par le narrateur pour sa folie et trompé par l'Antéchrist, dans le second, d'anges : ils ne sont pas représentatifs de la position des ascètes du désert égyptien.

On voit que l'ouvrage n'est pas sans intérêt par l'état des lieux qu'il propose au début sur la collection alphabétique des Apophtegmes, mais aussi par le grand nombre de textes qu'il parcourt et commente, tant au sein de la production égyptienne qu'à son propos. Cependant, le cadre interprétatif est très discutable et la construction d'ensemble, qui conduit à de nombreuses répétitions et ne permet pas de dégager clairement les points essentiels, par exemple dans les rapports des ascètes aux ministères ordonnés, aurait pu être utilement revue.

Parmi les livres consacrés à la littérature ascétique qui sont présentés dans le bulletin de cette année, l'ouvrage de Paul C. DiLley se signale par son choix de privilégier le monachisme cénobitique ${ }^{109}$. Comme les autres ouvrages présentés dans cette section, mais dans une moindre mesure, il prétend également intégrer les apports et les perspectives de la psychologie cognitive et de l'anthropologie à son enquête; cependant, ce trait reste ici secondaire, au profit d'un tableau assez ample du soin des âmes dans le monachisme de l'Antiquité tardive. C'est que l'auteur propose une enquête qui n'est pas limitée dans le temps et l'espace et qui mêle sources occidentales et orientales, latines, grecques, coptes et syriaques, traités ascétiques, homélies, hagiographie, textes régulateurs du monachisme,

${ }^{106}$ Voir dans le Bulletin de 2017, Rev. Sc. ph. th. 101, 2017, p. 508-512, quels que soient par ailleurs les désaccords avec l'interprétation que l'auteur propose du traité évagrien. Sur Évagre, plutôt que l'étude de seconde main citée n. 122, p. 59, sans doute aurait-il été plus utile de renvoyer à A. GuILLAUMONT, Un philosophe au désert. Évagre le Pontique, Paris (coll. « Textes et traditions » 8), 2004.

107 S. VAN DER MEEREN, Exhortation à la philosophie: le dossier grec. Aristote, Paris (coll. «Fragments » 11), 2011. Voir aussi S. VAN DER MEEREN, «Le protreptique en philosophie : essai de définition d'un genre », Revue des études grecques 115, 2002, p. 591-621.

108 «Les Écritures suffisent à notre instruction, mais il est bon de nous encourager mutuellement dans la foi et de nous fortifier par des discours » (trad. G. J. M. Bartelink [SC 400], p. 179, légèrement modifiée).

${ }^{109}$ Paul Dilley, Monasteries and the Care of Souls in Late Antique Christianity: Cognition and Discipline, Cambridge, New York, Cambridge University Press, 2017 ; 23,5 × 16, relié, XII + 350 p. ISBN 978-1-10718401-5. 
lettres, etc. Là réside le principal intérêt de l'ouvrage, qui propose ainsi une approche panoramique de la littérature monastique, à travers différents sujets : le livre est structuré en trois parties, consacrées successivement à l'entrée au monastère, aux disciplines cognitives et au travail intérieur collectif.

Issu d'une thèse de doctorat soutenue à l'Université de Yale en 2008, l'étude a été largement amplifiée au fil du temps et nourrie, en particulier, par la pratique directe des textes coptes et plus largement égyptiens, qui sont très présents tout au long du livre. P. C. Dilley propose une approche intéressante, qui s'attache à étudier les mécanismes cognitifs et les pratiques qui leur sont liées dans la perspective du salut, but ultime du moine. Se situant dans la perspective de M. Foucault et du «souci de soi », il écarte cependant un peu vite le parallèle entre les exercices spirituels des moines et la philosophie, alors même qu'on sait, au moins depuis les travaux de P. Hadot, que la dimension d'exercice spirituel est constitutive de la philosophie antique ${ }^{110}$. La limite principale de l'ouvrage vient cependant de l'un des traits qui fait aussi son intérêt principal : la perspective englobante, diachronique et sans limite géographique qui a été choisie conduit à minorer les différences de contexte et les divergences de pensée, au profit sinon d'un concordisme, du moins d'une approche qui minore les écarts.

Sans entrer dans une étude détaillée de l'ouvrage, qui la mériterait cependant, on signalera simplement de manière cursive les principaux sujets abordés. La première partie porte sur l'entrée au monastère, sous le double aspect du discernement de la vocation puis des épreuves initiales pour l'entrée dans le monachisme (procédures d'entrée, vœux, etc.). La seconde partie traite des «disciplines cognitives » : intériorisation de l'Écriture - avec une attention particulière prêtée à la rhétorique et aux usages de l'Écriture - crainte de Dieu et ses manifestations, y compris dans la discipline physique, prière (qu'il n'aurait pas fallu restreindre à la seule définition de la «conversation avec Dieu », définition dont les sources ne sont d'ailleurs jamais évoquées). Enfin, la dernière partie étudie, de manière très intéressante, le travail intérieur pris dans une dimension collective, tout d'abord autour du culte du fondateur, en particulier dans le cadre pachômien, puis pour la pénitence collective, avec Shénouté.

La bibliographie, ample, témoigne parfois de quelques manques, en particulier hors du domaine anglo-saxon; on signalera par exemple les volumes d'A. de Vogüé sur le monachisme grec ${ }^{111}$, dont l'auteur déplore précisément l'absence (p. 23), ou encore les travaux de B. Flusin sur le monachisme de Palestine (p. 33) ${ }^{112}$ ou ceux de Lorenzo Perrone sur le Traité de la prière d'Origène (p. 187) ${ }^{113}$. Certains rapprochements sont aussi parfois un peu surprenants, dans la mesure surtout où ils ne sont pas explicités, ainsi quand l'entrée au monastère est lue à travers le filtre d'une étude contemporaine sur l'entrée en asile psychiatrique (p. 92) : le rapprochement n'est pas à rejeter a priori, mais devrait être au moins expliqué. Le choix de réduire la perspective aux cénobites introduit également des déformations, comme quand l'examen des pensées est présenté à partir de textes basiliens, tandis qu'il serait rare dans les textes pachômiens : il n'aurait pas été inutile de rappeler la place centrale de cette question chez Évagre ou dans les Apophtegmes. Quelques erreurs

${ }^{110}$ P. Hadot est brièvement mentionné (p. 107) comme précurseur de M. Foucault à propos du souci de soi, mais sans que son apport propre soit clairement dégagé et sans prendre en compte les réponses de P. Hadot aux positions de M. Foucault. En outre, Hadot est totalement absent de la discussion initiale du problème dans l'introduction.

111 A. DE VoGÜE, Histoire littéraire du mouvement monastique dans l'Antiquité. 2, Le monachisme grec, Roma (coll. «Studia Anselmiana »165-167), 2015).

112 B. Flusin, Miracle et histoire dans l'œuvre de Cyrille de Scythopolis, Paris (coll. «Études Augustiniennes, série Antiquité »96), 1983 ; IDEM, Saint Anastase le Perse et l'histoire de la Palestine au début du VII siècle, Paris (coll. «Le Monde byzantin »), 1992.

${ }^{113}$ L. PERRONE, La preghiera secondo Origene : l'impossibilità donata, Brescia (coll. « Letteratura cristiana antica »n. s. 24), 2011. 
surprenantes subsistent, comme l'affirmation selon laquelle Grégoire de Nazianze est le frère de Basile de Césarée (ce Grégoire n'est que son ami, c'est Grégoire de Nysse qui est le frère de Basile), ou encore la présentation de deux rhétoriciens successifs, Théon et l'orateur Aelius Théon (p. 140), qui sont bien sûr une seule et même personne. On s'étonne aussi de voir identifier le métier de copiste avec un niveau supérieur d'éducation, mis sur le même plan que la rhétorique, ce qui ne correspond pas au profil des copistes de métier, qui sont certes alphabétisés, mais pas forcément des lettrés. Il est également pour le moins surprenant de présenter l'usage antirrhétique de l'Écriture, qui choisit un verset adapté pour répondre à une tentation donnée, comme un usage oraculaire.

Cependant, ces erreurs de détail ne privent pas de son intérêt cette vaste fresque, même si le lecteur peu familier de ces mondes monastiques devra cependant vérifier avec soin certains éléments. Le tableau d'ensemble, de même que ses parties, entre autres à propos de l'entrée au monastère, présentent un apport réel à la connaissance du monachisme ancien ; réduit par exemple à l'Égypte, ce panorama aurait sans doute gagné en précision, sans pour autant perdre de son ampleur.

Le troisième livre qui, dans le Bulletin de cette année, est consacré aux ascètes du désert égyptien - et à quelques autres - est dû à Inbar GRAIVER ${ }^{114}$. Comme les deux premiers, le soin des âmes et des esprits est au cœur de l'approche qui y est retenue ; cependant, l'auteur a ici choisi d'étudier les processus liés à l'attention et à la transformation de soi en les confrontant aux approches de la psychologie et des sciences cognitives, ce qui fait toute l'originalité de l'ouvrage. De ce fait, I. Graiver a choisi une approche synoptique et synchronique, qui ne cherche pas à distinguer entre les traits propres à tel auteur, tel milieu, tel époque, mais à éclairer les phénomènes et les procédés décrits par les textes anciens à l'aide des approches contemporaines. Appuyé sur de très vastes lectures, l'ouvrage propose une perspective thématique fort intéressante autour de la notion d'attention, et en particulier d'attention interne, d'attention aux pensées - en leur sens monastique de pensées mauvaises et nuisibles, suscitées en particulier par les démons - et aux phénomènes intérieurs à l'âme et à l'intellect. L'éclairage des sciences cognitives passe nécessairement par une juxtaposition de deux discours, celui des sources anciennes et celui de la clinique et de la théorie modernes; cependant, l'apport du regard des approches contemporaines offre une perspective renouvelée sur les sources anciennes, par exemple dans le cas du siège de l'âme par les démons et les pensées, qui est étudié en comparaison avec les différentes formes d'obsession. On aurait parfois pu souhaiter que les deux approches soient davantage intégrées, mais une telle succession des points de vue est sans doute inévitable, du moins dans un premier temps; on peut espérer par la suite des approches plus intégrées, pour poursuivre le fil qu'a commencé à tresser l'auteur.

L'ouvrage se déploie en cinq chapitres, traitant successivement du moi ascétique, de son contrôle, des défis posés à l'attention, de l'esprit assiégé et finalement de la levée du blocus de l'âme. On notera en particulier l'intérêt que prête l'auteur aux échecs, difficultés et contreparties négatives induits par les processus d'entraînement qui sont au cœur de l'ascèse intérieure pratiquée par les moines qu'elle étudie, et non aux seuls avantages qu'ils en retirent. En effet, si ces procédés visent à améliorer l'attention et à la tourner vers Dieu, en cas d'échecs dans le processus, les conséquences psychologiques peuvent être graves et conduire jusqu'à la folie. Cependant, l'apport de la psychologie moderne n'est pas toujours décisif, ainsi lorsque l'auteur consacre plusieurs pages à établir que l'anxiété rend l'attention plus difficile, à grand renfort de citations de publications savantes. D'autres développements sont

\footnotetext{
${ }^{114}$ Inbar GRAIVER, Asceticism of the Mind: Forms of Attention and Self-Transformation in Late Antique Monasticism, Toronto, Pontifical Institute of Mediaeval Studies (coll. «Studies and Texts» 213), 2018 ; 24,5 × 16, relié, $\mathrm{X}+237$ p. ISBN 978-0-88844-213-0.
} 
plus attendus, comme la comparaison avec les pratiques de méditation de l'Extrême-Orient, qui aurait d'ailleurs sans doute pu s'appuyer sur d'autres travaux comparatistes déjà menés en la matière. On relèvera également l'attention prêtée aux formulations linguistiques, par exemple pour les formules d'introduction employées dans la littérature monastique ancienne pour parler des pensées, de leur survenue dans l'esprit.

L'auteur opère, du côté des sources anciennes, de constants va-et-vient entre les traités théoriques sur l'ascèse et les textes qui reflètent, au moins en apparence, plus directement la pratique des ascètes eux-mêmes, apophtegmes, histoires édifiantes, lettres, etc. Cependant, elle définit clairement son objet: non expliquer le fonctionnement de l'esprit des anciens ascètes, mais la manière dont ils se représentaient leur esprit et ses opérations, et les articulaient avec leur conception de l'homme, du monde et de Dieu. Même si quelques formules maladroites laissent parfois entendre, surtout au début de l'ouvrage, que ces textes qui décrivent la pratique monastique seraient des sources documentaires - alors que la médiation littéraire est presque toujours présente - l'analyse est cependant menée d'une manière qui prend en compte à la fois la représentation des réalités du désert et leur mise en scène ; toutefois, le choix d'une approche synchronique conduit nécessairement à affaiblir les différences et les contextes propres à chaque source. L'attention prêtée aux démons, aux procédures de guérison mais aussi les formules qui rappellent combien ces ascètes du désert égyptien sont, au contraire des surhommes du désert de Syrie, des hommes, de simples hommes, qui luttent, tombent et se relèvent parfois, tout autant que les analyses fines et toujours prudentes que propose l'auteur dans cet ouvrage offrent donc au lecteur une très intéressante approche des procédures d'entraînement de l'esprit, de contrôle de son fonctionnement dans le cadre du désert Égyptien. Il n'est donc que juste d'en recommander vivement la lecture : c'est un livre qui se lit bien et ouvre des perspectives riches et des questions nombreuses, y compris pour des lecteurs qui ne seraient pas des spécialistes des ascètes d'Égypte.

\section{Mondes copte et syriaque}

Copte

Le livre de Renate DEKKER, consacré aux réseaux de deux évêques de l'Église copte orthodoxe de la fin du $6^{\mathrm{e}}$ siècle $^{115}$, nous ramène aux marges du désert égyptien, mais dans un tout autre contexte institutionnel et ecclésial que les textes ascétiques évoqués plus haut. La différence ne tient pas seulement aux méthodes employées, mais surtout à l'approche globale et au type de sources dont nous disposons sur Abraham d'Hermonthis et Pésynthios de Koptos, deux évêques de la région thébaine. Ces deux personnages, qui sont au centre de l'étude, sont en effet essentiellement connus par des sources documentaires, conservées tant sur papyrus que sur ostracon, et très majoritairement en copte - à l'exception du testament d'Abraham, qui est en grec ; il y a bien quelques textes hagiographiques sur Pésynthios, ainsi qu'une homélie qui lui est attribuée, mais ces sources, dont beaucoup sont tardives, ne fournissent à l'auteur qu'un éclairage complémentaire. Le cœur de son étude porte sur les réseaux d'hommes et de lieux que structurent autour d'eux les deux évêques, à une période charnière qui est celle de la mise en place d'une hiérarchie dite «théodosienne », du nom du patriarche d'Alexandrie Théodose $\mathrm{I}^{\mathrm{er}}$ (535-566), non chalcédonienne, miaphysite, dans la région de Thèbes, en Haute Égypte. Pour ce faire, l'auteur met en œuvre une double approche, fondée d'une part sur l'analyse de réseaux sociaux (Social Network Analysis), à partir de données quantitatives, et d'autre part sur l'étude des modèles d'autorité épiscopale et

\footnotetext{
${ }^{115}$ Renate DEKKER, Episcopal Networks and Authority in Late Antique Egypt: Bishops of the Theban Region at Work, Leuven, Paris, Bristol, Peeters (coll. « Orientalia Lovaniensia analecta », 264), 2018 ; 25,5 × 17,5, relié, $\mathrm{XV}+350$ p. et 1 CD-rom. ISBN 978-90-429-3560-0.
} 
de leur mise en œuvre. Elle connaît de première main le dossier de Pésynthios, puisqu'elle participe à l'édition, toujours en cours, des textes documentaires qui lui sont liés.

Issu d'une thèse de doctorat soutenue à Leiden en 2017 sous la direction de J. van der Vliet et $\mathrm{O}$. Kaper, le présent livre en a gardé de (trop) nombreux traits, qui dérouteront sûrement le lecteur et risquent de lui faire manquer les aspects intéressants et originaux de l'étude. En effet, l'auteur a conservé de longs développements méthodologiques sur la constitution des jeux de données et l'usage des deux programmes d'analyses de réseaux qu'elle a utilisés (Ucinet 6 et NetDraw); si ces explications ont sûrement leur intérêt pour qui s'intéresse aux méthodes de l'analyse de réseau, et si elles avaient sans doute leur place dans la thèse, elles sont ici hors de propos et encombrent largement la démonstration. L'analyse des documents, de la topographie, de la chronologie et de la prosopographie, qui occupe une autre part importante du livre, est sûrement plus essentielle ; cependant, là encore, par sa technicité et la difficulté qui attend le lecteur non spécialiste lorsqu'il s'agit de déterminer les apports propres de l'auteur et les points déjà bien établis, cette analyse prend sans doute trop de place. Enfin, on comprend bien qu'il fallait présenter les résultats de l'analyse des différents réseaux (réseau théodosien de la région thébaine, réseaux respectifs des deux évêques, et toutes leurs subdivisions) sous une forme non seulement graphique, ce qui est fait en fin d'ouvrage, mais aussi discursive. Cependant, le lecteur, pourtant bienveillant et point trop rétif, peine à comprendre l'intérêt et la portée de ces présentations. Au contraire, les interprétations des résultats présentent un réel intérêt, tant dans la différenciation des réseaux respectifs des deux évêques que dans la caractérisation d'ensemble du réseau thébain, dans lequel des prêtres et des ermites occupent des positions tout aussi centrales que les deux évêques considérés.

La seconde dimension de l'ouvrage, qui concerne l'autorité épiscopale, ses formes, ses manifestations et ses justifications, ouvre une seconde fenêtre assez différente de la première, et bénéficie d'ailleurs, de manière générale, d'un traitement à part, assez isolé de l'analyse des réseaux - ce que l'on peut regretter, mais peut-être n'était-il pas possible d'intégrer pleinement ces deux approches. Cependant, en ce domaine, qui repose beaucoup plus largement sur une lecture des textes et sur leur analyse traditionnelle, l'étude paraît peu novatrice. R. Dekker dit reprendre le modèle de l'autorité épiscopale développé par Claudia Rapp, tout en le modifiant et le complétant - mais cette intervention, qui pourrait présenter un réel intérêt, n'est pas clairement exposée et l'apport propre de l'auteur n'est pas dégagé. Il est surtout regrettable que les chapitres consacrés à cette autorité consistent surtout à illustrer, à partir des documents relatifs aux deux évêques, et parfois simplement à partir du formulaire employé, la typologie des formes d'autorité définie au préalable. On semble être loin d'une étude historique approfondie de l'autorité épiscopale, même réduite aux cas de ces deux évêques et à leur contexte spécifique. Les conclusions qui en sont tirées sont d'ailleurs réduites, qui confirment l'autorité ascétique de Pésynthios, déjà connue par les textes hagiographiques qu'étudie d'ailleurs l'auteur. D'autres éléments, plus ponctuels, ne sont pas sans intérêts, mais paraissent trop isolés, voire anecdotique, pour permettre une généralisation.

Enfin, certains choix demeurent problématiques (ainsi de traiter le patriarche d'Alexandrie comme une personne morale unique, à travers les différents hommes qui se sont succédé sur le siège pendant la période considérée, alors que ce n'est bien sûr pas le cas des évêques de la même période) et la nature même de la documentation qui, si abondante soit-elle, a pourtant subi la sélection aléatoire que supposent les conditions de conservation de papyrus et d'ostraca pendant plus de 1400 ans parait rendre périlleuse une reconstitution qui est à la fois fondée sur un dossier réduit (deux évêques) et sur une approche quantitative. Il y a pourtant à apprendre de ce livre et une lecture attentive, malgré les lourdeurs méthodologiques déjà évoquées, pourra sûrement tirer profit des éléments rassemblés ici, y compris dans le domaine de la topographie (localisation de monastères et d'ermitages, de toponymes, frontières de 
diocèses, etc.), de la chronologie (des documents, des personnes et des événements) et de l'étude et de l'identification des personnes mentionnées dans les nombreux documents utilisés, en particulier pour distinguer ou identifier les homonymes, en fonction des autres personnes nommées dans les documents; on en viendrait à souhaiter, cependant, que l'auteur offre à la communauté scientifique plus large que les seuls spécialistes de cette zone géographique pendant cette étroite période une version allégée et révisée, qui mette mieux en évidence les apports d'une telle analyse, dans le cas précis de la région thébaine à la fin du $6^{\mathrm{e}}$ siècle.

\section{Syriaque}

L'excellente collection des Testi del Vicino Oriente a publié, grâce aux bons soins d'Emanuele ZIMBARDI, une traduction italienne du mimro attribué à Éphrem de Nisibe sur Ninive et Jonas ${ }^{116}$. Ce texte de 2141 vers forme une sorte d'interprétation homilétique et parénétique à partir du texte biblique du livre de Jonas, et plus particulièrement de sa seconde partie, à partir du moment où Jonas annonce à la ville de Ninive sa destruction prochaine. Le texte syriaque a été édité par E. Beck en 1970 et Sebastian Brock a depuis publié une étude sur la tradition textuelle de l'œuvre et l'établissement du texte, dans les mélanges Carl Laga (1994). Outre la traduction du mimro, qui constitue la pièce essentielle de l'ouvrage, E. Zimbardi a également fourni une traduction des Hymnes sur la virginité 42-50, qui traitent du même sujet dans une perspective assez différente - au contraire du texte principal, ces hymnes sont dépourvus de tout appareil critique, tant sous forme d'introduction que de notes.

L'ample introduction (plus d'une cinquantaine de pages) fait d'abord le point sur la question de la paternité de l'œuvre; en effet, au moins depuis une étude d'A. de Halleux ${ }^{117}$ parue en 1990, on a mis en doute l'attribution à Éphrem, entre autres parce que ce texte a été utilisé comme lecture pour les Rogations des Ninivites (jeûne de trois jours, situé trois jours avant le début du carême, et propre aux Églises syriaques), une pratique qui n'est pas attestée avant la seconde moitié du $6^{\mathrm{e}}$ siècle. Cependant, E. Zimbardi montre, de manière assez convaincante, que l'utilisation du texte pour cette pratique liturgique, qui s'appuie sur quatre vers seulement (v. 1385-1388), est secondaire et ne doit pas conduire à rejeter l'authenticité ephrémienne. Comme les autres arguments pour rejeter cette authenticité sont également faibles - l'auteur reprend ici des discussions menées avant lui et les complète - l'attribution ephrémienne reste possible et les autres arguments employés pour dater les versions ne permettent pas une plus grande précision chronologique. Le texte a en effet connu une large diffusion dans différentes langues (grec, latin, arménien, géorgien, éthiopien), avec parfois d'importantes variations dans le texte. L'introduction comporte surtout une ample analyse littéraire de l'œuvre, depuis sa structure, ses personnages et ses thèmes jusqu'aux formes rhétoriques et aux motifs exégétiques employés, ainsi qu'aux tours poétiques propres à l'écriture ephrémienne; une assez ample section est également consacrée aux rapports, conflictuels, avec le judaïsme, puisque l'auteur du mimro non seulement use de la polémique directe, mais a aussi ajouté à la fin un ample développement sur les turpitudes du peuple juif que découvrent les Ninivites lorsqu'ils raccompagnent Jonas jusqu'aux frontières de son pays - et ce malgré le stratagème du prophète, qui les empêche d'entrer en Terre promise pour qu'ils ne voient pas ce spectacle peu édifiant. Une dernière section porte sur les autres œuvres poétiques syriaques qui ont été consacrées à cet épisode.

Si l'introduction est ample et riche, la traduction est presque totalement dépourvue d'annotation; les citations bibliques sont signalées, mais c'est loin d'être le cas pour les allusions, et aucune indication de lecture (sources, parallèles, mise en contexte) n'est fournie

\footnotetext{
${ }^{116}$ Emanuele ZIMBARDI, Efrem Siro, Sermone su Ninive e Giona, Torino, Paideia (coll. « Testi del Vicino Oriente antico. 7, Letteratura della Siria cristiana », 5), $2019 ; 21 \times 13,5,153$ p., $34 €$. ISBN 978-88-394-0934-8.

${ }^{117}$ Le savant était, n'en déplaise à l'auteur, belge et non français ; voir par exemple J. LISON, «André de Halleux (1929-1994) », Revue des Sciences Religieuses 68, 1994. p. 403-408.
} 
avec la traduction. En revanche, cette dernière parvient à rendre une bonne part de l'art poétique d'Éphrem, avec le recours à une disposition en stique, à une langue rythmée et assonancée et à une grande attention aux reprises du vocabulaire, si caractéristiques de l'auteur. Voilà donc un volume qui intéressera non seulement les spécialistes d'Éphrem, mais aussi tout lecteur curieux de prendre un aperçu des modalités d'écritures poétiques de cet auteur et de son œuvre d'exégète et de prédicateur.

Le titre du livre de Nestor KAVVADAS indique clairement qu'Éphrem et Basile ne constituent qu'une des facettes de son étude ${ }^{118}$ : Justinien et Édesse, ou pour le dire plus clairement, le contexte syriaque du $\mathrm{VI}^{\mathrm{e}}$ siècle conditionne l'interprétation de ces deux figures. Le point de départ de l'enquête est constitué par l'état le plus ancien des Vies syriaques d'Éphrem ; or il se trouve que cet état ancien est loin de remonter à l'époque d'Éphrem, mais peut être daté, comme le montre N. Kavvadas, de la première moitié du $\mathrm{VI}^{\mathrm{e}}$ siècle et doit être situé dans le contexte des controverses entre myaphisites, Église de l'Est et Église chalcédonienne impériale. De manière assez paradoxale, cette Vie dans son état le plus ancien reprend des motifs déjà diffusés en grec, en particulier la légende de la rencontre entre Basile de Césarée et Éphrem, à Césarée de Cappadoce. Cette légende, dont l'auteur étudie le développement, se trouve entre autres attestée dans la Vie et miracles de Basile, faussement attribuée à Amphiloque d'Iconium, dans un Éloge de Basile et un Éloge des Quarante martyrs qui figurent dans le corpus de l'Éphrem grec, ainsi que dans l'Éloge d'Éphrem faussement attribué à Grégoire de Nysse - l'auteur examine également les témoignages des historiens ecclésiastiques, en particulier Sozomène (HE III, 16). Le lien avec Basile de Césarée, qui a des motifs idéologiques sur lesquels on reviendra, pourrait venir de la double mention par Basile d'un informateur syriaque, anonyme, que des Grecs ont voulu identifier avec le plus célèbre des Syriaques, Éphrem - alors qu'il semble s'agir, au moins dans le cas des Homélies sur l'Hexaemeron, d'Eusèbe d'Émèse. Partant des textes les plus anciens, N. Kavvadas montre comment les strates les plus anciennes, par exemple chez Sozomène, témoignent d'une mise en parallèle de Basile et d'Éphrem, mais pas encore d'une rencontre, ou du moins très indirectement. La légende se serait ensuite développée en plusieurs phases, et dans des contextes différents; là où trois des textes évoqués plus hauts seraient d'origine cappadocienne, pour N. Kavvadas, l'Éloge pseudo-nysséen devrait être mis en relation avec la Palestine, tant du fait de la version de la légende que de la connaissance de Choricios de Gaza dont témoigne le texte. On notera aussi que l'image d'Éphrem que transmet ces textes est en désaccord avec ce que les sources permettent de reconstituer avec plus d'assurance : carrière ecclésiastique poussée au-delà du diaconat, figure d'ascète, production littéraire tournée principalement vers l'ascétisme, etc. L'étude de ces documents, la reconstitution de leur contexte de production et des raisons qui ont présidé à leur écriture occupe le chapitre 2 qui, après une brève introduction, constitue la première partie de l'ouvrage.

La seconde (chap. 3), un peu plus longue, est consacrée à l'étude du contexte de rédaction supposée de l'état ancien de la Vie syriaque. N. Kavvadas cherche à montrer comment le contexte édessénien de la première moitié $\mathrm{du} \mathrm{VI}^{\mathrm{e}}$ siècle explique bien des traits de la Vie, et en particulier le rapprochement avec Basile qu'elle emprunte aux versions grecques de la légende. La mise en relation des deux figures témoignerait des rapports complexes entretenus par l'Église myaphisite avec l'Église chalcédonienne impériale, dont les deux personnages seraient en quelque sorte les représentants d'autorité ; ce premier niveau de lecture serait également redoublé par les rapports concrets entre les deux cités, leurs clergés et leurs

118 Nestor KaVVADAS, Ephraem der Syrer und Basilios der Große, Justinian und Edessa. Die Begegnung griechischer und syrischer Traditionsautorität in der Ephraemvita und der miaphysitisch-chalkedonische Konflikt, Leiden, Boston, Brill (coll. «Supplements to Vigiliae christianae»146), 2018 ; 24,5 × 16, relié, VII + 206 p., $104 €$. ISBN : 978-90-04-36185-0. 
positions ecclésiales. D'autres traits de la Vie (rapports avec les empereurs Julien et Valens, martyrs, etc.) complèteraient ce tableau.

L'enquête est riche, même si elle est parfois menée d'une manière un peu sommaire - ainsi quand le rôle de Basile de Césarée au Concile de Ferrare-Florence n'est présenté qu'à partir de la seule Turcograecia de Martin Crusius. On peine cependant souvent à mesurer quel est l'apport propre de l'auteur, au regard des études nombreuses déjà menées sur tous ces textes, et plus particulièrement sur le dossier des Vies d'Éphrem. Ce bref petit livre, un peu dispendieux au regard de son nombre de pages, présente une intéressante étude du dossier Basile-Éphrem qui, s'il ne le renouvelle sans doute pas radicalement - mais en était-il besoin ? - le présente d'une manière intéressante. Comme l'auteur l'indique lui-même, la plupart des textes grecs qui en constituent les antécédents attendent encore une édition critique et une étude détaillée ; c'est particulièrement le cas pour le dossier épais et épineux de la Vie et miracles de Basile du pseudo-Amphiloque: espérons qu'un ou plusieurs savants parviendront un jour à clarifier ce cas compliqué et à fournir une édition satisfaisante à la communauté scientifique.

J'avais présenté, dans le précédent Bulletin, le premier tome de la traduction des Hymnes contre les hérésies d'Éphrem le Syrien par Dominique CERBELAUD ${ }^{119}$; le deuxième tome en est paru depuis, qui comprend, outre les Hymnes XXX-LVI contre les hérésies, une Hymne sur l'Église et les quatre Hymnes contre Julien, ainsi que divers index (scripturaire, onomastique, thématique) et un très bref appendice sur la métrique des hymnes par D. Gonnet et J. Pflieger. Il est dû au même traducteur ${ }^{120}$. Je ne m'attarderai pas sur ce volume, pour diverses raisons, mais en particulier parce que les remarques faites sur le premier valent également pour le second. En outre j'ai présenté récemment une autre traduction des mêmes Hymnes contre les hérésies, due à Flavia Ruani, et qui est beaucoup plus satisfaisante pour l'appareil scientifique qu'elle fournit au lecteur ${ }^{121}$. On rappellera simplement, à propos du volume des Sources chrétiennes, qu'il présente le texte d'E. Beck et une traduction française, à peu près totalement dépourvue de notes, avec des notices par hymnes qui sont marquées par un fort anachronisme des jugements.

\section{Approches thématiques}

\section{Tolérance}

L'Antiquité tardive fut-elle une période de tolérance ou d'intolérance ? Y a-t-il eu, à cette période, un changement de nature ou de degré dans la tolérance? L'avènement du christianisme joue-t-il un rôle dans un tel changement? La violence religieuse change-t-elle de nature ou de degré à cette période et dans ces circonstances ? Ces questions ont souvent été soulevées, pesées voire agitées ces dernières décennies. Un très petit livre, par son format, son épaisseur et son prix, vient pourtant jeter une lumière nouvelle et précieuse sur ces questions : nous le devons à Peter VAN NUFFELEN ${ }^{122}$, qui l'a tiré d'une série de conférences données, comme directeur d'études invité par Michel-Yves Perrin et Philippe Hoffmann, à la section des sciences religieuses de l'École pratique des hautes études en 2013. L'approche choisie par l'auteur reflète d'ailleurs la double nature de cette invitation par un historien du christianisme

119 «Bulletin de Patrologie », Rev. Sc. phil. et th. 102, 2018, p. 299-375, ici p. 309-311.

${ }^{120}$ Dominique Cerbelaud, Éphrem de Nisibe, Hymnes contre les hérésies. Hymnes contre Julien. II, Hymnes contre les hérésies XXX-LVI, Hymnes contre Julien, Paris, Cerf (coll. «Sources chrétiennes » 590), $2017 ; 19,5 \times 12,5,547$ p., $54 €$. ISBN : 978-2-204-12638-0.

${ }^{121}$ Revue des études byzantines 77, 2019, p. ******* Flavia RUANI, Éphrem de Nisibe, Hymnes contre les hérésies, Paris (coll. «Bibliothèque de l'Orient chrétien »), 2018.

${ }^{122}$ Peter VAn Nuffelen, Penser la tolérance durant l'Antiquité tardive, Paris, Éditions du Cerf (coll. « Les conférences de l'École pratique des hautes études »10), 2018 ; $19 \times 12,183$ p, $16 €$. ISBN : 978-2-204-12648-9. 
et un historien de la philosophie: P. Van Nuffelen a en effet étudié, dans une démarche d'histoire intellectuelle, « la façon dont on réfléchissait sur la tolérance et la violence durant cette période » (p. 11). Au contraire de nombre d'approches récentes à ce propos, qui ont voulu montrer l'Antiquité tardive comme un moment de changement radical dans la société du bassin méditerranéen dû à l'avènement d'une religion monothéiste, le christianisme, qui mettrait fin brusquement à une société de tolérance, en particulier en matière de religion, pour la remplacer sinon par une société totalitaire, du moins par un cadre dans lequel non seulement la contrainte en matière de religion est le fait du pouvoir politique, mandaté par l'Église, mais où la violence est pratiquée et légitimée par l'Église et par l'État, l'auteur reprend de plus haut et de plus loin. Sa visée d'ensemble consiste à « montrer que durant l'Antiquité tardive la persuasion, et non pas la violence, se trouvait au cœur de la pensée » (p. 11).

L'introduction reprend la question historiographique de la tolérance et permet à l'auteur de reconstituer la distance qui existe entre la conception actuelle de la tolérance, son utilisation ancienne et récente dans les débats religieux, philosophiques, politiques et historiques, et le rôle que joua dans ce cadre la référence à l'Antiquité tardive. De ce point de vue, P. Van Nuffelen rappelle que, du point de vue du concept actuel de tolérance, l'Antiquité tardive était bien intolérante - mais au même titre que toutes les époques qui nous précèdent, surtout lorsque la notion de vérité et son importance sociale essentielle étaient présentes et structurantes pour la société. En outre, il intègre également une réflexion sur les limites et frontières de la tolérance, qui lui sont inhérentes : où passent-elles, et comment sont-elles définies? L'autre point de départ de l'auteur consiste en un élargissement du champ chronologique pour envisager la tolérance tardo-antique; il rappelle en effet que, si changement il y a dans la politique de l'empire romain au regard de la religion, il intervient dès le milieu du $3^{\mathrm{e}}$ siècle, lorsque l'empire promeut activement une unité religieuse, sans lien donc avec l'avènement du christianisme. De manière plus large, la démarche de $\mathrm{P}$. Van Nuffelen vise à mieux rendre compte de la complexité du sujet, c'est-à-dire du réel, en intégrant non seulement des listes de faits violents, incontestés, mais aussi leur interprétation et les discours tardo-antiques sur la tolérance et la violence: c'est bien d'une histoire intellectuelle qu'il s'agit, telle que l'auteur l'a déjà menée avec brio à propos des historiens ecclésiastiques Socrate et Sozomène.

Après cette riche introduction, le volume est construit en quatre chapitres : la conception tardo-antique de la tolérance ; la persuasion à l'épreuve ; la contrainte ou la transformation des habitudes ; violence religieuse. Si l'ouvrage se présente explicitement comme un essai, qui ne prétend pas traiter la question et ses multiples cas de manière exhaustive, l'auteur s'attache cependant régulièrement à des exemples représentatifs ou cruciaux, qu'il étudie en détail, comme le dossier de Sévère de Minorque, celui de la destruction du Sérapéum d'Alexandrie ou encore divers groupes de textes d'Augustin d'Hippone. Il serait trop long d'entrer ici dans tous les détails d'un livre important, dont on ne peut que conseiller vivement la lecture à tous ceux qui travaillent sur cette époque. Relevons seulement la mise en évidence du rôle central de la persuasion, qui demeure l'idéal régulateur des relations entre confessions, religions ou écoles philosophiques tout au long de la période considérée - ce qui conduit d'ailleurs à une intéressante lecture des dialogues anti-judaïques ou autres, dont il faut moins chercher la véracité que la fonction et le rôle -, les précisions sur la place de la contrainte, qui a pour fonction essentiel de faire tomber les barrières non rationnelles (habitudes, préventions, croyances irrationnelles, etc.) qui empêchent un débat rationnel et le phénomène normal de la persuasion, la comparaison avec le fonctionnement des débats philosophiques mais aussi les processus internes aux écoles en la matière. La réflexion sur l'incarnation de la persuasion rationnelle qui, du fait de la nature complexe de l'homme, doit être précédée par une préparation qui vise à redresser les jugements faussés est très éclairante, surtout lorsqu'elle est 
mise en perspective avec les procédures des écoles philosophiques. On notera aussi que la question de la violence religieuse, si elle est plus brièvement traitée, est aussi abordée suivant la même approche, qui conduit à mettre en évidence la complexité de l'objet et les justifications multiples qui y président.

On aura compris qu'il importe vivement de lire ce petit livre - qui aurait d'ailleurs gagné à une présentation plus aérée de la part de l'éditeur, avec des marges plus spacieuses, ainsi qu'à bénéficier d'index, en particulier pour les textes et personnes cités; l'ouvrage contribue efficacement à rejeter des visions trop simplistes et tout à la fois trop orientées de cette histoire de la tolérance.

\section{Christologie}

De Brian E. DALEY, sj., le précédent bulletin présentait déjà un important ouvrage, l'édition et traduction anglaise des œuvres de Léonce de Byzance, issue de sa thèse de doctorat $^{123}$. C'est pour un tout autre genre de livre que nous le retrouvons cette année : l'auteur offre en effet au lecteur une étude diachronique de la christologie patristique, du $2^{\mathrm{e}}$ siècle jusqu'à la fin de la crise iconoclaste ${ }^{124}$. Ce livre est né des Martin D'Arcy Lectures données à Oxford en 2001, dont il constitue une version revue et largement augmentée. De ce fait, l'approche est, comme l'indique lui-même l'auteur, pour l'essentiel celle d'un grand récit sur le développement progressif de la christologie dans l'Église grecque ancienne. En effet, mis à part Augustin, les latins sont volontairement laissés de côté, de même que tous les écrits des chrétientés orientales; en outre, en grec même, la sélection des auteurs a été assez drastique et a écarté tous ceux qui n'étaient pas centraux, ou plutôt qui n'entraient pas dans le fil principal de l'évolution des conceptions christologiques - ainsi Évagre n'apparaît-il à aucun moment dans l'ouvrage. B. E. Daley a en effet choisi de centrer son propos sur une tradition théologique vue rétrospectivement comme celle qui a été la plus féconde et la plus durable dans l'Église, en particulier en Occident ; ce choix, assumé et clairement exprimé, peut être discuté mais il sert de point de départ à l'ensemble de l'enquête.

En effet, le cœur du livre s'articule autour de la définition christologique de Chalcédoine, non que l'auteur la tienne pour un point indépassable et réglant toutes les questions, mais justement parce qu'il veut en évaluer la portée, mais aussi la resituer dans un contexte plus large, la prendre non comme un point d'arrivée mais comme une étape au sein d'un processus plus long et plus ample. Le livre s'ouvre sur un chapitre consacré précisément à la christologie de Chalcédoine, point d'articulation de l'enquête, et retrace le contexte historique des travaux dans le domaine de la christologie patristique, en particulier autour de la figure d'Aloys Grillmeier, de l'ouvrage collectif sur Chalcédoine de 1951-1954 ${ }^{125}$, du premier congrès patristique d'Oxford puis de l'ouvrage fleuve d'A. Grillmeyer sur la christologie ancienne ${ }^{126}$. Cette approche historiographique initiale est essentielle et le lecteur ne peut que souhaiter en trouver un récit plus détaillé en un autre lieu, ne serait-ce que sous la forme des souvenirs des participants encore en vie. Le propos se déploie ensuite de manière chronologique, en commençant par le $2^{\mathrm{e}}$ siècle (Odes de Salomon, Ignace d'Antioche, Ascension d'Isaïe, Méliton de Sarde, Justin), puis avec Irénée et Origène, les débuts de la

${ }^{123}$ Voir « Bulletin de patrologie », Rev. Sc. ph. th. 102, 2018, p. 299-375, ici p. 337-339.

${ }^{124}$ Brian E. DALEY, God Visible: Patristic Christology Reconsidered, Oxford, New York, Oxford University Press (coll. «Changing Paradigms in Historical and Systematic Theology »), $2018 ; 24 \times 16$, relié, XVII + 294 p. ISBN 978-0-19-928133-6.

${ }_{125}$ A. GRILlmeIER et H. BACHT (éd.), Das Konzil von Chalkedon: Geschichte und Gegenwart, I-III, Würzburg, 1951-1954.

${ }^{126}$ A. GRILLMEIER et alii, Christ in der Christian Tradition / Jesus der Christus im Glauben der Kirche, Oxford / Freiburg, Basel, Wien, 1965-, 5 volumes parus, en allemand et en traduction anglaise (on signalera que le volume II.3, qui n'est signalé [p. 3, n. 6] que dans son original allemand, est aussi paru en anglais en 2013). On s'étonne un peu que ces volumes fondamentaux ne figurent pas dans la bibliographie finale, sans doute du fait de leur évidence. 
controverse arienne ${ }^{127}$; viennent ensuite les deux Grégoire et Apolinaire, domaine que l'auteur avait déjà étudié et éclairé à plusieurs reprises, Augustin, une confrontation entre Antioche et Alexandrie (Diodore de Tarse, Théodore de Mopsueste, Nestorius, Théodoret de Cyr, face à Cyrille d'Alexandrie). Dans la mesure où Chalcédoine a été traité dans le chapitre d'introduction, B. E. Daley passe ensuite directement aux suites du concile, qu'il parcourt d'un pas ample (Léonce de Byzance, Maxime le Confesseur, Jean Damascène), avant de se tourner vers la controverse iconoclaste - ce n'est pas dans ce volume qu'il faut chercher ni un traitement détaillé des controverses monothélites et monoénergistes, ni une présentation détaillée de la christologie byzantine.

La mise en situation de la formule de Chalcédoine est donc double : au sein d'une tradition théologique en élaboration constante, mais aussi au sein d'une tradition de formulations conciliaires de la foi, dans laquelle la formule chalcédonienne est l'une des tentatives. C'est cette double perspective qui fait la valeur principale de l'ouvrage - et elle est grande. Le récit de l'histoire de la christologie se lit agréablement et, s'il peut certes être complété et corrigé sur bien des points, il constitue une introduction ou un rappel utile en la matière ; mais il sert surtout de trame à une réflexion plus large sur les modalités de l'élaboration doctrinale et de sa fixation progressive. Au début du livre, B. E. Daley rappelle les reproches adressés à la reconstitution d'A. Grillmeyer, orientée par une perspective rétrospective qui est celle de la théologie catholique romaine; il veut lui substituer une approche plus large, qui fait entre autres meilleur droit à une christologie qui se formule comme un récit du salut, plutôt que dans des formulations scholastiques. Et l'apport est ici réel; l'auteur n'échappe pas, cependant, à cette perspective téléologique, d'une part, et au choix d'une orientation canonisée a posteriori, phénomène de plus en plus marqué avec l'avancée du livre. Les perdants de l'histoire théologique ont ici peu de place; seuls ceux qui ont précédé la cristallisation christologique se voient remis en avant, non ceux qui ont choisi des options interprétatives qui ont été écartées par la suite. Une fois ces points éclaircis, on ne peut que conseiller au lecteur de prendre une connaissance précise du schéma d'interprétation proposé par B. E. Daley, de même que du point historiographique qui ouvre son livre.

\section{Éducation}

Au sein du renouvellement des travaux sur les Apophtegmes et plus largement sur la littérature ascétique et monastique, il convient de faire une place particulière à un ouvrage collectif dirigé par Lillian I. LARSEN et Samuel RUBENSON ${ }^{128}$, qui rassemble quinze contributions issues d'un colloque tenu à l'Université de Lund en octobre $2013^{129}$. Fruit du

${ }^{127}$ En ce domaine, la présentation et la bibliographie ne sont pas vraiment à jour ; on aurait attendu que soient pris en compte tant les évolutions récentes sur le parti eusébien que les études sur Athanase, aussi bien pour la chronologie et le contexte historique (voir en particulier A. MARTIN, Athanase d'Alexandrie et l'Église d'Égypte au IV siècle (328-373), Roma (coll. «Collection de l'École française de Rome » 216), 1996; EADEM, «Athanase d'Alexandrie et l'Église d'Égypte: un réexamen », Adamantius 12, 2006, p. 91-104) que pour la théologie (voir en particulier X. MORALES, La théologie trinitaire d'Athanase d'Alexandrie, Paris (coll. «Études augustiniennes, série Antiquité »180), 2006).

${ }^{128}$ Lillian I. LARSEN et Samuel RUBENSON (éd.), Monastic Education in Late Antiquity: The Transformation of Classical Paideia, Cambridge, New York, Cambridge University Press, 2018 ; $25 \times 18$, relié, X + 399 p. ISBN : 978-1-107-19495-3.

${ }^{129}$ I, The Language of Education : Samuel RUBENSON, «Early monasticism and the concept of a "School" », p. 13-32 ; Peter GEMEINHARDT, «Translating paideia: education in the Greek and Latin versions of the Life of Anthony », p. 33-52 ; Andreas WESTERGREN, «Paideia, piety and power: Emperors and Monks in Socrates' Church History », p. 53-72. II, Elementary Education and Literacy : Roger BAGNALL, «The Educational and Cultural Background of Egyptian Monks », p. 75-100 ; Lillian I. LARSEN, «"Excavating the Excavations" of early monastic education », p. 101-124; Anastasia MARAVELA, «Homer and Menandri Sententiae in Upper Egyptian monastic settings», p. 125-149. III, Grammar and Rhetoric : Blossom STEFANIW, « The school of Didymus the Blind in the light of the Tura find », p. 153-181; Ellen MUEHLBERGER, «Affecting rhetoric: the adoption of Ethopoeia in Evagrius of Pontus' ascetic program », p. 182-194 ; Mark SHERIDAN, «Classical 
programme de recherche Early Monasticism and Classical Paideia (MOPAI, 2009-2015), il propose une étude des relations entre le monachisme naissant et l'éducation gréco-romaine. Contre les tenants d'une rupture fondamentale entre les institutions et surtout les pratiques d'éducation de l'Antiquité, d'une part, et les pratiques et les institutions monastiques, d'autre part, le présent volume plaide pour une continuité des pratiques et des savoirs dans le domaine de l'éducation; les différentes contributions cherchent à mettre en évidence les liens, les continuités et les transformations qui permettent à la fois la transmission de pans entiers de l'héritage culturel non chrétien à travers le monachisme, mais aussi de pratiques de formation et d'éducation, au sein même des monastères et des regroupements d'ascètes. Contre l'image dominante dans l'historiographie, et qui prend racine dans un certain nombre d'affirmations des textes ascétiques anciens eux-mêmes, c'est le rejet du savoir profane au sein du monachisme ancien et la rupture volontaire de ce dernier avec les procédés d'éducation non chrétiens qui est remise en cause. Les études ici présentées s'appuient tant sur des textes littéraires, bien connus ou moins bien explorés, que sur des sources documentaires, papyrus, ostraca, inscriptions.

L'ouvrage est structuré en cinq parties; la première s'attache à la notion même d'éducation et à son vocabulaire, ainsi qu'à sa mise en scène dans les textes; les trois suivantes abordent les différents stades de l'éducation, de l'apprentissage des lettres, de la lecture et de l'écriture jusqu'à la philosophie, en passant par la grammaire et la rhétorique ; enfin, la dernière partie, qui ouvre sur un champ d'enquête un peu différent, présente trois contributions sur les modalités propres de transmission des textes monastiques, avec une attention particulière prêtée au caractère fluide de ces transmissions.

Il n'est pas question de présenter en détail l'ensemble des contributions de ce riche et important volume, dont la lecture sera stimulante non seulement pour les spécialistes du monachisme ancien, ou de l'histoire de l'éducation dans l'Antiquité, mais aussi pour tous ceux qui s'intéressent à cette période et aux transformations qu'introduit le développement du christianisme dans la société antique et tardo-antique. On relèvera simplement quelques approches ou thèmes, au gré des intérêts du recenseur. Dans sa contribution liminaire, S. Rubenson reprend, autour de quatre thèmes (loisir, tradition, exercice, organisation collective), la définition de l'éducation, afin de la confronter aux pratiques monastiques, et de l'en rapprocher. Roger Bagnall, à partir de quelques exemples de papyrus, étudie de manière très riche le niveau d'éducation des moines, en croisant une étude des textes, des supports et des modalités d'écriture. Lillian I. Larsen s'attache pour sa part à montrer comment l'interprétation d'un certain nombre d'objets inscrits est restreinte en fonction des caractéristiques que leur ont appliquées leurs éditeurs, et comment leur réinsertion dans un champ éducatif et monastique plus large leur donne un sens nouveau, souvent inaperçu. Dans la troisième partie, ce sont davantage des corpus textuels (Didyme, Évagre, Rufus de Shotep) qui servent de support à l'enquête, plutôt que des textes documentaires. On notera aussi, sans être tout à fait convaincu par la thèse de l'auteur, la tentative d'A. Urbano d'interpréter l'Historia religiosa de Théodoret de Cyr dans un contexte platonicien de compétition entre écoles philosophiques et monastiques; si les exemples relevés dans la Thérapeutique des maladies helléniques, où l'attitude de Théodoret au regard de la philosophie est explicite, sont

education in sixth century Coptic monasticism: the example of Rufus of Shotep », p. 195-216. IV, Philosophy : Henrik RYDELL JOHNSEN, «The virtue of being uneducated: attitudes towards classical paideia in early monasticism and ancient philosophy », p. 219-235; Arthur URBANO, «Plato between school and cell: biography and competition in the fifth-century philosophical field», p. 236-255; Daniele PEVARELlO, «Pythagorean traditions in Early Christian asceticism », p. 256-277. V, Manuscript and Literary Production : Britt DAHLMAN, «Textual fluidity and authorial revision: the case of Cassian and Palladius », p. 281-305; Hugo LUNDHAUG and Lance JENOTT, «Production, distribution, and ownership of books in the monasteries of Upper Egypt: the evidence of the Nag Hammadi Colophons », p. 306-325 ; Jason ZABOROWSKI, «Greek thought, Arabic culture: approaching the Arabic recensions of the Apophthegmata Patrum », p. 326-342. 
probants, la transposition du raisonnement à l'Histoire des moines de Syrie parait parfois un peu forcée. On relèvera encore la présence de collections de sentences qui courent à travers les différentes parties, des Sentences de Ménandre en contexte archéologique à la filiation pythagoricienne par l'intermédiaire des Sentences de Sextus. Dans la dernière partie, l'étude de B. Dahlman revient sur la question extrêmement complexe de la priorité du texte grec ou latin des différents ouvrages de Cassien. S'écartant à bon droit des hypothèses difficilement soutenables émises récemment par P. Tzamalikos, qui attribue la totalité du corpus à un Cassien grec, dit le Sabaïte, B. Dahlman reprend patiemment le dossier des états textuels et montre comment le texte latin, les traductions grecques et les témoignages externes, dont les Apophtegmes, permettent d'esquisser une composition en plusieurs étapes, où l'état textuel actuellement conservé en latin n'est pas forcément l'état d'origine. On restera cependant plus réservé sur l'attribution de l'ensemble des états à l'auteur Cassien. Une étude du même genre est menée sur l'Histoire lausiaque. La contribution de H. Lundhaug et L. Jenott s'inscrit dans la perspective de leur ouvrage, qui a été présenté dans une livraison précédente de ce Bulletin $^{130}$.

Si le renouvellement de l'approche sur l'histoire de l'éducation et le monachisme n'est pas aussi absolu que veulent le laisser penser les éditeurs, les différentes contributions de ce volume collectif contribuent cependant très utilement à construire, à partir de fragments divers, une vue plus riche et plus adéquate de l'éduction en contexte monastique.

Un second ouvrage collectif concerne cette année l'éducation dans l'Antiquité tardive ; dirigé par Peter Gemeinhardt, Olga Lorgeoux et Maria Munkholt Christensen ${ }^{131}$, il réunit les contributions présentées lors d'un workshop tenu à Göttingen en Août 2016 et rassemble treize études ${ }^{132}$. La lecture du présent ouvrage à la suite de celui qui vient d'être présenté laissera sûrement au lecteur une moins forte impression; c'est sans doute que les figures étudiées ne sont pas toutes aussi originales - on trouve, aux côtés des Apophtegmes, de Cyrille de Scythopolis ou de l'auteur du Récit sur le martyre des moines du Sinaï, Augustin, Ambroise ou Cyrille de Jérusalem - mais aussi que l'approche est plus traditionnelle, ou du moins met moins en scène son originalité. Comme la liste, très incomplète, des auteurs abordés qui vient d'être présentée le laisse déjà entendre, la perspective est riche et large; elle l'est plus encore dans la mesure où tel article ajoute l'apport des textes canoniques à propos de la formation des évêques, tel autre une

\footnotetext{
${ }^{130}$ Voir «Bulletin de patrologie », Rev. Sc. ph. et th. 100, 2016, p. 459-531, ici p. 510-513.

${ }^{131}$ Peter GemeinhardT, Olga LoRgeoux et Maria MunkHolt CHRISTENSEN (éd.), Teachers in Late Antique
} Christianity, Tübingen, Mohr Siebeck (coll. «Studies in Education and Religion in Ancient and Pre-Modern History in the Mediterranean and Its Environs » 3), 2018 ; $24 \times 16$, relié ; XI + 278 p. ISBN : 978-3-16-1558573.

132 Arthur P. URBANO, «Literary and Visual Images of Teachers in Late Antiquity », p. 1-31; Peter GEMEINHARDT, «Men of Letters or Fishermen? The Education of Bishops and Clerics in Late Antiquity », p. 32-55 ; Juliette DAY, «The Bishop as Mystagogical Teacher», p. 56-75; Olga LoRgEOUX, «Cyril of Jerusalem as Catechetical Teacher: Religious Education in Fourth-Century Jerusalem », p. 76-91 ; Carmen Angela CVETKOVIC, «Si docendus est episcopus a laico, quid sequetur? Ambrose of Milan and the Episcopal Duty of Teaching », p. 92-110 ; David RYLAARSDAM, «John Chrysostom on the Human and the Divine Teacher of Christianity», p. 111-128; Therese FUHRER, «Ille intus magister. On Augustine's Didactic Concept of Interiority », p. 129-146; Maria MunkHOlt CHRISTENSEN, «Holy Women as Humble Teachers. An Investigation of Hagiographical Texts from Late Antiquity», p. 147-164; Katharina GRESCHAT, " "Early Impressions are Hard to Eradicate from the Mind". The Lasting Influence of Domestic Education in Western Late Antiquity », p. 165-183 ; Henrik RYDELl JOHNSEN, «Physicians, Teachers and Friends: Lower Egyptian Desert Elders and Late Antique Directors of Souls », p. 184-205; Christoph BIRKNER, «Between Monastic Leadership and Spiritual Instruction: Aspects of Teaching in the Hagiographical Corpus of Cyril of Scythopolis », p. 206-227; Andreas MüLLER, «The Monastic Fathers of Mount Sinai as Teachers of Spirituality », p. 228-240; Peter GemeInhardT, Olga LorgeOuX, Maria MunkHolt Christensen, «Concluding Remarks », p. 241-252. 
confrontation entre représentations écrites et figurées du maître dans l'Antiquité tardive, tandis que tel autre encore se concentre sur les figures féminines d'enseignantes dans l'hagiographie. Toutes ces approches, ou presque, tiennent pour acquise une définition large du maître (teacher), qui ne se limite pas au cadre bien définit d'une école, mais s'ouvre à tout contexte de transmission d'un savoir, intellectuel, moral ou pratique. Peut-être est-ce là ce qui risque d'affaiblir quelque peu le propos d'ensemble, en rendant malaisés les rapprochements entre les différentes situations et les différentes figures; la diversité des contextes linguistiques, géographiques, sociaux et culturels contribue également à rendre difficiles les comparaisons. Il est d'ailleurs significatif que les éditeurs du volume aient choisi de présenter non une introduction mais des remarques conclusives, qui commencent par rassembler utilement l'apport des différentes contributions, avant de tenter de dégager quelques points d'accord et pistes de réflexion. On notera parmi ceux-là les emprunts chrétiens, qu'ils soient épiscopaux ou ascétiques, aux maîtres des différents courants philosophiques. Il est plus étonnant de lire que les évêques se sont peu à peu réservé le droit exclusif d'enseigner : encore faudrait-il préciser que la chose ne vaut qu'en matière doctrinale, et non pour l'ascèse ; un tel oubli, relatif, des modèles ascétiques transparaît également dans l'intéressante remarque sur l'apprentissage de l'articulation entre vie personnelle et idéal commun, qui ne saurait là encore être réduit au cadre épiscopal.

Pourvu d'utiles index, ce volume sera sûrement profitable à beaucoup, soit pour une lecture continue, quelque peu fragmentée, soit pour des plongées thématiques plus ponctuelles. Les activités du Centre de recherche collectif Education and Religion in Cultures of the Mediterranean and Its Environment from Ancient to Medieval Times and to the Classical Islam, financé par la DFG et à l'origine de cette publication, continueront sûrement à faire ainsi progresser les études sur l'éducation dans l'Antiquité, sous ses diférentes formes.

\section{Instruments de travail : chaînes exégétiques et conciles}

Le cinquième et dernier tome de la monumentale étude de Gilles DORIVAL sur les chaînes exégétiques grecques sur les Psaumes est paru en $2018^{133}$. Il s'agit du dernier fruit d'un travail entamé il y a près de 45 ans, sous la forme d'une thèse de doctorat d'État soutenue en Sorbonne sous la direction de Marguerite Harl en 1984 ; les quatre premiers tomes en ont paru dans la même collection entre 1986 et 1995, et proposaient une étude analytique de la presque totalité des différentes chaînes exégétiques sur les Psaumes, mêlée à une réflexion sur la genèse de ces œuvres et leur évolution. Ce dernier volume, prêt mais longtemps différé pour des raisons sur lesquelles l'auteur revient dans l'Avertissement initial, était essentiel pour les utilisateurs et les lecteurs de l'ensemble, dans la mesure où il contient les index de la totalité de l'ouvrage, tant pour les manuscrits que, sous forme de deux annexes, pour la concordance avec le répertoire fondamental de G. Karo et I. Lietzmann et surtout pour la synthèse par auteur des extraits transmis dans les chaînes sur les Psaumes. C'est également dans ce cinquième tome que figure la bibliographie d'ensemble : elle est là aussi indispensable, dans la mesure où l'auteur a fait le choix, de prime abord déroutant, de ne pas proposer de notes de bas de page. Toutes les références critiques sont donc traitées de manière réduite, voire allusive, dans le corps du texte, et l'identification des études citées demandait jusqu'ici une grande familiarité avec le domaine concerné. Enfin, le volume comprend également, après les deux derniers chapitres sur les formes les plus complexes de chaînes (« chaînes complexes de type variable » et «chaînes fragmentaires, réfections de chaînes, juxtaposition de chaînes »), une importante conclusion d'environ 70 pages qui reprend de manière synthétique l'ensemble

${ }^{133}$ Gilles DorIVAL, Les chaînes exégétiques grecques sur les Psaumes. Contribution à l'étude d'une forme littéraire, V, Leuven, Peeters (coll. «Spicilegium Sacrum Lovaniense » 54), $2018 ; 24 \times 16$, IX + 420 p. ISBN : 978-90-429-3411-5. 
de la matière et ouvre des pistes de recherche. On voit donc que ce dernier tome, outre son contenu propre, contient également les instruments de travail nécessaires à l'exploitation des quatre premiers volumes : jusqu'ici, il fallait savoir à quel type de chaîne appartenait un manuscrit pour le retrouver dans les quelques 1800 pages des tomes déjà parus; pour identifier les témoins caténaires d'un auteur, voire d'une œuvre donnée, il n'y avait pas d'autre solution que de parcourir tout l'ouvrage, pour repérer chaque occurrence relevée. De ce double point de vue, l'index des manuscrits et l'annexe 2 sur les auteurs et œuvres cités dans les chaînes, extrêmement riches et précieux, vont changer la vie des éditeurs de textes et des savants.

Ces chaînes sur les Psaumes, qui forment le plus important corpus caténaire de langue grecque, avait déjà fait l'objet d'études importantes, outre le répertoire de Karo et Lietzmann rappelé plus haut ; qu'il suffise ici de mentionner les travaux de M. Richard, E. Mühlenberg ou M.-J. Rondeau. Rappelons brièvement la méthode de Gilles Dorival, qu'il avait présenté dans le premier volume: son enquête, qui ne pouvait couvrir toutes les chaînes dans leur entièreté, ne pouvait procéder que par sondage ; si l'auteur a choisi de retenir toutes les chaînes et tous les manuscrits, dans la mesure du possible, il a en revanche sélectionné un certain nombre de Psaumes $(1,11,21,31,41,51,61,91,101,131,141,150$, auxquels il faut joindre le Ps 118, qui avait fait l'objet de sa thèse de $3^{\mathrm{e}}$ cycle en 1974), pour lesquels il a analysé en totalité le témoignage des chaînes. Il faut donc bien garder à l'esprit la somme considérables de dépouillements, effectués directement sur les manuscrits ou, souvent, sur microfilms, qui fournissent à l'étude une base large et beaucoup plus solide que les études antérieures, dont l'échantillon d'analyse était plus réduit en nombre de Psaumes et moins systématique dans le champ couvert. Il est bien sûr évident qu'une telle étude ne prétend pas remplacer une analyse, moins encore une édition complète des chaînes sur les Psaumes : si des auteurs ou des œuvres ne sont pas présents dans les lieux sondés, ils ont pu échapper à l'auteur, par exemple ; si une irrégularité dans la source de la chaîne intervient sur moins de dix Psaumes, elle peut être passée inaperçue; mais l'ampleur du champ couvert, avec des dizaines d'auteurs et environ 200 manuscrits, est considérable et assure d'ores et déjà une assise aussi sûre que possible.

La conclusion permet de prendre une vue d'ensemble du processus reconstitué par l'auteur; sans doute est-ce dans cette reconstruction théorique et historique qu'il y a le plus de place pour une discussion car, comme G. Dorival le dit clairement, il s'agit d'hypothèses élaborées à partir du travail de dépouillement et d'analyse, et non plus de données factuelles. Voici, à grands traits, les conclusions de G. Dorival sur la naissance et l'évolution des chaînes exégétiques sur les Psaumes. L'auteur distingue d'abord deux périodes principales de composition des chaînes, liées à deux lieux, la Palestine et Constantinople. Il situe en Palestine la composition des premières chaînes aux Psaumes, peu après Procope de Gaza (milieu du $\mathrm{V}^{\mathrm{e}}$ siècle); elles auraient d'abord été composées à partir de commentaires et d'homélies sur les Psaumes, complétées par des extraits d'autres œuvres, le tout pris à des auteurs principalement liés à la Palestine ; ce type de chaîne aurait été composé à pleine page.

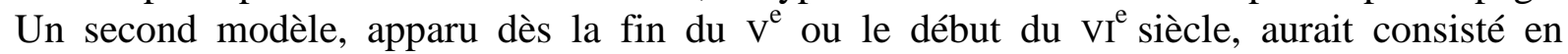
chaînes-scholies, formées à partir de collections de scholies aux Psaumes, et mises en page à deux colonnes ; serait ensuite apparu un modèle mixte, mêlant commentaires, homélies et scholies, soit à pleine page, soit à deux colonnes. La seconde étape est située par G. Dorival à Constantinople, à partir de la deuxième moitié du VII ${ }^{\mathrm{e}}$ siècle. Elle est marquée, selon l'auteur, par la diffusion croissante de la disposition marginale, avant un retour à la pleine page à partir du XII ${ }^{\mathrm{e}}$ siècle; elle est également caractérisée par l'ajout de sources qui étaient demeurées secondaires auparavant, Jean Chrysostome, Théodoret de Cyr, Théodore de Mopsueste, et par l'introduction d'auteurs plus secondaires (Diodore de Tarse, Métrophane de Smyrne, etc.), y compris d'œuvres qui ne commentent pas directement le Psautier. Un premier modèle serait 
centré sur Chrysostome et Théodoret, un deuxième verrait l'apparition des chaînes à deux auteurs, donnant en leur intégralité, et en alternance, les commentaires des deux auteurs utilisés ; un modèle mixte fusionnerait le premier modèle avec le modèle mixte palestinien, à partir du VIII siècle. Enfin, G. Dorival étudie l'apparition de chaînes secondaires, utilisant parmi leurs sources une ou plusieurs chaînes antérieures.

La conclusion étudie ensuite la postérité des chaînes sur les Psaumes, avec en particulier l'apparition de commentaires continus formés entre autres à partir de la matière des chaînes mais aussi directement à partir des œuvres originales - comme celui qui est attribué à Pierre de Laodicée, mais aussi divers commentaires anonymes ou d'attribution douteuse, ou encore la formation de collections de scholies et d'homélies dérivées des chaînes et des œuvres. Une troisième section de la conclusion tente de replacer les chaînes dans l'histoire de la religion et de la culture byzantines. Elle est plus difficile à résumer, même s'il faut souligner la discussion qu'y mène G. Dorival, sur la question du rattachement confessionnel de plusieurs chaînes au monophysisme, avec L. Vianès et $\mathrm{M}$. Aussedat, et qui le conduit à nuancer largement ses propres hypothèses antérieures. Il avait en effet soutenu, à la suite de M. Richard, le caractère nettement monophysite de plusieurs séries de chaînes, en particulier sur les prophètes, du fait de leur usage de Sévère d'Antioche. La dernière section ouvre quelques pistes à poursuivre, sur les différentes formes de réécriture dans les chaînes, mais aussi sur l'évolution de l'exégèse des Psaumes, à la lumière des chaînes et en comparaison avec elles.

L'auteur de ces lignes vient de passer quelques années en compagnie des quatre premiers tomes de l'ouvrage de G. Dorival, à l'occasion de la préparation de la première édition des Scholies aux Psaumes d'Évagre le Pontique, préparée avec P. Géhin; cette œuvre, redécouverte par M.-J. Rondeau, n'est transmise que par les chaînes aux Psaumes. C'est donc en pleine connaissance de cause qu'il peut rappeler la valeur et l'importance de cet ouvrage, qui constitue un guide extrêmement précieux dans cette forêt des chaînes psalmiques. Il y a bien évidemment des erreurs de détails, inévitables dans une telle masse; les travaux d'édition, d'un auteur ou d'une chaîne, amènent nécessairement à corriger, compléter ou nuancer les conclusions de G. Dorival ${ }^{134}$. Cependant, le cadre d'ensemble est pour le moment irremplaçable; certes, les hypothèses de datation et d'origine des chaînes, les théories proposées sur l'évolution de la mise en page des chaînes, etc. restent des hypothèses historiques et sont donc amenées à évoluer et à être corrigées. Mais l'auteur montre en la matière lui-même le chemin, dans sa discussion avec des collègues plus jeunes, comme L. Vianès et $M$. Aussedat, qui ont toutes deux travaillées sur les chaînes aux prophètes (respectivement Ézéchiel et Jérémie, deux thèses malheureusement restées inédites) : ces hypothèses et interprétations proposent une lecture des données matérielles et textuelles, que la poursuite des travaux sur les chaînes grecques feront nécessairement évoluer. Il y a encore fort à faire : édition des chaînes, édition des œuvres transmises uniquement par les chaînes et des commentaires dérivés des chaînes, étude des manuscrits, histoire des pratiques de composition et de lecture des chaînes, etc. Ce dernier volume de l'ouvrage monumental de G. Dorival, paru si longtemps après les quatre premiers, constitue un apport fondamental à ces travaux philologiques et historiques.

La catégorie des instruments de travail n'attire souvent que peu l'attention du lecteur ou tend à le rebuter, et ce plus encore lorsqu'on lui présente la seconde édition d'un ouvrage. Il ne faudrait pas, cependant, qu'il en aille ainsi pour le très important volume dont Jacques NORET vient de donner une nouvelle édition revue et largement augmentée : le quatrième

\footnotetext{
${ }^{134}$ Voir par exemple l'article récent de L. VANDERSCHELDEN, « Two Alleged Witnesses of the Catena of the Paris Psalter : Vaticani graeci 617 and $1519 »$, Sacris Erudiri, 57, 2018, p. 403-437.
} 
tome de la Clauis Patrum graecorum, publiée naguère par M. Geerard ${ }^{135}$. La première édition de ce volume comportait deux cent soixante-treize pages, la nouvelle en comprend quatre cent trente : le décompte suffit à dire l'enrichissement de la matière. Pour ceux des lecteurs de ce bulletin qui ne seraient pas familiers de l'ouvrage - chose impossible ! - rappelons que ce quatrième tome présente les textes relatifs aux synodes (Concilia), d'une part, et aux chaînes exégétiques d'autre part. Si l'on prend l'ouvrage par la fin, il faut tout d'abord noter deux nouveaux et fort utiles index : le premier donne la correspondance entre les numéros des trois premiers tomes de la Clauis et les notices qui leur correspondent dans ce quatrième tome, permettant ainsi aisément de repérer les reprises et transmissions de textes dans le cadre des synodes ; le second répertorie, par auteur puis par numéro de Clauis (et ensuite, de manière globale, les textes au titre indéterminé), les œuvres qui sont mentionnées et transmises dans les chaînes exégétiques de la seconde section de ce tome IV. Ce deuxième index supplémentaire, de taille imposante, pourra rendre des services importants aux chercheurs en les aidant à repérer les traces de transmission d'une œuvre ou d'un auteur dans les chaînes même si, comme le remarque l'auteur lui-même, il ne peut reposer que sur les dépouillements menés dans les études citées, et non sur une étude directe et exhaustive des chaînes, tâche qui relève des éditeurs, non de l'auteur de la Clauis.

J. Noret a noté dans sa préface, avec beaucoup de justesse, que les travaux sur les textes de la première partie avaient bien moins progressé, dans le domaine qui concerne la Clauis, que ceux qui portent sur les chaînes exégétiques. Peut-être pourrait-on nuancer quelque peu ce propos, cependant, si l'on prend en compte, comme l'a fait à juste titre l'auteur, les travaux sur la transmission de ces textes conciliaires dans les langues orientales, notamment en éthiopien ; il est vrai cependant que $\mathrm{J}$. Noret a eu à signaler de très nombreuses rééditions, ou plutôt reproductions, d'éditions antérieures, éventuellement munies de traductions. Comme il l'a remarqué, ce sont les études historiques sur ces textes, leur datation et leur authenticité, qui ont le plus progressé, tandis que seule la période tardive, à partir du vII siècle, a vu de nouvelles éditions critiques des textes originaux, dans les Acta conciliorum ocumenicorum. Les très utiles commentaires de l'auteur, rédigés maintenant en français plutôt qu'en latin, accompagnent ces notices et guident utilement le lecteur.

La seconde partie, consacrée aux chaînes exégétiques, est sans doute celle qui a vu le plus de changements et d'éditions nouvelles - il est vrai qu'on partait, à l'époque de la première édition, de fort peu de choses. Les travaux de F. Petit sur les chaînes sur l'Octateuque - dont J. Noret nous fournit, avec la collaboration de F. Petit, un stemma d'ensemble (p. 241), ou ceux de G. Dorival sur les Psaumes sont largement exploités et permettent de réelles avancées. On notera d'ailleurs l'humour avec lequel J. Noret rappelle, dans sa préface, le rôle qu'il a joué dans la publication enfin menée à bien du cinquième et dernier tome de l'étude monumentale de G. Dorival sur les chaines sur les Psaumes ${ }^{136}$, volume sans lequel l'ensemble restait très difficilement utilisable - autre titre à la reconnaissance des savants qu'il s'est acquis. On pourra encore relever les chaînes sur Job, dont U. et D. Hagedorn ont donné une remarquable édition critique des états anciens, tandis que la chaîne de Nicétas attend encore une édition critique. Les chaînes sur les prophètes ont pour certaines fait l'objet de thèses de doctorat (L. Vianès sur Ézéchiel, M. Aussedat sur Jérémie), qui n'ont malheureusement pas été publiées; si la tradition en a été débrouillées dans les thèses citées, elles attendent encore une édition intégrale et aisément accessible à tous. Parmi les livres salomoniens, ce sont les chaînes sur le Cantique qui ont vu les plus grands progrès, avec les travaux de J.-M. Auwers (et en particulier son édition et son étude de l'Épitomé de la Chaîne de Procope) et de

135 Maurice GeERARD et Jacques Noret, Clauis Patrum Graecorum. IV, Concilia. Catenae. Deuxième édition revue et mise à jour, Turnhout, Brepols (coll. «Corpus Christianorum. Clauis Patrum Graecorum » IV), 2018 ; 25 × 15,5, relié ; XXX + 430 p. ISBN : 978-2-503-57963-4.

${ }^{136}$ Voir supra, p. ***_***. 
R. Ceulemans. Pour les Proverbes, il faut ajouter au relevé précieux de J. Noret la thèse toute récente de M. Danezan, soutenue après la parution du volume ${ }^{137}$. Pour le Nouveau Testament, en revanche, la situation des études a peu progressé - ce qui ne veut pas dire que la présente édition n'apporte pas du neuf, et en particulier des clarifications. On signalera quelques études de K. Zawadzki pour les épîtres. Divers projets sont en cours, en particulier sous la direction de $\mathrm{H}$. Houghton à Birminghma, avec la préparation d'une liste des manuscrits mise à jour et vérifiée, réalisée par G. Parpulov. Il faudra cependant attendre la parution de ces divers travaux pour juger de leur apport à la connaissance des chaînes sur le Nouveau Testament.

Très riche volume, et extrêmement utile à la communauté scientifique, donc : il doit figurer dans toute bibliothèque qui s'occupe des textes chrétiens antiques, et rendra de grands services à qui aura la patience d'y chercher tant des renseignements sur tel auteur ou tel texte que des sujets de recherche. Mais la clarté avec laquelle J. Noret a présenté les choses ne doit pas tromper le lecteur : les textes de l'une et l'autre parties sont éminemment complexes, tant par leur transmission que par leur forme, et le travail abondant qui reste à mener est loin d'être simple.

${ }^{137}$ M. DANEZAN, Du texte d'auteur aux textes des chaînes. Édition et traduction des chaînes aux Proverbes (1-3; 8, 22-36 ; 30, 15-33 et 31, 10-31), dir. O. Munnich, Sorbonne Université, Paris, 2018. 